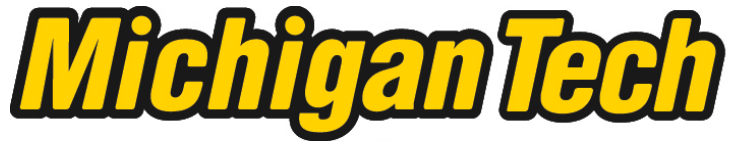 \\ Michigan Technological University Create the Future Digital Commons @ Michigan Tech
}

Investigation of using waste engine oil blended with reclaimed asphalt materials to improve pavement recyclability

Christopher Daniel DeDene

Michigan Technological University

Follow this and additional works at: https://digitalcommons.mtu.edu/etds

Part of the Civil and Environmental Engineering Commons

Copyright 2011 Christopher Daniel DeDene

\section{Recommended Citation}

DeDene, Christopher Daniel, "Investigation of using waste engine oil blended with reclaimed asphalt materials to improve pavement recyclability ", Master's Thesis, Michigan Technological University, 2011.

https://doi.org/10.37099/mtu.dc.etds/229

Follow this and additional works at: https://digitalcommons.mtu.edu/etds

3 Part of the Civil and Environmental Engineering Commons 


\title{
INVESTIGATION OF USING WASTE ENGINE OIL BLENDED WITH RECLAIMED ASPHALT MATERIALS TO IMPROVE PAVEMENT RECYCLABILITY
}

\author{
By \\ Christopher Daniel DeDene
}

\begin{abstract}
A THESIS
Submitted in partial fulfillment of the requirements for the degree of MASTER OF SCIENCE (Civil Engineering)
\end{abstract}

\section{MICHIGAN TECHNOLOGICAL UNIVERSITY 2011}

Copyright: Christopher D. DeDene 2011 
This thesis, "Investigation of Using Waste Engine Oil Blended with Reclaimed Asphalt Materials to Improve Pavement Recyclability,” is hereby approved in partial fulfillment of the requirements for the Degree of MASTER OF SCIENCE IN CIVIL ENGINEERING

Department of Civil and Environmental Engineering

Signatures:

Thesis Advisor

Dr. Zhanping You

Committee Member

Dr. Jacob Hiller

Committee Member

Dr. David Shonnard

Department Chair

Dr. David Hand

Date 
For Dad, who came to all of my football games 


\section{Table of Contents}

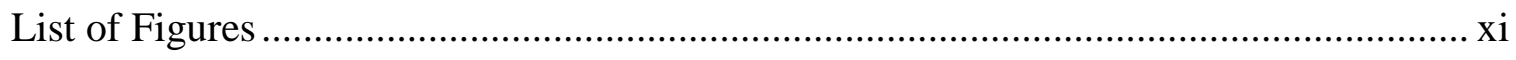

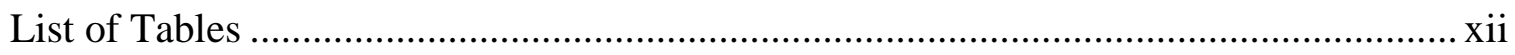

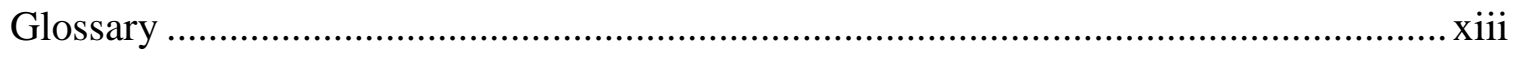

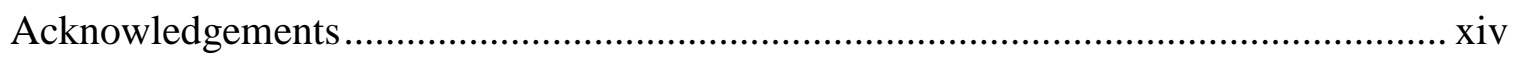

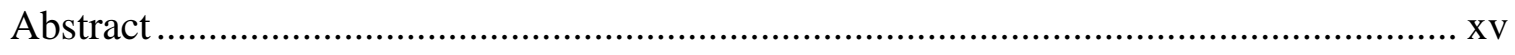

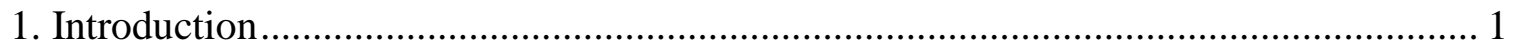

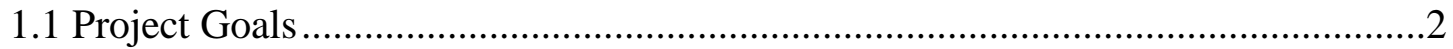

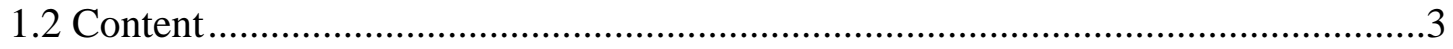

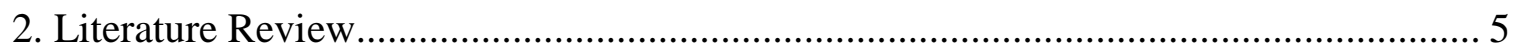

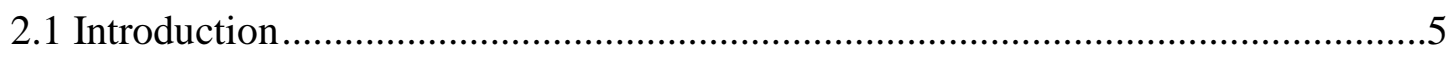

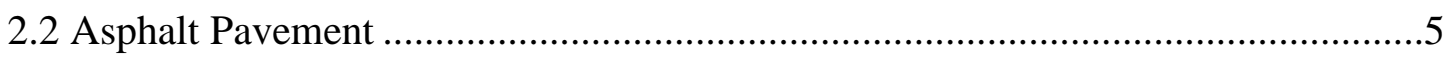

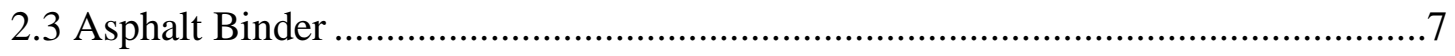

2.4 Asphalt Failure Mechanisms...................................................................

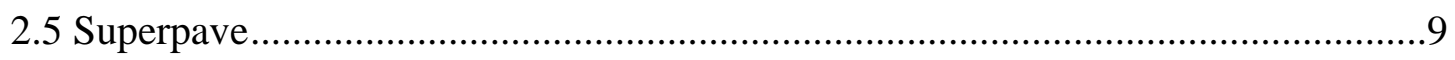

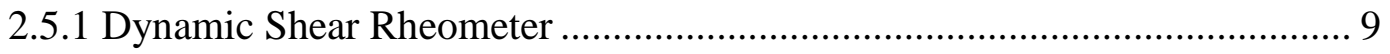

2.5.2 Rotational Viscometer ...................................................................... 11

2.5.3 Laboratory Aging of Asphalt Binder ................................................... 11

2.6 Reclaimed Asphalt Pavement ...................................................................... 12

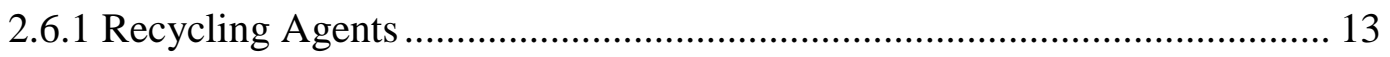

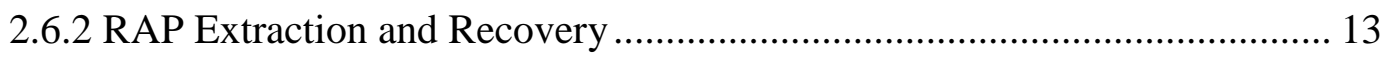

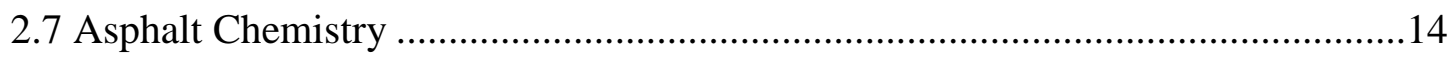

2.7.1 Chemical Structure............................................................................. 14 


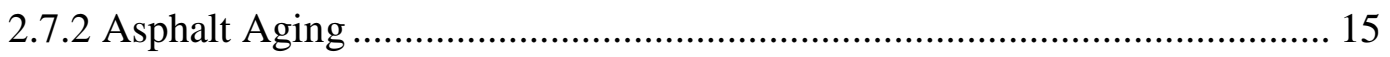

2.8 Waste Engine Oil .................................................................................................

2.9 Fourier Transform Infrared Spectroscopy (FTIR) ……………………………....16

2.10 Asphalt Mixture Testing ..................................................................................18

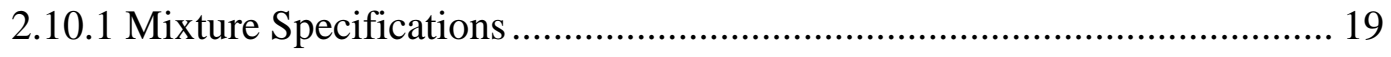

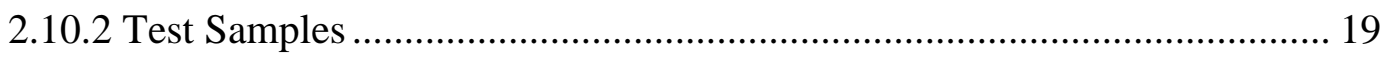

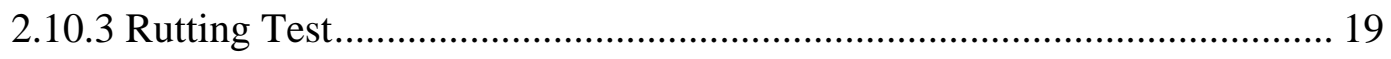

2.10.4 Tensile Strength Ratio Test........................................................................... 20

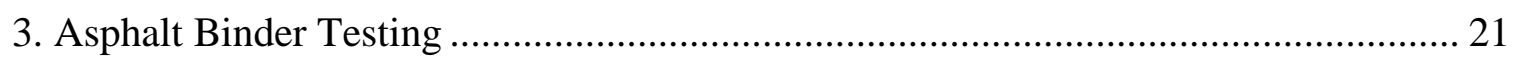

3.1 Introduction ..................................................................................................21

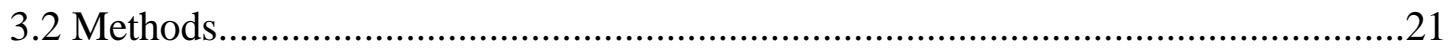

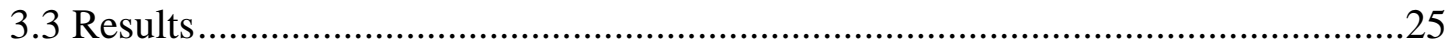

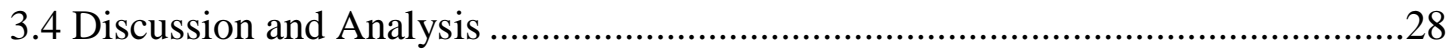

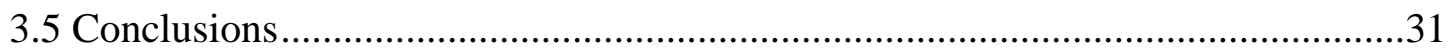

4. Advanced Asphalt Binder Testing................................................................................. 34

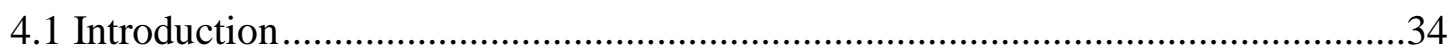

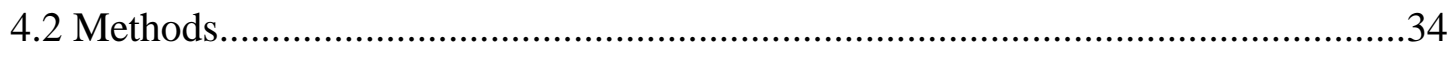

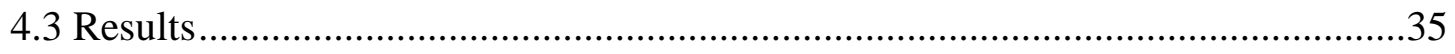

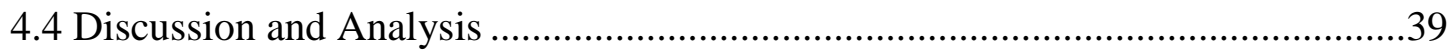

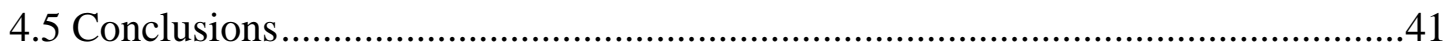

5. Mixture Testing........................................................................................................ 42

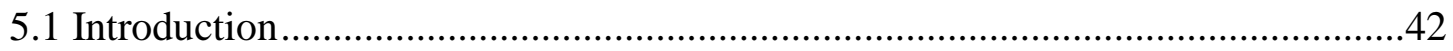

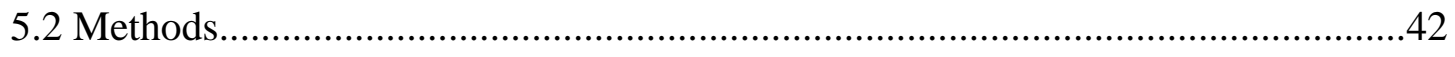

5.2.1 Mixture Specifications ............................................................................. 42 


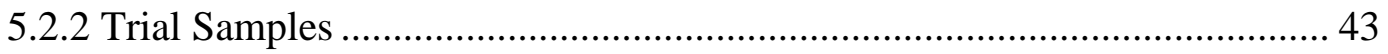

5.2.3 Mixing and Compaction ............................................................................... 43

5.2.4 Rutting Test......................................................................................... 45

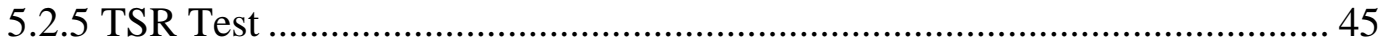

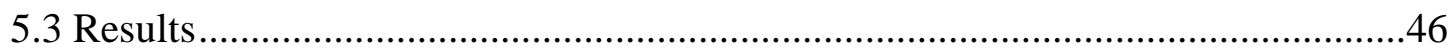

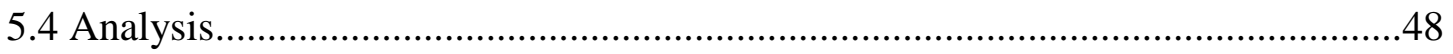

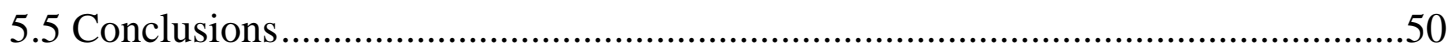

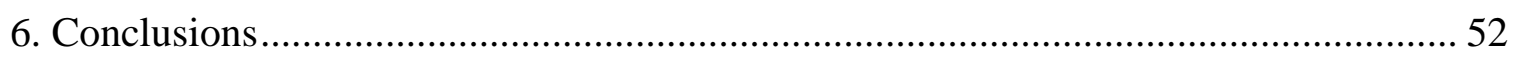

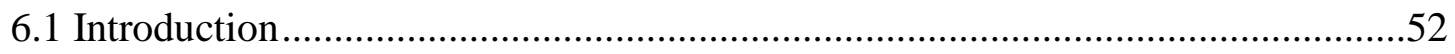

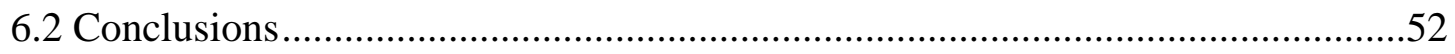

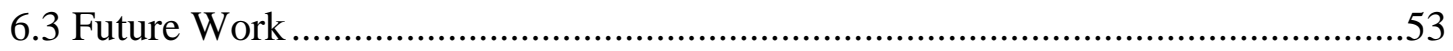

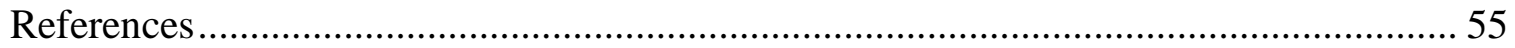

Appendix A. Job Mix Formula (JMF) ……………………..................................... 59

Appendix B. Compaction Results................................................................................. 60

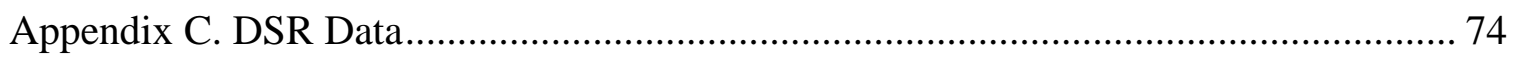

Appendix D. Rotational Viscometer Data ..................................................................... 77

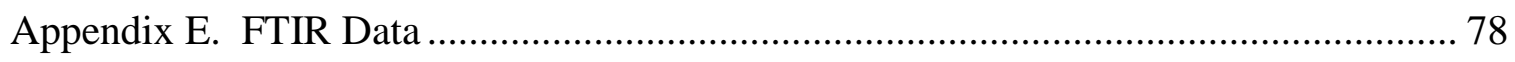

Appendix F. APA Rutting Data ................................................................................. 79

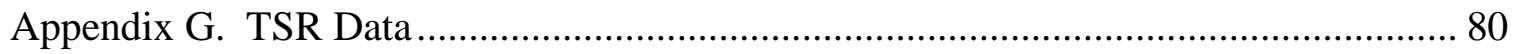

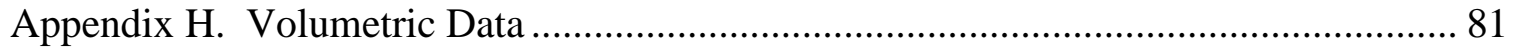




\section{List of Figures}

Figure 2.1 Typical Asphalt Pavement Cross Section................................................... 6

Figure 2.2 Complex Modulus and Phase angle ......................................................... 10

Figure 3.1 Viscosity of PG 70-22 original binder blended with 25\% RAP and waste

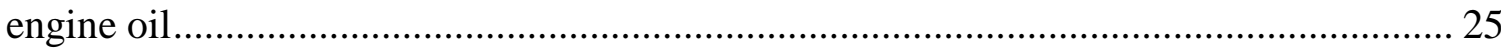

Figure 3.2 DSR results of PG 70-22 original binder blended with 25\% RAP and waste

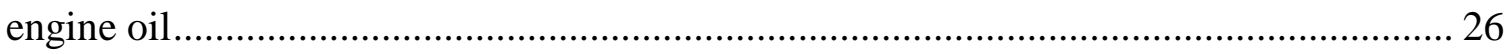

Figure 3.3 DSR Results for Oven Aged binder blended with waste engine oil............... 27

Figure 3.4 DSR Results for RTFO aged binder blended with RAP and waste engine oil 27

Figure 3.5 DSR Results for PAV aged binder blended with RAP and waste engine oil.. 28

Figure 3.6 Results from DSR Testing with PG 70-22 Asphalt Binder........................... 29

Figure 3.7 Results from DSR Testing with Oven Aged Asphalt Binder ......................... 30

Figure 3.8 Results from DSR Testing with RTFO Aged Asphalt Binder ....................... 30

Figure 3.9 Results from DSR Testing with PAV Aged Asphalt Binder.......................... 31

Figure 4.1 FTIR Results for (a) pure binder and engine oil (b) pure RAB and virgin binder blended with 25\% RAB (c) blends of virgin binder, RAB and waste engine oil .. 37

Figure 4.2 FTIR Results: Virgin Binder vs. Pure RAB Binder ....................................... 38

Figure 4.3 FTIR Results: Engine Oil vs. Waste Engine Oil ........................................ 39

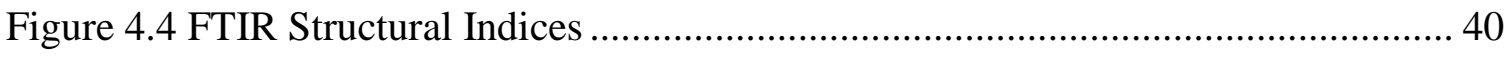

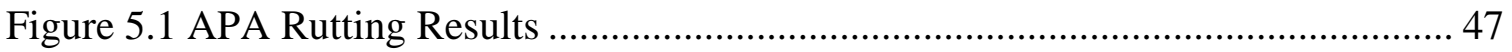

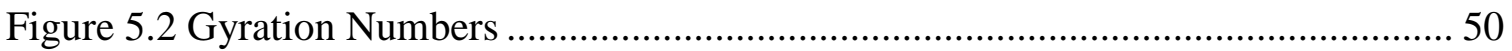




\section{List of Tables}

Table 2.1 FTIR Compounds and Functional Groups....................................................... 17

Table 3.1 Waste Engine Oil Chemical Composition ........................................................ 23

Table 3.2 Composition of asphalt blends...................................................................... 24

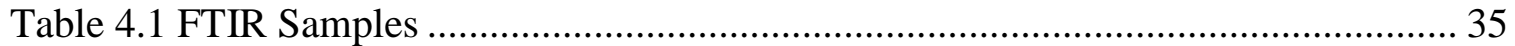

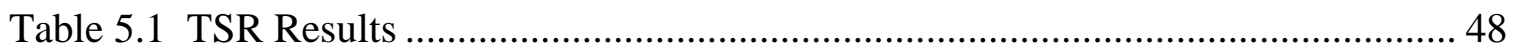




\section{Glossary}

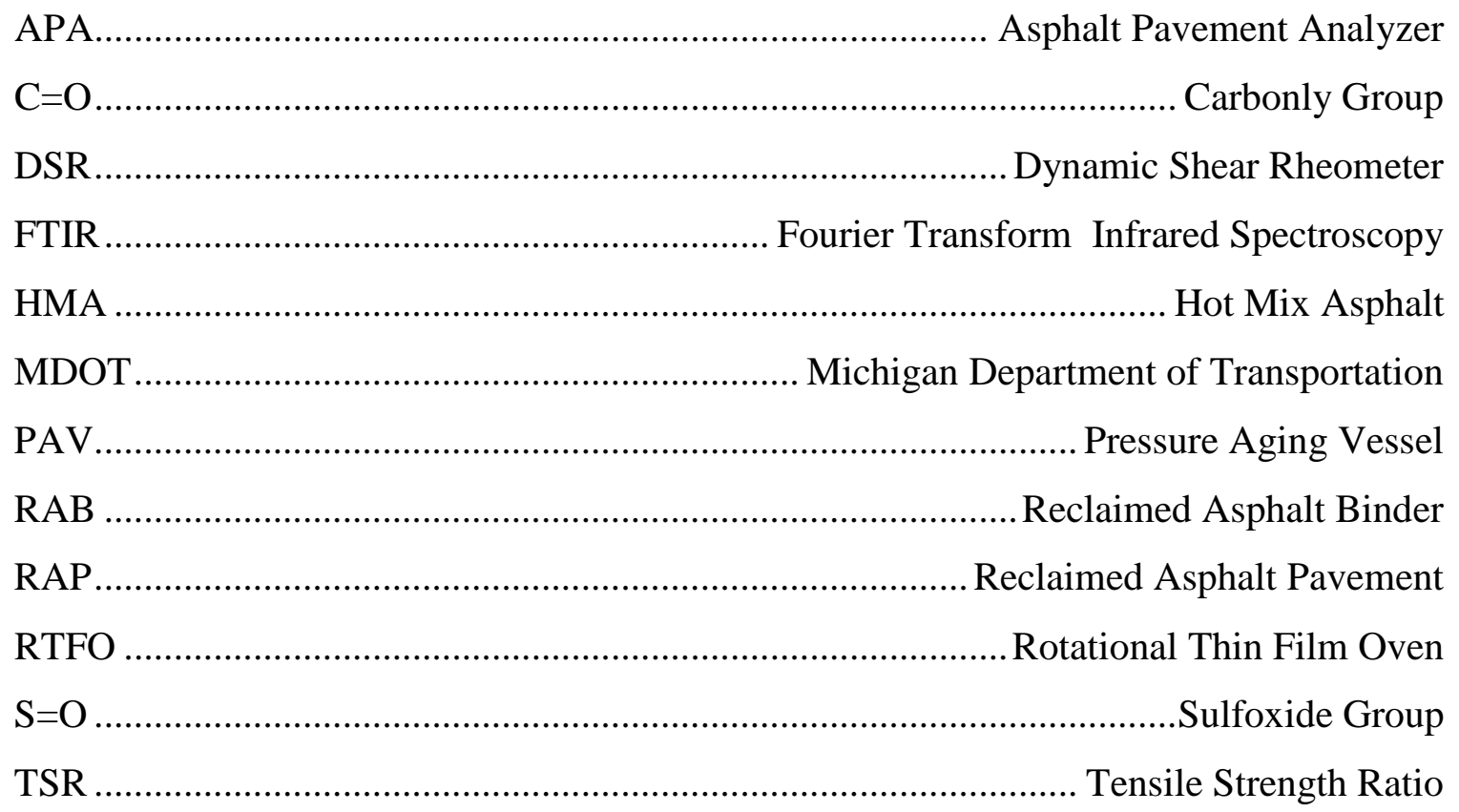




\section{Acknowledgements}

First and foremost, I would like to thank my Advisor, Zhanping You, for his guidance on how to conduct my research. I would also like to thank, Jacob Hiller and David Shonnard for serving on my committee and offering their input on my thesis. Jake, thanks for answering all of my quick questions with responses that lasted for hours. I'd also like to acknowledge the contributions made by my research group: Baron Colbert, Shu Wei Goh, Yao Hui, Yu Liu, Julian Mills-Beale and Xu Yang. Thanks to all of you for aiding me in my research plan and testing. Many thanks are due to our laboratory technicians, Edwin (Ed) Tulppo and James (Jim) Vivian, whose expertise and years of experience spared me from having to learn things the hard way.

Last but not least, I'd like to thank my friends and family for all of their love and support. Special thanks to Rita Lederle for all of her hard work proofing my thesis, and to Khatereh Vaghefi for sitting through my defense presentation not once, but twice.

Much thanks to the NSF for making me feel awesome. This material is based upon work supported by the National Science Foundation Graduate Research Fellowship

under Grant No. DGE-105103. University Transportation Center for Materials in Sustainable Transportation Infrastructure (UTC-MiSTI) funded by USDOT, has provided partial support. 


\section{Abstract}

With the increasing importance of conserving natural resources and moving toward sustainable practices, the aging transportation infrastructure can benefit from these ideas by improving their existing recycling practices. When an asphalt pavement needs to be replaced, the existing pavement is removed and ground up. This ground material, known as reclaimed asphalt pavement (RAP), is then added into new asphalt roads. However, since RAP was exposed to years of ultraviolet degradation and environmental weathering, the material has aged and cannot be used as a direct substitute for aggregate and binder in new asphalt pavements. One material that holds potential for restoring the aged asphalt binder to a usable state is waste engine oil.

This research aims to study the feasibility of using waste engine oil as a recycling agent to improve the recyclability of pavements containing RAP. Testing was conducted in three phases, asphalt binder testing, advanced asphalt binder testing, and laboratory mixture testing. Asphalt binder testing consisted of dynamic shear rheometer and rotational viscometer testing on both unaged and aged binders containing waste engine oil and reclaimed asphalt binder (RAB). Fourier Transform Infrared Spectroscopy (FTIR) testing was carried out to on the asphalt binders blended with RAB and waste engine oil compare the structural indices indicative of aging. Lastly, sample asphalt samples containing waste engine oil and RAP were subjected to rutting testing and tensile strength ratio testing. These tests lend evidence to support the claim that waste engine oil can be used as a rejuvenating agent to chemically restore asphalt pavements containing RAP. Waste engine oil can reduce the stiffness and improve the low temperature properties of asphalt binders blended with RAB. Waste engine oil can also soften asphalt pavements without having a detrimental effect on the moisture susceptibility. 


\section{Introduction}

Asphalt cement is the oldest engineering material in the world. Dating back to ancient Sumeria in 6,000 B.C. asphalt was used to seal ship hulls. From there many other ancient civilizations used naturally occurring asphalts for everything from waterproofing masonry used for public baths, in the Indus Valley, to mummification in Egypt (NCAT 1996). In the early 1800's naturally occurring rock asphalt was used to construct sidewalks in France and the United States. In 1876, the first asphalt road was paved in Washington D.C. (Institute 1960). This precursor to the modern asphalt road was constructed using naturally occurring lake asphalt. In the early 1900's, the discovery of petroleum refining led to the modern refined asphalt cement that we use today (NCAT 1996).

Despite asphalt being an integral part of human society for over 6,000 years and modern society for over a century, many complexities of asphalt pavement still elude researchers. In particular, this research focuses on the ability to recycle spent asphalt pavement into new pavements. When old asphalt pavement is in need of maintenance or replacing, the old material can be mechanically ground and then reused as a substitute for raw materials in new roads. This old, recyclable material is known as reclaimed asphalt pavement (RAP). Since the old material has undergone oxidation, it is stiffer and more brittle than unaged asphalt pavements, therefore in order to use RAP, a chemical recycling agent must be added to counteract the aging (Lins et al. 2008). The use of RAP and its effects on the performance of the new pavement is well documented and the use of RAP without modification is known to produce an overall stiffer asphalt pavement (Widyatmoko 2008). One waste material that may be able to rejuvenate RAP is waste engine oil from cars and trucks (Villanueva et al. 2008). This is the oil removed from the vehicle during a routine oil change. Large quantities of engine oil on pavements impose damage on the asphalt pavement. However, small amounts of waste oil well blended in the mix may prove beneficial when combined with RAP by offsetting the increased stiffness in order to produce a pavement with performance similar to one made of virgin materials. 
The acceptable range of high and low in service ambient temperatures for asphalt binder, called performance grade (PG), can be established from laboratory testing. The dynamic shear rheometer (DSR) and rotational viscometer measure engineering properties of asphalt binder such as dynamic modulus, phase angle, and viscosity. These two tests were used to demonstrate an increase in viscosity and high temperature performance grade (PG) with the addition of RAP binder. Further testing on asphalt binder blended with RAP and waste engine oil showed this stiffening and increase in PG can be reduced. Advanced asphalt binder testing, in the form of Fourier Transform Infrared Spectroscopy (FTIR), was used to study asphalt binder that had been combined with RAP binder and then waste engine oil (Lamontagne et al. 2001). The FTIR testing showed an increase in the chemical compounds indicative of aging when RAP binder was added, followed by a reduction in the aging indices when waste engine oil was added. Mixture testing showed wasted engine oil increased the rutting potential of the asphalt samples, but did not change the moisture susceptibility, measured by the tensile strength ratio (TSR) test (Borhan et al. 2009; Lin et al. 2010). The TSR test gives a ratio of tensile strength of conditioned samples to unconditioned samples. Even though the TSR was relatively constant, the addition of waste engine oil does reduce the indirect tensile strength of the asphalt samples.

\subsection{Project Goals}

The goal of this project is to research the feasibility of using waste engine oil as an asphalt rejuvenator to increase the recyclability of asphalt pavements. In order to explore this problem, several testing methods were used. Traditional asphalt binder testing, advanced asphalt binder testing and performance testing on scale asphalt mixtures were all conducted. Using the dynamic shear rheometer and rotational viscometer, traditional asphalt binder testing was conducted to analyze the change in engineering properties of asphalt binder when aged binder is mixed with waste engine oil.

Advanced asphalt testing, in the form of Fourier Transform Infrared Spectroscopy testing was implemented to study the change in chemistry, if any, when waste engine oil was added to asphalt binder. 
Lastly, mixture testing was conducted to quantify the change in performance caused by the addition of reclaimed asphalt pavement and waste engine oil. For the mixture testing, the resistance to permanent deformation under repeated loadings and moisture susceptibility of the mixtures were investigated to see if the addition of waste engine oil has a detrimental effect on the performance of asphalt pavements.

\subsection{Content}

Chapter two is a comprehensive review of the literature involving asphalt, asphalt pavements, waste engine oil and asphalt testing. This chapter will cover the basics of asphalt pavements, including construction and failure mechanisms. The Superpave performance grading system and corresponding tests are discussed in detail. Also introduced are experiments conducted in this research, including the testing methods, background and theory required to understand them.

Chapter three covers the procedures, results and discussions resulting from Superpave testing on virgin asphalt binder, reclaimed asphalt binder blended with virgin asphalt binder and a blend of asphalt binder, reclaimed asphalt binder and waste engine oil. This testing includes dynamic shear rheometer and rotational viscometer testing on unaged, rolling thin film oven aged asphalt and pressure-aging vessel aged asphalt binder.

Advanced asphalt binder testing is presented in chapter four. Fourier Transform Infrared Spectroscopy testing was conducted on unaged engine oil, waste engine oil, virgin asphalt binder, reclaimed asphalt binder blended with virgin asphalt binder and a two different blends of asphalt binder, reclaimed asphalt binder and waste engine oil. With these results the amount of aging on the samples can be quantified.

Chapter five contains procedures, results and discussions from performance testing on laboratory made asphalt pavement specimens. The chapter discusses how the specimens were created and details of the rutting testing and tensile strength ratio testing. Since rutting and fatigue cracking are the two most common forms of pavement failure, these two performance tests will give insight into how the addition of waste engine oil will affect asphalt pavement performance.

The final chapter, chapter six, summarizes the results obtained from the previous

three chapters. The results from advanced asphalt binder testing are used to explain the 
changes seen by binder and mixture testing. Conclusions and recommendations for future research are also stated. 


\section{Literature Review}

\subsection{Introduction}

In the United States, there are an estimated 250 million registered vehicles traveling on 4 million miles of public road at any given time (FHWA 2008). With this much infrastructure, over 50 million tons of pavement material are generated in the US every year (R. Collins and Ciesielski 1994). The used motor oil from the vehicles traveling on the highway may be able to aid in the recycling of the asphalt pavement material. When RAP is recycled in pavements, previous research has shown increased pavement stiffness and a loss in the low temperature cracking resistance (Kandhal et al. 1995; Chen et al. 2007a; Ma et al. 2010). In pavements without RAP, the addition of waste engine oil into asphalt binder has been shown to reduce the stiffness and improve fatigue resistance (Villanueva et al. 2008). When blended with RAP, waste engine oil may offset the stiffening imposed by the RAP and improve the low temperature performance of the pavement. Together these two waste streams may combine to produce a pavement with performance similar to one made of entirely virgin materials.

\subsection{Asphalt Pavement}

A typical asphalt pavement is comprised of three layers, the subbase, base and asphalt layer all of which sit on top of the subgrade. Figure 2.1 is a schematic of a typical asphalt pavement structure. The subgrade is the existing soil on which the pavement structure sits. Below the base and subbase layer is a layer of coarse grained rock placed on top of the subgrade. The two base layers vary in thickness between 4 and 12 inches and their primary purpose is to provide structure for the asphalt pavement. The asphalt pavement layer itself varies between as thin as four inches to over two feet thick in the case of perpetual pavements (Huang 1993). 


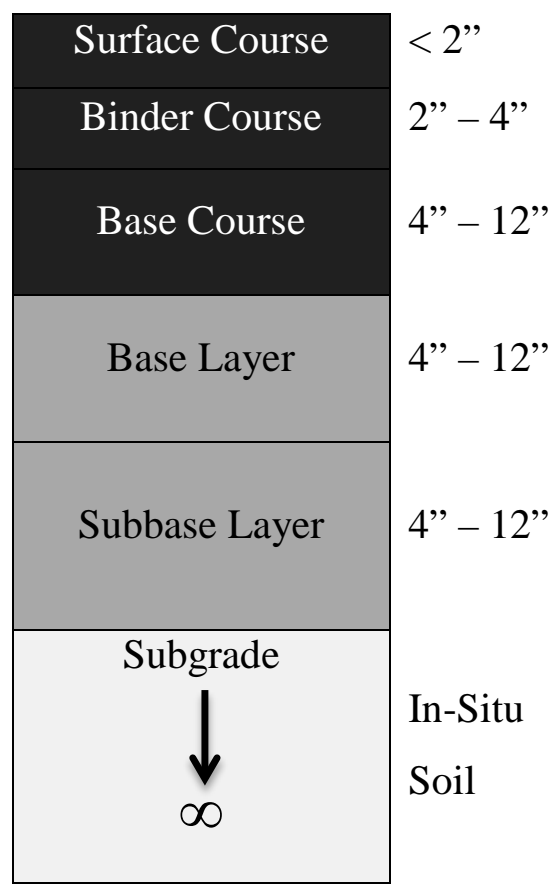

Figure 2.1 Typical Asphalt Pavement Cross Section

The asphalt pavement layer can be further divided into three sub layers: base course, binder course and surface course. The top layer of asphalt concrete, which is exposed to traffic, is the surface or wearing course. The surface course is seldom ever more than two inches in thickness and is chiefly responsible for pavement friction and smoothness. Often this layer uses smaller aggregates than the two layers of asphalt beneath it. Most importantly, this layer can be replaced at the onset of distress to protect the underlying support layers from being damaged. The binder coarse, or leveling course, serves as an intermediary layer to transfer loads between the surface course and the base course. This layer is also used to smooth any discontinuities and ensure surface course of uniform thickness. A typical binder course is between 2-4 inches thick. The final layer, the base course, is constructed of larger aggregates to transfer load through the pavement and into the aggregate layers beneath. The base course can vary in thickness from 4-12 inches, and is often optimized as the thickest pavement layer since it uses less asphalt binder than the two layers on top of it (Institute 1960; Huang 1993). 
Volumetrically speaking, asphalt pavement is comprised of three materials: aggregate, asphalt binder and air. Although a majority of asphalt pavement is aggregate (about 90\%), the two remaining components play a vital role in the stability of the pavement. The level of air voids in the pavement is set to a standard $4 \%$ by volume. This entrapped air is essential for allowing freezing water to escape into the void structure instead of cracking the pavement. The last component, asphalt binder, is the "glue" that holds the pavement together. The binder is by far the most complex component of the pavement system, even though it only represents about five percent of the total weight.

\subsection{Asphalt Binder}

Asphalt binder is a black, sticky, odorous, viscous substance which is semi-solid at ambient temperatures. Since asphalt binder has excellent waterproofing properties and chemical resistance to corrosion from acids and salts, it has also been used as an industrial sealant; however of the chief use of asphalt binder is in the construction of asphalt pavements. Upon heating, asphalt binder becomes more liquid and easily flows. At elevated temperatures (around $160^{\circ} \mathrm{C}$, or $320^{\circ} \mathrm{F}$ ) the heated binder is mixed with aggregates to form asphalt concrete. Upon cooling, the binder will return to its semisolid state with the aggregates suspended inside its matrix.

Asphalt binder is a coproduct of petroleum distillation. Several useful hydrocarbons can be extracted from crude oil by use of a distillation column. From lightest distillate to the heaviest, crude oil also contains gasoline, kerosene, diesel oil, and lubricating oil. Engine oil is derived from the lubricating oil distillates. Still even heavier than lubricating oil is the residual material at the bottom of the distillation column. Within this residual material is asphalt binder (Institute 1960). The importance to this research is not how asphalt binder is produced, but understanding the relationship between asphalt binder and engine oil coming from the same source.

\subsection{Asphalt Failure Mechanisms}

Asphalt pavement is a flexible pavement, meaning it will deform under loading, and the load will transfer through the pavement into the base and subbase layers. The 
load is transferred through aggregate to aggregate contact within the asphalt concrete. As a load passes through the pavement layers it is dissipated with depth. This dissipation of force allows each subsequent pavement layer to be weaker than the ones preceding it. At the bottom of the pavement structure, the load should be small enough that the in-situ soil can withstand the loading without inducing damage. If the pavement is not of sufficient thickness, a failure in the subgrade may result. Such a failure is not a result of the pavement materials, and therefore is beyond the scope of this research.

Asphalt is also a viscoelastic material, meaning it has both viscous and elastic properties. The viscous nature of asphalt allows the pavement to deform to dissipate loads, while the elastic component means the road will return to its original shape after loading. However, if a load is beyond the asphalts ability to deform and maintain its shape, damage in the form of permanent deformation may occur. The damage from permanent deformation is known as rutting and it usually occurs in the wheel path due to the binder having insufficient stiffness to support traffic loads. Rutting is only a problem at high ambient temperatures, since that is when the asphalt binder is the least viscous.

Rutting it is one of the two main failure mechanisms in asphalt pavements, the other is cracking. There are two main types of cracks that occur in asphalt pavement, fatigue cracking and thermal cracking. Fatigue cracking occurs when the asphalt binder is not elastic enough to handle repeated traffic loadings. The stresses induced from traffic loading will cause the pavement to fracture if the asphalt binder is unable to handle repeated loading. Thermal cracking occurs when the asphalt binder is subjected to a rapid change in ambient temperature. A sudden drop in temperature will cause the road to contract, however if the rate of contraction is faster than the rate at which binder can relax, stresses build in the pavement. After enough thermal stress is generated, the road will fracture.

These two failure mechanisms cause problems for designers of asphalt pavements. The binder must be stiff enough to resist damage from rutting, but soft enough to dissipate stresses built up without fracturing. Several methods of asphalt binder characterization have been developed over the years to address the need for asphalt binder to handle high and low temperature failure mechanisms. The most current 
materials characterization system is the Superior Performing Asphalt Pavements system, or Superpave system.

\subsection{Superpave}

In the United States, asphalt pavements are designed with the Superpave design method. This method, developed in the 1980's, is a way to classify asphalt binder and provide a design aid for asphalt pavements. Superpave specifies limits to which the binder must conform in order to achieve a performance grading. The performance grading of asphalt binder is based on two temperatures, a high temperature and a low temperature. The high temperature refers to the maximum seven day average temperature the pavement will see during its design life. The low temperature is the lowest single-day temperature the pavement will experience during its design life. This range is denoted by a binder classification off PG XX-YY, where XX is the acceptable high temperature in ${ }^{\circ} \mathrm{C}$, and $\mathrm{YY}$ is the low temperature rating of the binder in negative ${ }^{\circ} \mathrm{C}$. Several tests have been developed to determine the performance grade (PG) temperature of asphalt binder. The dynamic shear rheometer (DSR) and rotational viscometer are two of the standard tests used in the Superpave mix design to classify binder. Superpave also has standard ways in which simulated aging of asphalt binder is conducted. The rolling thin film oven is used to simulate short term aging, and the pressure aging vessel simulates long term aging.

\subsubsection{Dynamic Shear Rheometer}

The Dynamic Shear Rheometer (DSR) is used to measure asphalt binder's engineering properties when subjected to a sinusoidal load. The testing is best described by ASTM D 7175 (ASTM 2008c). The DSR test involves a sample of asphalt binder placed between circular parallel plates that have a sinusoidal load applied and the response of the binder is then measured. Depending on whether the binder is aged or unaged, two variations of the test are performed. For unaged binder, the plates measure $25 \mathrm{~mm}$ in diameter and are spaced a distance of 1000 microns apart. For aged binder, the plates are $10 \mathrm{~mm}$ in diameter and placed 2000 microns apart. The smaller sample size is 
used on aged binder because of a mechanical limitation of the DSR being unable to accurately shear the stiffened binder.

To conduct the test, the binder is submerged in a water bath at a fixed temperature equal to the PG high temperature grade. After ten minutes of temperature acclimation, the binder is loaded and the DSR measures the Complex Modulus $\left(\mathrm{G}^{*}\right)$ and phase angle $(\delta)$ of each sample. Figure 2.2 shows the relationship between complex modulus and phase angle. The Superpave system uses the parameter $\mathrm{G}^{*} / \mathrm{Sin}(\delta)$ as an indication of the rutting or permanent deformation standard performance criterion and $\mathrm{G}^{*} \cdot \operatorname{Sin}(\delta)$ as an indication of the resistance to cracking for the low temperatures.

When the $\mathrm{G}^{*} / \mathrm{Sin}(\delta)$ parameter is greater than $1.00 \mathrm{kPa}$ for unaged binder or greater than $2.2 \mathrm{kPa}$ for RTFO aged binder at a given PG temperature, the binder meets that the rutting criterion for performance. Binder is tested at progressively higher PG temperatures until it exceeds the test parameter, or fails. For Pressure Aging Vessel (PAV) aged binder, the $\mathrm{G}^{*} \cdot \operatorname{Sin}(\delta)$ has a ceiling of $5000 \mathrm{kPa}$ and if the binder exceeds that limit, it fails specification.

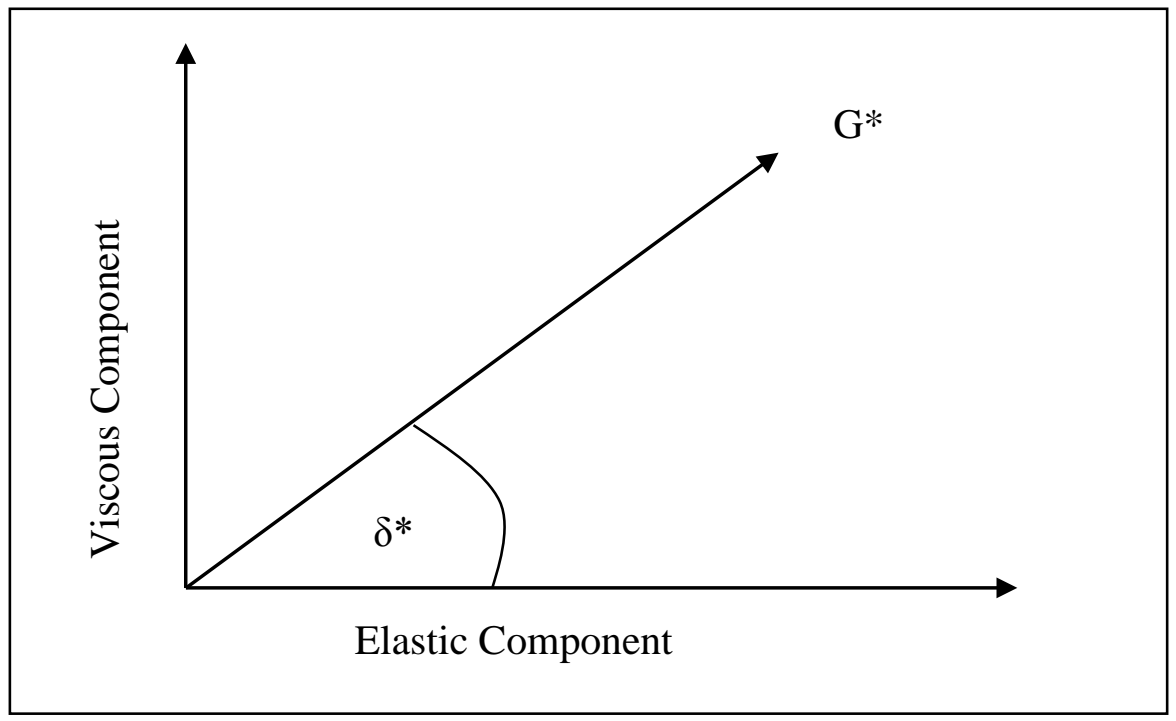

Figure 2.2 Complex Modulus and Phase angle 


\subsubsection{Rotational Viscometer}

The rotational viscometer test is used to determine the viscosity of the asphalt samples. ASTM D 4402 describes the procedures for the rotational viscometer test (ASTM 2008d). Since the properties of asphalt binder are temperature dependent, the rotational viscometer is run at different temperatures to determine the change in viscosity of asphalt binder relative to the change in temperature.

To conduct this test, ten grams of asphalt binder are placed inside a temperature controlled thermo cell. A spindle attached to a rotating motor is suspended inside the binder and forced to spin at a constant rate. Once the spindle and binder have equilibrated, the machine with the spindle attached displays the viscosity of the binder in units of centipoise (cP). Superpave sets a maximum of $3000 \mathrm{cP}$ at $135^{\circ} \mathrm{C}$ to pass specification; however because of the temperature dependency of asphalt binder, tests are conducted at several temperatures are read to better understand the behavior of the material.

\subsubsection{Laboratory Aging of Asphalt Binder}

Laboratory aging of the binders was also specified under the Superpave system. The system uses two machines, the rolling thin film oven (RTFO) and pressure aging vessel (PAV) to simulate different periods of aging for asphalt binder. The RTFO testing procedure is described by ASTM D 2872 (ASTM 2008e). In this test, glass bottles are filled with 35 grams of asphalt binder and freely spun in a $163^{\circ} \mathrm{C}$ oven for 75 minutes. This process is often referred to as short term aging, as it is meant to simulate the aging binder undergoes during mixing and transporting to the construction site.

The pressure aging vessel (PAV) is used to simulate long term aging. ASTM D 6521 outlines the procedures for obtaining PAV aged asphalt binder (ASTM 2008f). To perform this test, RTFO aged binder is poured into shallow steel pans at a weight of 50 grams of binder per pan. The PAV is then loaded with the pans and sealed. The sealed chamber is heated to $100^{\circ} \mathrm{C}$ and a pressure of $2.10 \mathrm{MPa}$ (305 psi). Even though the sample is held under heat and pressure for only 20 hours, the end result is binder that has

a simulated field age of 5 to 10 years. The accelerated aging occurs in an oxygen rich 
environment in which the high pressure forces oxygen into the asphalt binder to simulate field oxidation.

\subsection{Reclaimed Asphalt Pavement}

Reclaimed asphalt pavement (RAP) is the material produced from the removal of old asphalt highways. When a highway is in need of maintenance, the old road can either be completely removed or have only the top few inches ground off, a procedure called milling. In either case, this waste material, called RAP, is typically ground into aggregates, which are inherently coated with aged asphalt binder. This ground material can be added into new roads at the asphalt plant, to reduce the amount of virgin aggregates and virgin binder needed. The primary benefit of RAP is a direct cost savings due to the reduction in virgin materials. The aggregate in RAP replaces some of the aggregate in new asphalt pavement, and the aged binder attached to the aggregates is assumed to replace a portion of virgin binder required for new road construction (Ozer et al. 2009). Research has shown that a secondary benefit of RAP is that a pavement containing recycled material ages more slowly when compared with pavements constructed entirely from virgin materials (Dunning and Mendenhall 1978).

Although many DOTs have adopted the practice of using RAP in their pavements, the quantity at which it is added is fairly low; $10-15 \%$ in the wearing course per Superpave specifications with only few state agencies allowing for high RAP contents (Widyatmoko 2008; Ma et al. 2010). There are several issues with using RAP to replace some virgin materials. Most notably, there is an increased stiffness associated with using RAP, which may improve rutting resistance, but cause premature failure in low temperature cracking (Ma et al. 2010). There is also debate about how much of the asphalt binder contained in the RAP contributes to the pavement, since some of the binder may be trapped inside of the pores of the RAP aggregates (Ozer et al. 2009). This uncertainty contributes to the reluctance of using higher RAP pavements.

Another problem with using RAP as an engineering material is the variability between RAP sources and stockpiles. Depending on where the RAP originated, there could be different source binder PG's, different degrees and types of aging, and different binder additives. This variability is the main reason DOT's will only allow RAP to be 
added in small percentages, because small percents of recycled binder have little effect on the overall pavement performance. Ultimately, to use high percentages of RAP as standard practice, every stockpile must be thoroughly tested and classified before being implemented in higher percentages.

\subsubsection{Recycling Agents}

In order to limit the amount of variation seen with different RAP sources and to improve the properties of the aged binder, chemical additives, known as recycling agents, are blended into the asphalt mixture. The purpose of recycling agents is to restore asphalt consistency and chemistry. In general, there are two types of chemical additives that can be added to pavements containing RAP: rejuvenating agents and softening agents. The primary difference between a softening and rejuvenating agent is that a rejuvenating agent will try to restore the chemical structure of aged asphalt while a softening agent blends into a mix to reduce the overall viscosity of the binder (Chen et al. 2007). Unless it can be proven the recycling agent is chemically altering the asphalt binder, it is considered a softening agent. In either case, recycling agents are usually made out of a petroleum product comprised of either highly polar or aromatic oils (Newcomb et al. 1984).

Much literature exists on recycling agents. In general, more than ten percent recycling agent, by weight of binder, proves detrimental to the asphalt binder (Katamine 2000; Borhan et al. 2009). Despite having potentially negative effects on the asphalt binder, recycling agents are recommended for mixtures containing either high amounts of RAP or heavily oxidized RAP. In fact, recycling agents have been shown to improve low temperature performance properties and perform better than pavements with RAP and no recycling agent (Lin et al. 2010). With regards to Superpave performance classifications, usually reclaimed asphalts that are sufficiently blended with aromatic modifiers will meet the specification for virgin binder (Dunning and Mendenhall 1978).

\subsubsection{RAP Extraction and Recovery}

RAP is a heterogeneous mixture of asphalt binder and aggregates; however for research purposes it is necessary to isolate the binder from the aggregates. To separate 
the binder from the aggregates, binder must be chemically stripped from the aggregates, ultimately leaving only the aged binder for lab testing. ASTM D 2172 is the standard procedure for extracting the asphalt binder from the aggregates (ASTM 2005b). This process involves soaking the RAP in the industrial solvent, trichloroethylene, then using a filter and a high-speed centrifuge to separate the asphalt binder-solvent solution from the aggregates. Once separated, the original weight of the RAP and the dried weight of the remaining aggregates can be used to calculate the percentage of binder contained in the RAP.

The solution of trichloroethylene and asphalt binder can be separated in a distillation process using heat as the separating agent. ASTM D 1856 is the standard procedure for recovering asphalt binder from solution (ASTM 2005a). Once all of the trichloroethylene has been boiled off, only recovered asphalt binder (RAB) remains. This RAB can be combined with virgin binder and tested in a laboratory to simulate field applications where RAP was used. In practice, the process of extracting RAB would not be used for full-scale pavement construction as it is far too costly to be economically viable.

\subsection{Asphalt Chemistry}

Superpave specifications for asphalt binder target the engineering properties of the samples and focus little on the chemical composition of asphalt binder. Even though the engineering properties of the asphalt binder are what will control the performance of the pavement, it is important to acknowledge the need for understanding the interactions between asphalt binder and the additives being used. Authors have suggested that, based on the results from a few test cases, certain additives are undesirable as asphalt additives (Soleimani et al. 2009). However, it is important that in order to definitively advocate for or against additives, fundamental testing is needed that supports either claim.

\subsubsection{Chemical Structure}

At the molecular level, asphalt binder is made up of asphaltenes and maltenes. The asphaltenes are large dark brown to black polar compounds which are responsibility for the asphalts viscosity and adhesion. Maltenes are a colloidal combination of oils and 
resins in which the asphaltenes are dispersed (Katamine 2000; Mamlouk and Zaniewski 2006). The role of the maltenes to provide stability to the asphaltenes, therefore additives in the bitumen typically modify the maltene structure (Katamine 2000). Using selective adsorption characterization, the maltenes can be further broken down into saturates, and polar and non-polar aromatics. However, in order to break down maltenes into these three subgroups, advanced solubility testing or modified Clay-Gel absorption chromatography must be performed (Kiggundu et al. 1984; Newcomb et al. 1984). Since those advanced classification techniques are beyond the scope of this research, the furthest breakdown of asphalt binder to be used are asphaltenes and maltenes.

It is easiest to visualize asphaltenes and maltenes by comparing them to the relationship of asphalt binder and aggregate inside of an asphalt pavement. The molecular structure of asphaltenes and maltenes is best explained an analogy: asphalt binder is to aggregates as maltenes are to asphaltenes. In other words, the asphaltenes are much larger in size than their maltene counterpart, and give the binder form and structure. The resins contained in the maltenes act as a solvent to peptize the asphaltenes with oils to create a homogeneous binder (NCAT 1996; Mamlouk and Zaniewski 2006).

\subsubsection{Asphalt Aging}

As asphalt ages, there is a loss of aromatics that takes place due to volatilization. Recall from earlier, the polar and non-polar aromatics are two of the three sub compounds contained within maltenes. Upon oxidation, the maltenes will yield asphaltene type molecules (NCAT 1996). Since the maltenes are converted to asphaltenes, there is an overall loss of maltenes as a pavement ages. The loss of maltenes translates to a stiffer pavement that is more brittle due to a lack of cohesion inside the binder. One can relate this scenario to an asphalt pavement with not enough asphalt binder to visualize why the loss of maltenes has such a detrimental effect on the pavement structure.

One advantage to using RAP is that recycled asphalt binder that has been rejuvenated tends to age more slowly than a purely virgin pavement (Dunning and Mendenhall 1978). Since the main cause of asphalt aging is the loss of maltenes, in order 
to rejuvenate aged binder, the chosen rejuvenator must provide maltenes to the binder to restore the binders’ stability (Borhan et al. 2009).

\subsection{Waste Engine Oil}

There are varied opinions on the feasibility of lubricating oil as an additive in asphalt cement as most of the research has focused on trying to improve the low temperature properties of asphalt (Villanueva et al. 2008; Borhan et al. 2009; Soleimani et al. 2009). Although it is proven that the addition of engine oil can improve the low temperature properties of asphalt, little research has been done on waste engine oil as a recycling agent for lessening the stiffening effect of RAP in asphalt paving mixtures (Hayner 1999; J. H. Collins and Jones 2000).

\subsection{Fourier Transform Infrared Spectroscopy (FTIR)}

Fourier Transform Infrared Spectroscopy (FTIR) is an advanced technique aimed at classifying the organic chemical compounds found in various organic substances. This technology is based on the principle that a beam of infrared light is comprised of multiple wave lengths and that specific organic chemical compounds will absorb only one range of wavelengths. This allows the instrument to send a beam of infrared light through a sample mounted on a substrate and, using a detector on the other side of the sample, read the wavelengths that pass freely though the sample. Calibrating these results with pure, known substances, the wavelengths that are absorbed can be correlated with specific organic bonds (functional groups). One advantage to FTIR analysis is that the user is provided with both qualitative and quantities results. This will not only identify the different functional groups present in the sample, but it will also give some measure to the percentage contained.

When asphalt binder is analyzed with FTIR testing, a number of functional groups can be observed within the binder. Table 2.1 contains a comprehensive list of the common groups within asphalt binder (Ouyang et al. 2006a; Shakirullah et al. 2007; Zhang and Yu ; Zhang et al. 2011). Since both asphalt and engine oil are hydrocarbons, most of the samples are mostly comprised of aromatic and saturated hydrocarbons. The two compounds of most interest are the sulfoxides and carbonyls which peak at $1030 \mathrm{~cm}^{-}$ 
${ }^{1}$ and $1700 \mathrm{~cm}^{-1}$ respectively. These two compounds are commonly used as an indication of the amount of aging asphalt binder has undergone. As the amount of sulfoxides and carbonyls increase, the binder is shown to age (Ouyang et al. 2006b; Wu et al. 2009). The increase in either of these two compounds corresponds to an increase in polar compounds of higher molecular size (Cortizo et al. 2004).

Table 2.1

FTIR Compounds and Functional Groups

\begin{tabular}{|c|c|c|}
\hline Compound Name & $\begin{array}{c}\text { Functional } \\
\text { Groups }\end{array}$ & $\begin{array}{c}\text { Spectrum Range (cm } \\
1 \text { ) }\end{array}$ \\
\hline Alkanes & C-H & $650-910$ \\
\hline Butadiene & $\mathrm{HC}=\mathrm{CH}$ & 965 \\
\hline Sulfoxide & $\mathrm{S}=\mathrm{O}$ & 1030 \\
\hline $\begin{array}{l}\text { Aromatic } \\
\text { Hydrocarbons }\end{array}$ & $\begin{array}{l}\mathrm{C}-\mathrm{H}, \mathrm{CH}_{2} \text { and } \\
\mathrm{CH}_{3}\end{array}$ & $1375-1530$ \\
\hline Aromatics & $\mathrm{C}=\mathrm{C}$ & 1600 \\
\hline Carbonyl & $\mathrm{C}=\mathrm{O}$ & 1700 \\
\hline $\begin{array}{l}\text { Saturated } \\
\text { Hydrocarbons }\end{array}$ & C-H & $2850-3000$ \\
\hline
\end{tabular}

To quantify how much of the sample is representative of each peak, Lamontagne proposed a method of numerically integrating the bands around the peaks of interest then normalizing the area over the entire area of the spectral bands between $600 \mathrm{~cm}^{-1}$ and 2000 $\mathrm{cm}^{-1}$ (Lamontagne et al. 2001). This method can be represented by equations [2] and [3], where $\mathrm{I}_{\mathrm{C}=\mathrm{O}}$ is the structural index of the carbonyl compound and $\mathrm{I}_{\mathrm{S}=\mathrm{O}}$ is the structural index of the sulfoxide compound (Wu et al. 2009; Zhang and $\mathrm{Yu}$ 2009). Used individually, the structural index number is not very useful, since no standardized reference values have been accepted to compare different asphalts. FTIR testing is conducted on a series of binders and the indices of each binder are compared against each other to give a relative level of aging that has taken place. 


$$
I_{C=O}=\frac{\text { Area of carbonyl band centered around } 1700 \mathrm{~cm}^{-1}}{\sum \text { Area of the spectral bands between } 2000 \mathrm{~cm}^{-1} \text { and } 600 \mathrm{~cm}^{-1}}
$$

$$
I_{S=O}=\frac{\text { Area of sulfoxide band centered around } 1030 \mathrm{~cm}^{-1}}{\sum \text { Area of the spectral bands between } 2000 \mathrm{~cm}^{-1} \text { and } 600 \mathrm{~cm}^{-1}}
$$

One reason FTIR testing is useful is because it can provide insight as to the relative levels of maltenes contained in the asphalt samples. Asphaltenes are much larger and more polar then their maltene counterpart (Lins et al. 2008). When there is an increase in either the carbonyl or sulfoxide index, there is an increase in the amount of large polar molecules, or asphaltenes, contained inside the binder. Recall from earlier, as maltenes oxidize, they will tend to form into asphaltenes. This means the FTIR test can be used to quantify the change in the molecular structure inside asphalt binder from maltenes into asphaltenes. Further evidence of this conclusion can be inferred from Table 2.2; the only compounds bonded with oxygen are the carbonyls and sulfoxides. If the binder is to oxidize, it must show as in increase on either one of these indices.

\subsection{Asphalt Mixture Testing}

Sample testing using HMA specimens are common practice for testing asphalt binders, aggregates, or the combination of the two. In the laboratory, compacted cylinders of asphalt, known as pucks, are created in conditions that carefully mimic field construction of asphalt pavement. These pucks will have a final air void content, binder content and aggregate gradation similar to the same mixture that would be placed for a road. Once created, samples are subjected to laboratory tests that represent accelerated and worst case field conditions to see how resilient the mixture is. This research made use of two such tests: the APA rutting test and the Tensile Strength Ratio (TSR) test. The APA rutting test passes a heavy wheel over asphalt samples and measures their rutting potential. The TSR test soaks samples in water, and then freezes them to induce moisture 
damage. The damage from freezing is then normalized to an undamaged sample and a benchmark ratio can be established.

\subsubsection{Mixture Specifications}

The types and sizes of aggregate used in pavements have a huge impact on the overall strength and durability of the pavement. Ideally, aggregates should contain a good distribution of large and small particles. This distribution, or gradation, has a Michigan Department of Transportation (MDOT) specified standard to which it must conform. This research made use of an industry standard Job Mix Formula (JMF) which contains a manufacturer specification for gradations. One advantage to using a JMF is that it alleviates the need to design a new mixture every time an experiment starts. Also, if the JMF is followed, the laboratory mixtures can easily be compared to other mixtures using the same JMF and the corresponding field sections the JMF was designed for.

\subsubsection{Test Samples}

Superpave specification sets an optimal air void content of asphalt pavement for four percent (NCAT 1996). Empirically, at four percent air voids the asphalt pavement has the best performance, since there are enough voids for water trapped in the pavement to expand during a freeze event without damaging the pavement, but not enough voids to reduce strength, or to allow air to freely flow through the pavement, which would accelerate oxidation of the binder.

\subsubsection{Rutting Test}

Of the two failure mechanisms in asphalt pavements, rutting is one which can be directly simulated for in the laboratory. In order to test samples for rutting resistance, the propensity for rutting was measured using a rutting machine. The rutting machine simulates traffic loads by passing a 100 pound wheel load over HMA samples at the pavement's design high temperature. After repeated loads, the amount of damage in the different samples can be compared against each other.

For this research, the Asphalt Pavement Analyzer (APA) rutting machine was used to conduct the rutting test. There is no current accepted industry standard for performing the rutting test, however the manufacturer standards were followed for lack of 
a better standard testing procedure (Pavement-Technology-INC.(PTI) 2003). To ensure a rutting failure, the pavement samples are tested at their high temperature PG. Samples are loaded into the APA rutting machine and allowed to reach thermal equilibrium before testing began. The test runs for 7500 load cycles over the samples, and records the depth of the rut over the duration of the test.

\subsubsection{Tensile Strength Ratio Test}

The moisture susceptibility of asphalt pavement relates to the ability of pavement to withstand freeze-thaw cycles when moisture has penetrated into the asphalt concrete. To measure this susceptibility, a ratio of two different samples is used to quantify the change in tensile strength in laboratory specimens of asphalt concrete. The first set of samples, known as conditioned samples, are vacuum-saturated with water, and then frozen. Upon freezing, the expansion of the water inside the samples will induce damage into structure of the samples. After freezing, the conditioned samples are thermally shocked in a hot water bath to further induce damage. The second sets of samples, the unconditioned samples, are the same in composition as the conditioned samples, but no damage is induced. Both samples are crushed in indirect tension and the peak compressive strengths recorded.

The tensile strength ratio (TSR) is calculated with the peak values from the indirect tension testing. The test procedure for TSR testing is specified under AASHTO T 283 (AASHTO 2010). Dividing the maximum compressive strength of the conditioned samples by the maximum compressive strength of the unconditioned samples gives the TSR for each sample. The TSR is almost always less than one, since the conditioned samples are inherently weaker than unconditioned samples. 


\section{Asphalt Binder Testing}

\subsection{Introduction}

Previous research has suggested that the inclusion of reclaimed asphalt pavement (RAP) will make asphalt pavements stiffer in nature and increase performance grade (PG) (Kandhal et al. 1995). Research into the feasibility of waste engine oil as an asphalt modifier have concluded that waste engine oil will soften virgin binder and cause a reduction in PG (Villanueva et al. 2008). These two findings could be combined to utilize both the cost savings of RAP with the softening properties of waste engine oil to offset the unavoidable stiffening inherent with using RAP. In order to test the theory that waste engine oil can be combined with RAP as a recycling agent, small scale binder testing was performed. In this phase of research, asphalt binder recovered from the RAP stockpile was blended with virgin binder. The resultant blend of asphalt binder was combined with four and eight percent waste engine oil to produce three different modified samples in addition to the pure virgin control binder. The four types of binder were tested for viscosity, aged dynamic modulus and unaged dynamic modulus.

\subsection{Methods}

The virgin binder chosen for this study was a PG 70-22 neat binder obtained from a pavement project in Grand Rapids, Michigan. This binder was combined with RAPrecovered binder at the ratio of $75 \%$ neat binder to $25 \%$ RAP-recovered binder. The RAP-recovered binder was extracted from a RAP stockpile in Hancock, Michigan. In extracting the RAP binder, the ASTM D 2172 procedure was followed (ASTM 2005b). The extraction process involved soaking the RAP in trichloroethylene, then centrifuging the solution of asphalt binder and trichloroethylene from the aggregates. Once extracted, the binder was recovered using the rotary evaporation process as described in ASTM D 1856 (ASTM 2005a). The recovery process involved distilling the solution of trichloroethylene and asphalt binder. The solution was heated until the trichloroethylene boiled out of solution, leaving only the recovered asphalt binder (RAB). The extraction process yielded 88 grams of RAB from 2800 grams of the sample of RAP. 
A second source of aged asphalt was created in the laboratory by open air aging a PG 58-28 binder in a $100^{\circ} \mathrm{C}$ oven for several weeks. A thin layer of the PG 58-28 binder was placed in a laboratory pan inside of on oven. Inside the oven, hot air was circulated over the binder to encourage oxidation. In-house air aging was chosen to supplement $\mathrm{RAB}$ testing because a second source of RAB was unavailable for testing. There is a known variability in RAP stockpiles, so a second source of RAB is important for broad applicability.

The used engine oil was supplied by the Michigan Tech motor pool. The oil was a Chevron Delo 400 LE SAE 15W30 Diesel type oil with 144 machine hours. Due to perceived environmental concerns, there is some stigma over the idea of mixing used engine oil into asphalt pavements. To counter this opposition, Summit Environmental Technologies, INC. tested the oil waste stream for potentially hazardous contents. Both EPA and ASTM test methods were utilized for the testing of the oil. The results of the test show the contaminants Arsenic, Cadmium, and Polychlorinated biphenyls (PCBs) at concentrations of less than 1 part per million (ppm) and chromium at less than $4 \mathrm{ppm}$, is below the restrictions placed on hazardous waste by the EPA (e-CFR 2006). A complete table of the hazard content test results can be found in Table 3.1.

All of the contents of the waste engine oil, with the exception of lead, are below the EPA admissible limits for hazardous waste. However, if the waste engine oil remains locked inside the asphalt binder while inside the pavement, it may be possible to achieve permitting to use waste engine oil as a recycling agent. Previous research by Herrington examined the leachate potential of oil contained inside asphalt pavements that were subjected to laboratory-simulated environmental weathering (Herrington et al. 1993). In this experiment, the oil had a lead concentration of $29,000 \mathrm{mg} / \mathrm{kg}$. At 5 percent oil blended with the binder, the leachate test yielded a lead concentration of less than 0.05 $\mathrm{mg} / \mathrm{L}$. The oil used in the above study had a concentration significantly higher than that obtained for this report, and was shown to leach at a concentration much lower than the EPA acceptable level. 
Table 3.1

Waste Engine Oil Chemical Composition

\begin{tabular}{|l|c|c|}
\hline \multicolumn{1}{|c|}{ Parameter } & Waste Oil Test Results & Allowable Level \\
\hline Arsenic & $<1.0 \mathrm{ppm}$ & $5.56 \mathrm{ppm}$ \\
\hline Ash & $0.66 \%$ & -- \\
\hline BTU/Gal & $138795 / \mathrm{gal}$ & -- \\
\hline Cadmium & $0.28 \mathrm{ppm}$ & $1.11 \mathrm{ppm}$ \\
\hline Chromium & $<4.0 \mathrm{ppm}$ & $5.56 \mathrm{ppm}$ \\
\hline Flash Point & $>200^{\circ} \mathrm{F}$ & $140^{\circ} \mathrm{F}$ \\
\hline Lead & $14.0 \mathrm{ppm}$ & $5.56 \mathrm{ppm}$ \\
\hline PCB & $<1.0 \mathrm{ppm}$ & $1.11 \mathrm{ppm}$ \\
\hline pH & $6.69 @ 22.7^{\circ} \mathrm{C}$ & $2-12$ \\
\hline Sulfur, Wt\% & $0.19 \%$ & -- \\
\hline Total Halogen, ppm & $396 \mathrm{ppm}$ & -- \\
\hline
\end{tabular}

The waste engine oil was blended with the asphalt blends in two concentrations; $4 \%$ and $8 \%$ by total weight of binder. With the aid of a glass rod and under continuous stirring action, the binders were mixed homogenously in a standard specimen can over a hot plate at temperatures around $150^{\circ} \mathrm{C}$. The percentages were chosen based on a review of literature on recycling agents in which the authors advocate against using high concentrations of recycling agent because of the potential damage to the asphalt pavement (Villanueva et al. 2008; Widyatmoko 2008). With the blends, seven types of binder were tested: original binder (Original Binder), 25\% RAP blended with original binder at three percentages of oil, 0, 4, and 8 percent (RAP-0\%, RAP-4\%, RAP-8\% respectively), and in-house oven aged asphalt blended with 0, 4 and 8\% Oil (OA-0\%, OA-4\%, OA-8\%, respectively). Table 3.2 shows the breakdown of sample compositions. 
Table 3.2

Composition of asphalt blends

\begin{tabular}{|c|ccccccc|}
\hline & $\begin{array}{c}\text { Original } \\
\text { Binder }\end{array}$ & RAP-0\% & RAP-4\% & RAP-8\% & OA-0\% & OA-4\% & OA-8\% \\
\hline \% Aged & 0 & 25 & 25 & 25 & 100 & 100 & 100 \\
\hline \% Oil & 0 & 0 & 4 & 8 & 0 & 4 & 8 \\
\hline
\end{tabular}

After the samples had been prepared, rotational viscometer testing was performed according to ASTM D 4402. The tests were performed on a Brookfield model DV-II Viscometer. The viscosity readings were taken at four temperatures: $100^{\circ} \mathrm{C}, 125^{\circ} \mathrm{C}$, $140^{\circ} \mathrm{C}$ and $160^{\circ} \mathrm{C}$.

The binder was tested on a Bolhin CVO 120 Dynamic Shear Rheometer (DSR). Standard Strategic Highway Research Program (SHRP) Pass/Fail testing was conducted at various temperatures. SHRP Pass/Fail testing involves testing samples at low temperatures then progressively testing at the next highest PG until the sample fails by testing below the established Superpave control limits. At the point of failure, the test is discontinued since subsequent tests will fail at every temperature above the initial failure temperature.

The DSR measured the Complex Modulus $\left(\mathrm{G}^{*}\right)$ and phase angle $(\delta)$ of each sample. The Superpave system uses the parameter $\mathrm{G}^{*} / \operatorname{Sin}(\delta)$ as an indication of the rutting or permanent deformation standard performance criterion. When the $\mathrm{G}^{*} / \mathrm{Sin}(\delta)$ parameter is greater than $1.00 \mathrm{kPa}$ for unaged binder or $2.2 \mathrm{kPa}$ for RTFO aged binder at a given PG temperature, the binder meets the Superpave rutting criterion for performance and is then progressively tested at the next grade temperature until it fails, that is until the testing parameter is not met. For PAV aged binder, the $\mathrm{G}^{*} \cdot \operatorname{Sin}(\delta)$ has a ceiling of 5000 $\mathrm{kPa}$. Asphalt binder is tested at progressively lower temperatures inside the DSR until the $\mathrm{G}^{*} \cdot \operatorname{Sin}(\delta)$ reads above $5000 \mathrm{kPa}$, at that time the binder is said to have failed to meet specification and the test is discontinued. 


\subsection{Results}

From the DSR testing, the following data was obtained. Figure 3.1 is a plot of the viscosity results of the original binder, and then the original binder with $25 \%$ RAB and increasing amounts of engine oil. From this graph, it is shown that the binder blended with RAB experienced an upward shift in viscosity when compared to the control with no RAB. This shift corresponds to a stiffening of the binder once RAB has been added. The binders containing $4 \%$ and $8 \%$ waste engine oil then caused a downward shift in viscosity, which corresponds to a softening when the oil was added.

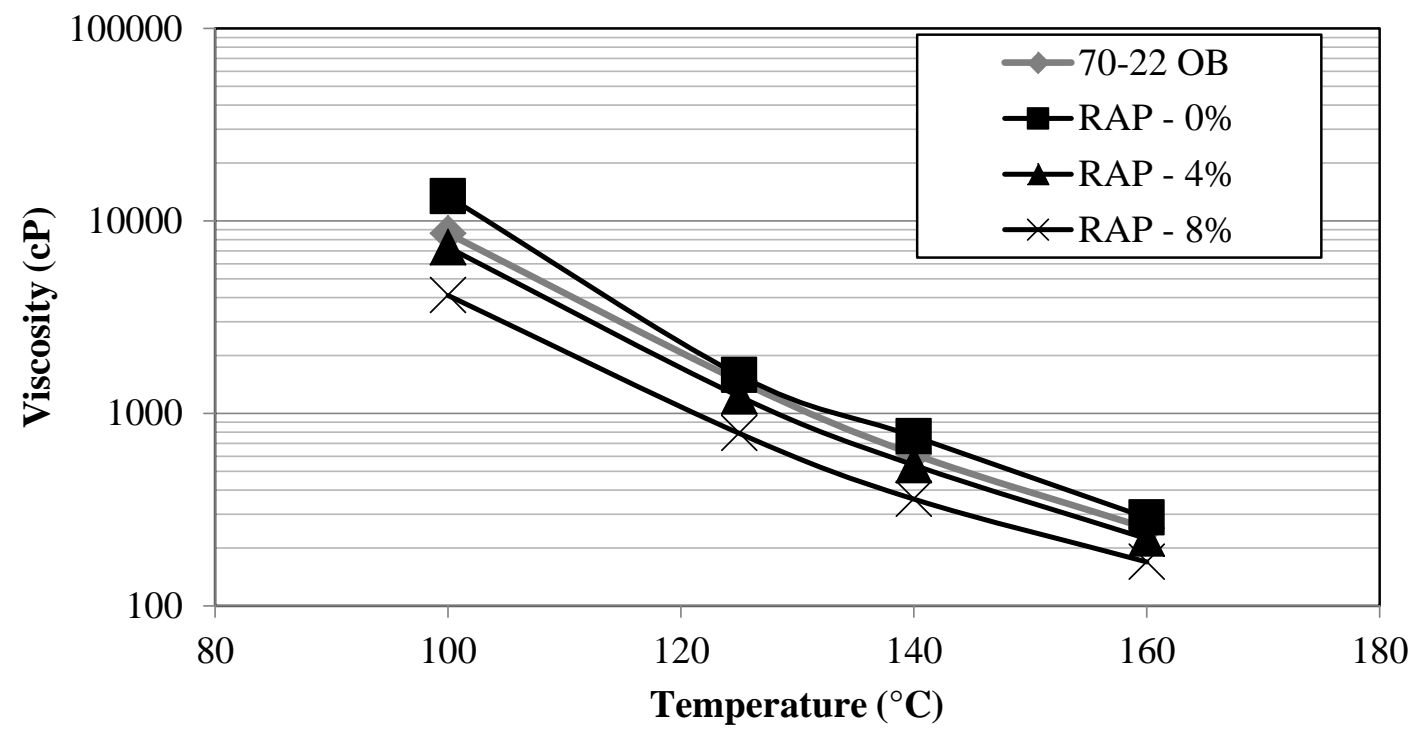

Figure 3.1 Viscosity of PG 70-22 original binder blended with 25\% RAP and waste engine oil

Figure 3.2 is a plot of the $G^{*} / \operatorname{Sin}(\delta)$ parameters obtained from the DSR test results. These results are for the PG 70-22 binder that was then blended with 25\% RAB and then four and eight percent waste engine oil for subsequent testing. The original binder, shown in gray, fails specification at $76^{\circ} \mathrm{C}$, which is expected for a PG 70 binder. The blend with 25\% RAB and 0\% waste engine oil experienced an upward shift for all data points, and had an overall PG increase to PG 76, indicating an improved resistance to rutting. The binder with $\mathrm{RAB}$ and $4 \%$ oil performed almost identically to the original 
binder, while $8 \%$ waste engine oil proved to reduce the PG to a 64 , as indicated by the $\mathrm{G}^{*} / \mathrm{Sin}(\delta)$ less than the specification of $1000 \mathrm{~Pa}$ at $70^{\circ} \mathrm{C}$.

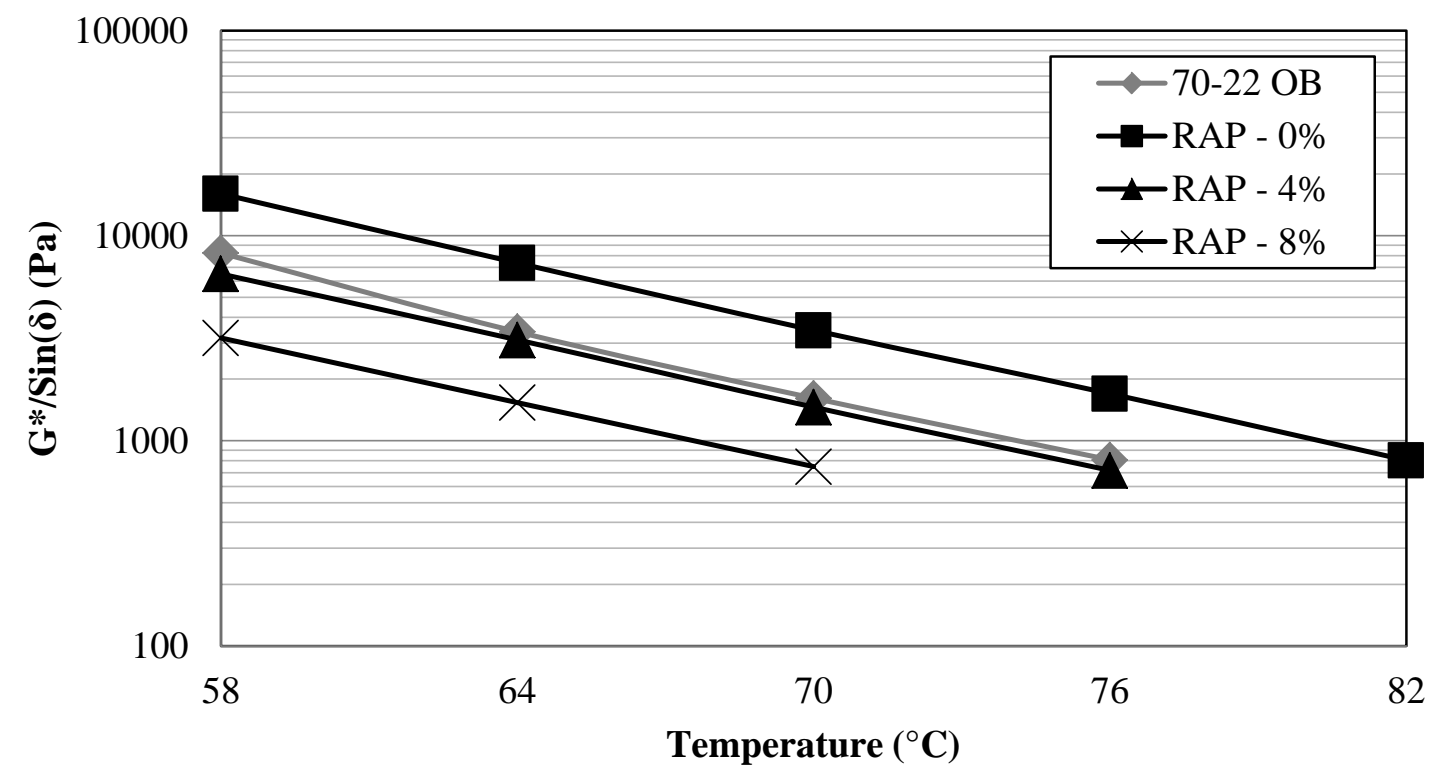

Figure 3.2 DSR results of PG 70-22 original binder blended with 25\% RAP and waste engine oil

Figure 3.3 is a plot of the DSR results from the in house aged asphalt binder. Since the entire binder was oven aged and not blended with original binder, the original PG of this binder becomes irrelevant. What is important from these tests is the ability to replicate aged binder in the laboratory, then to test the aged binder with waste engine oil to compare these results to the PG 70-22 test results. The graph shows a PG 76 binder experiencing a downward shift as increasing amounts of waste engine oil is added. 


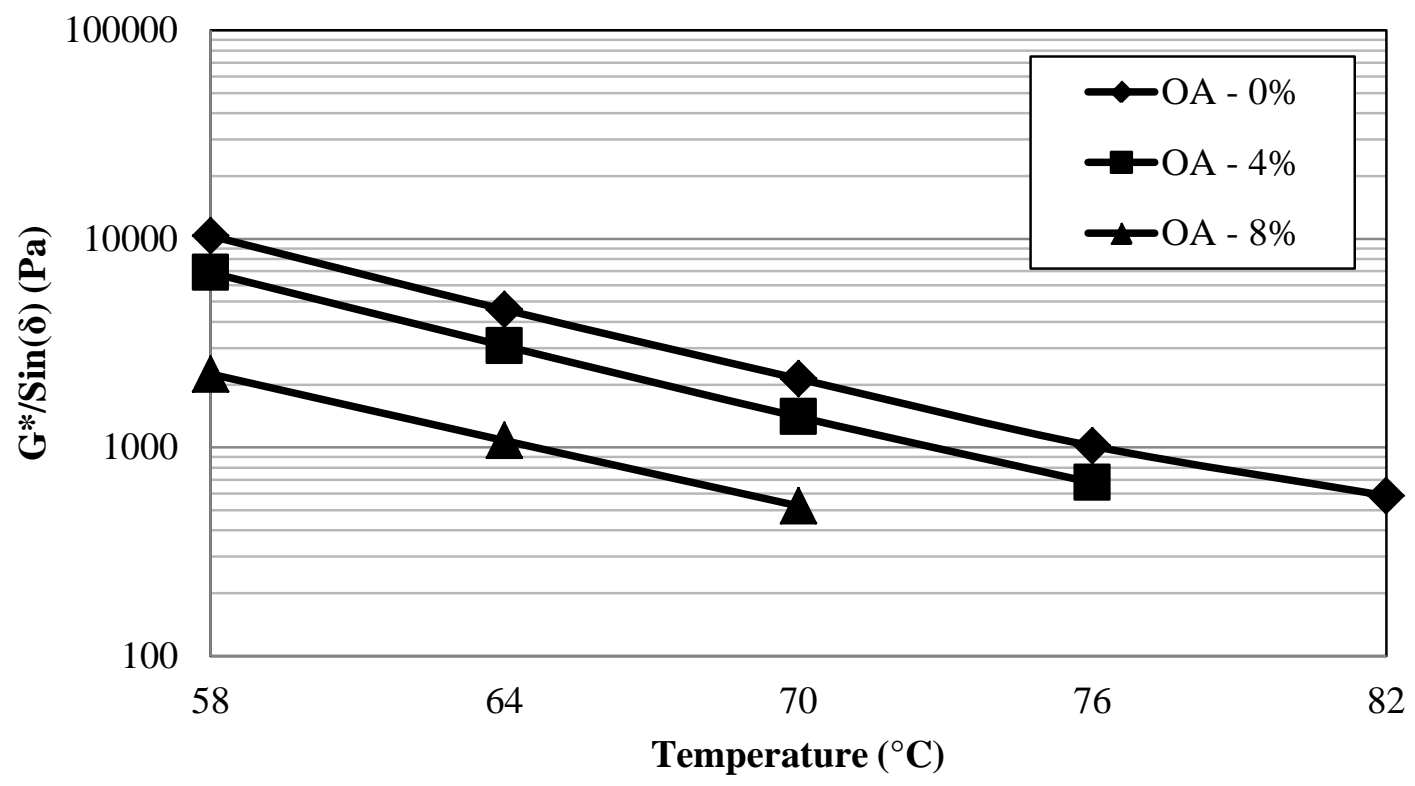

Figure 3.3 DSR Results for Oven Aged binder blended with waste engine oil

Figure 3.4 is of DSR results for a PG 70-22 binder that has undergone RTFO testing to see how binder blended with waste engine oil behaves. This experiment shows a two-grade decrease in high temperature acceptable binder with $8 \%$ waste engine oil.

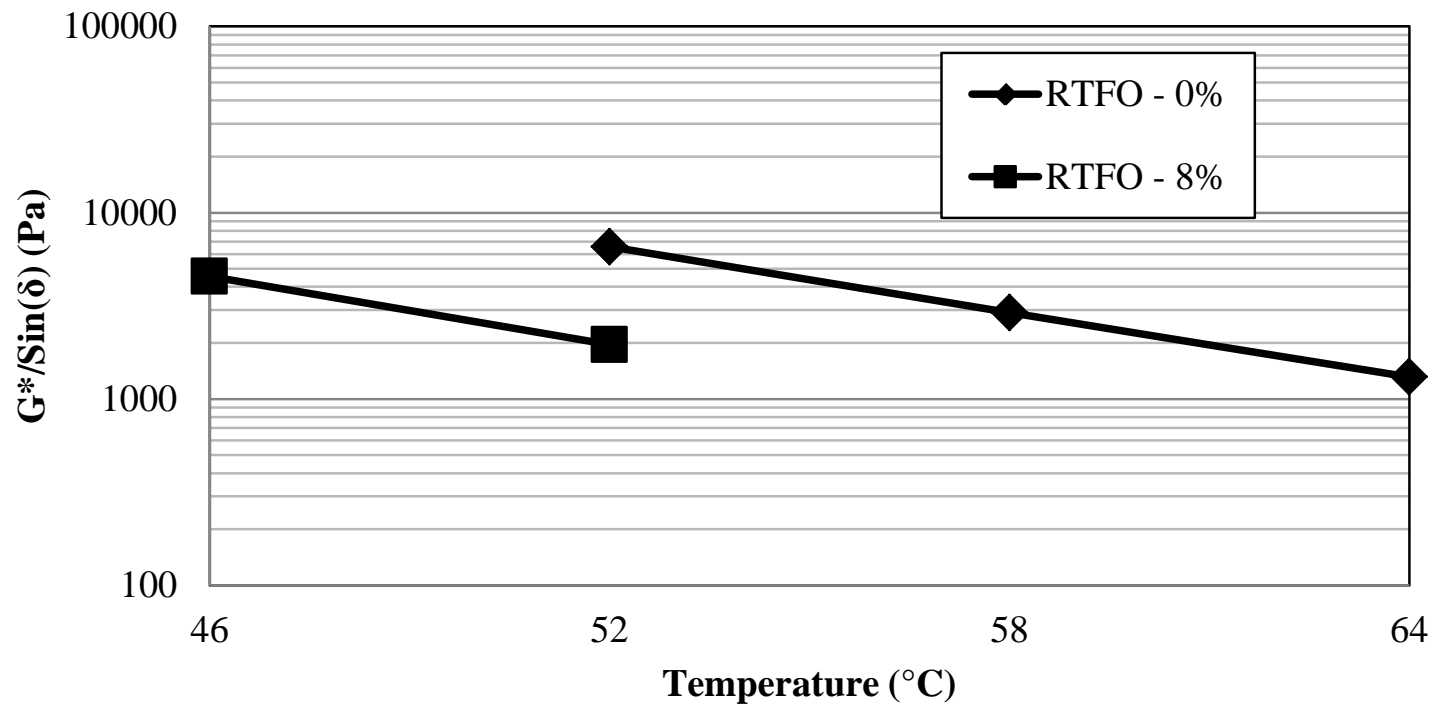

Figure 3.4 DSR Results for RTFO aged binder blended with RAP and waste engine oil 
PAV testing was also performed on the PG 70-22 asphalt binder blended with 25\% RAB and then blended with $0 \%$ and $8 \%$ waste engine oil. Based on the Superpave performance criterion maximum of $5000 \mathrm{kPa}$ for the $\mathrm{G}^{*} \cdot \operatorname{Sin}(\delta)$ the $8 \%$ binder underwent a downward shift after PAV aging, indicative of softening. The plot of this shift can be seen in Figure 3.5.

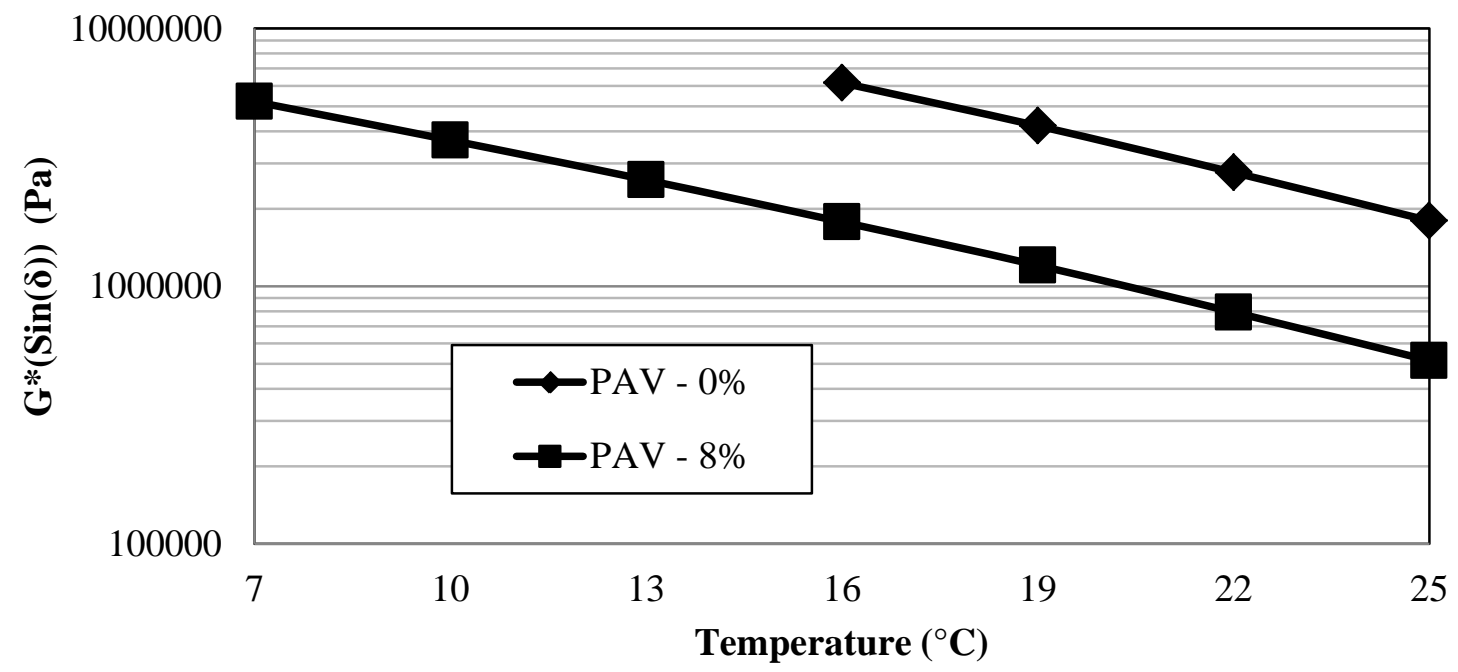

Figure 3.5 DSR Results for PAV aged binder blended with RAP and waste engine oil

\subsection{Discussion and Analysis}

From the data gathered in DSR testing of the PG 70-22 binder and the blends of RAP and oil, a comparison of the high temperature performance grades of the asphalt binders can be made, as shown in Figure 3.6. Initially the RAP caused an increase in PG because it increased the $\mathrm{G}^{*} / \mathrm{Sin}(\delta)$ parameter to a point where it was less than $1.0 \mathrm{kPa}$ at the test temperature. The increase in PG corresponds to an increase in stiffness and rutting resistance. With subsequent percentages of oil added, that stiffening was reduced and ultimately the binder was softened beyond the initial PG before RAP was added. 


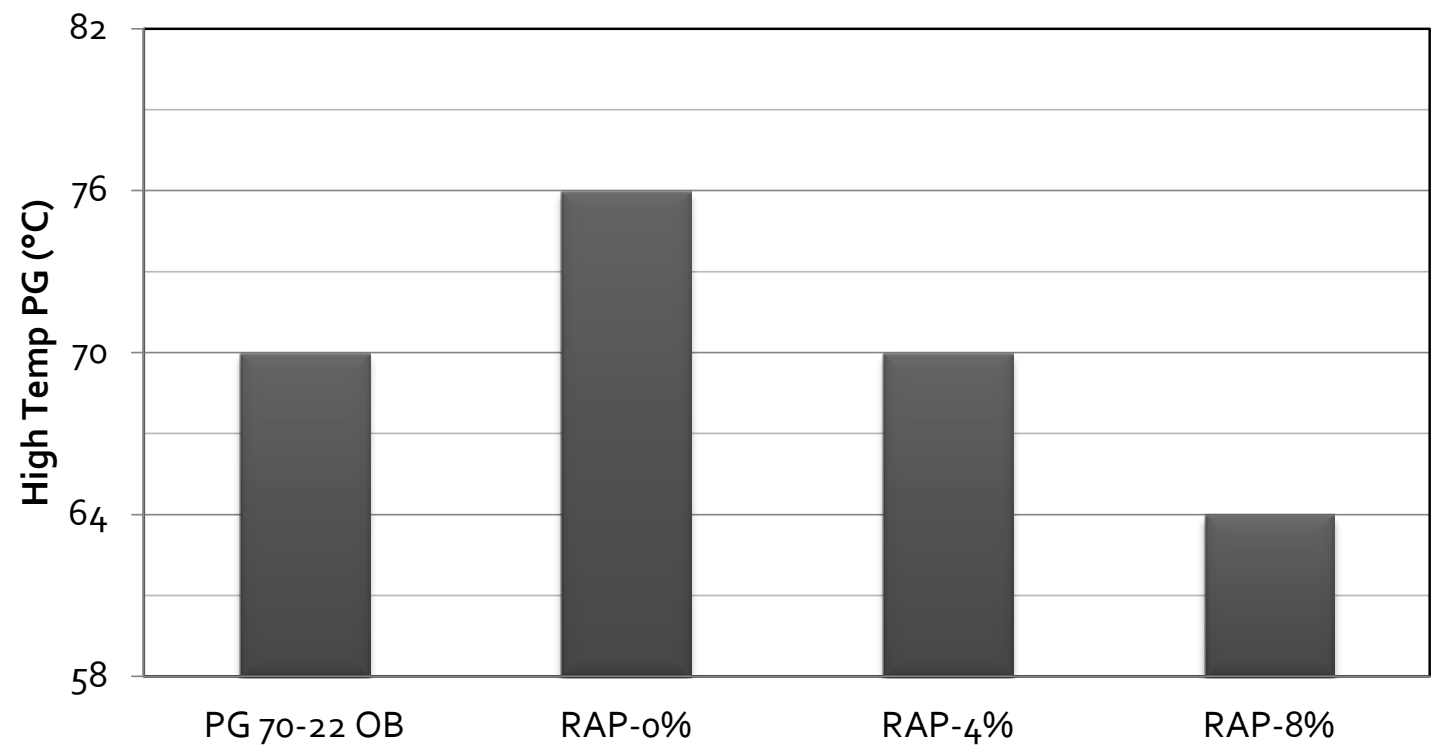

Figure 3.6 Results from DSR Testing with PG 70-22 Asphalt Binder

The results from the in house oven aged experiments are summarized in Figure 3.7. There was also an increase in the $\mathrm{G}^{*} / \operatorname{Sin}(\delta)$ parameter when comparing the virgin binder to the aged binder. This finding is significant because it shows oven aged binder has an increased stiffness, similar to the increased stiffness with the RAP tested previously. The addition of waste engine oil into the aged binder led to a drop in high temperature PG, which means the rutting resistance is moving toward the virgin binders PG. This drop in PG was one successive grade for $4 \%$ waste engine oil, and two grades for the $8 \%$. 


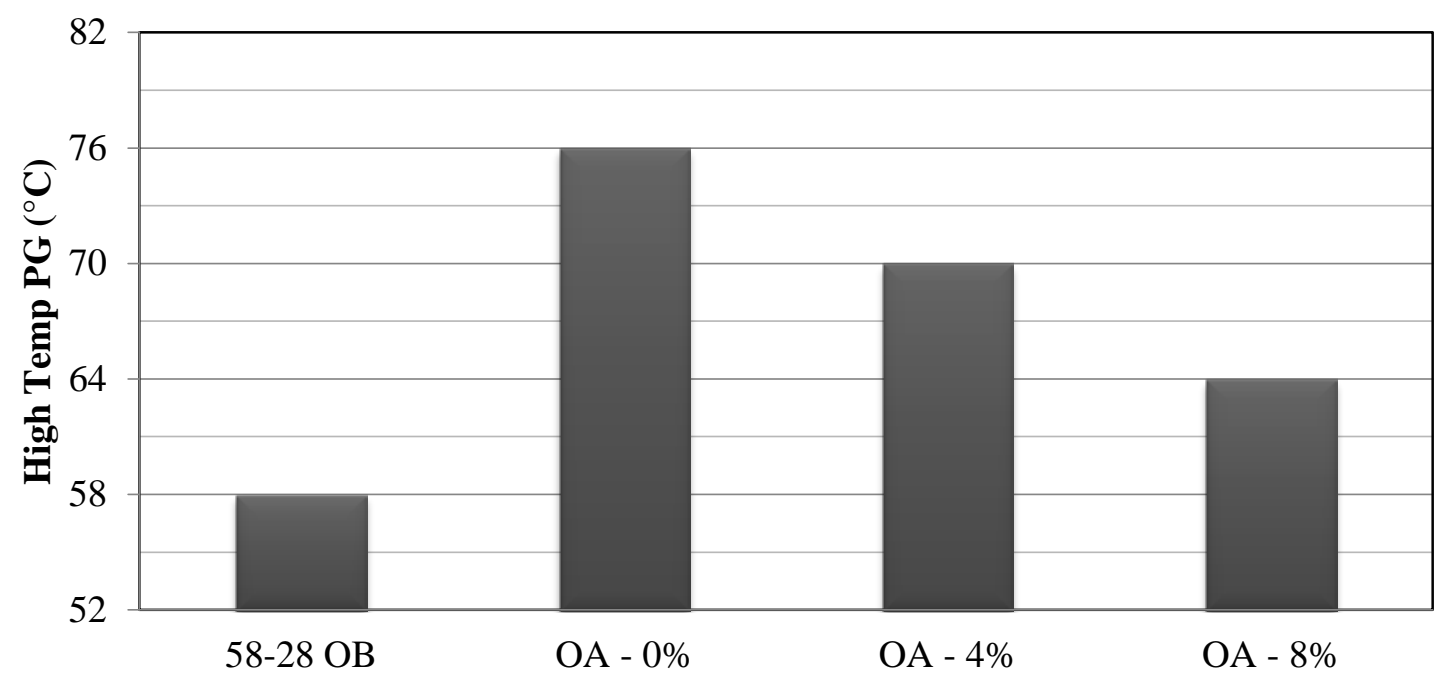

Figure 3.7 Results from DSR Testing with Oven Aged Asphalt Binder

The graphical results of the DSR tests performed on RFTO aged binder are seen in Figure 3.8. The aged binder exhibited a PG drop with $8 \%$ waste engine oil added. This result is the same as the unaged samples tested in the DSR. Due to the low smoke point of waste engine oil, the aging tests are a point of controversy. At small percentages of oil, however, the aging test returned the same two PG drop as unaged binder blended with waste engine oil, implying excessive aging did not take place with the waste engine oil.

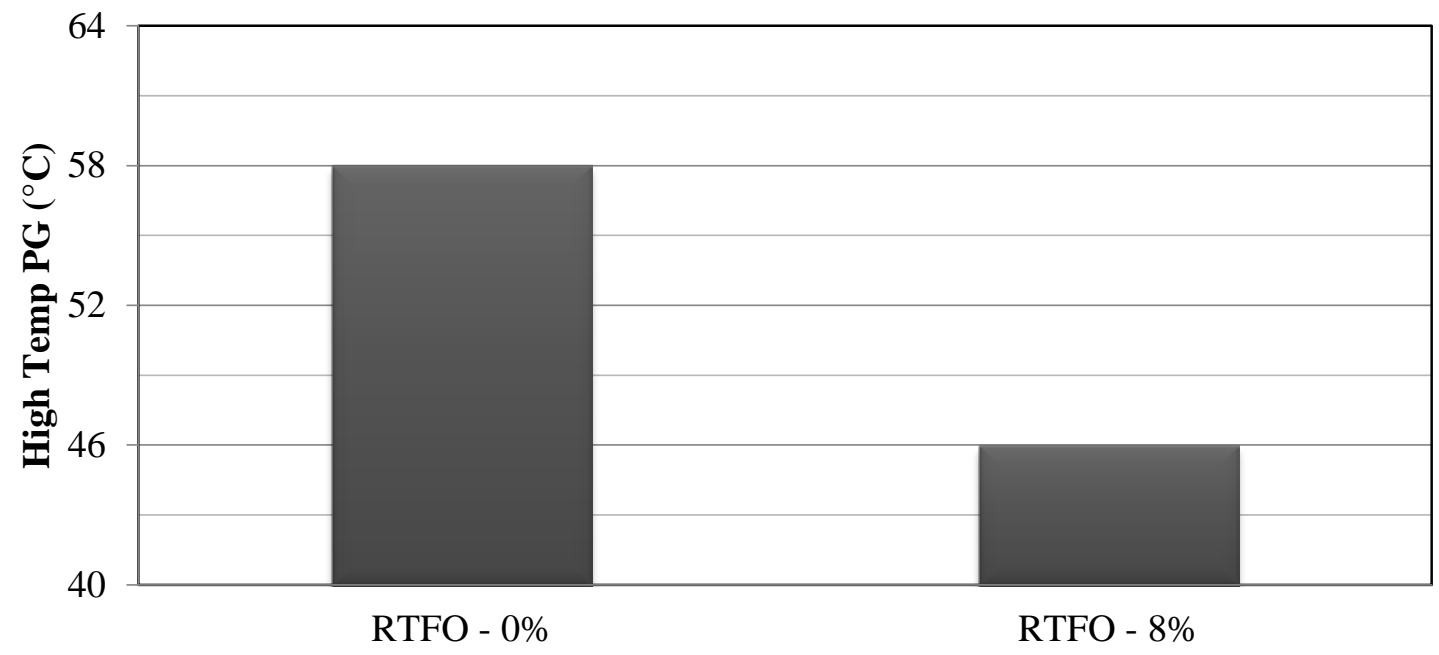

Figure 3.8 Results from DSR Testing with RTFO Aged Asphalt Binder 
When the PAV aged binder was tested in the DSR for $G^{*} \cdot \operatorname{Sin}(\delta)$ the binder underwent a two PG increase to low temperature cracking resistance. Figure 3.9 shows the two PG increase caused by the waste engine oil. This result matches what has been said in the literature about waste engine oil acting to reduce fatigue and extend the cracking life of asphalt pavements (Villanueva et al. 2008).

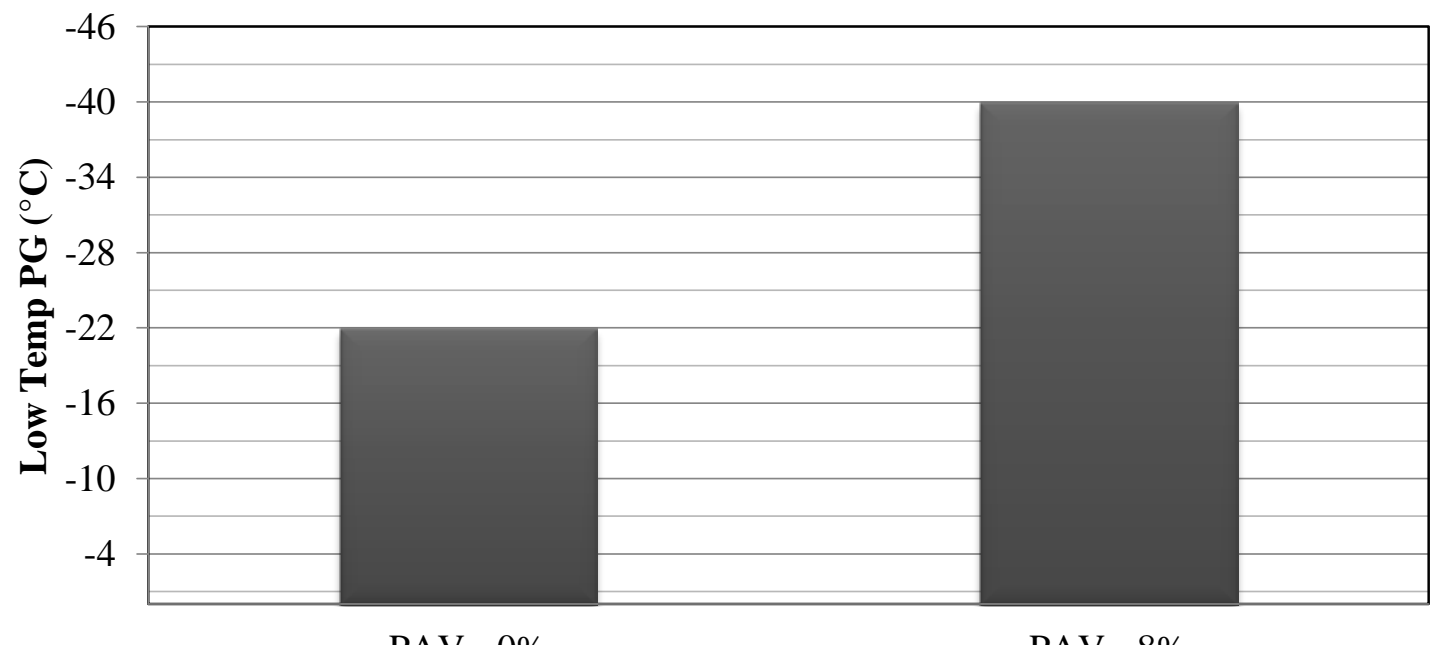

Figure 3.9 Results from DSR Testing with PAV Aged Asphalt Binder

\subsection{Conclusions}

Superpave asphalt binder testing is the accepted standard for establishing a usable service range of temperatures for which different asphalt binders are acceptable. DSR and rotational viscometer testing was performed first on virgin asphalt binder to establish a baseline for modification. Aged asphalt binder was tested in the same fashion as the virgin binder. Then waste engine oil was added to the aged binder in the hopes of showing the aging effects can be offset with the oil acting as a softening agent.

Based on the rotational viscometer results, the addition of RAB into virgin asphalt binder caused an increase in viscosity. The asphalt blends with RAB and waste engine oil were shown to decrease in stiffness as oil was added. These results support the claim that waste engine oil can be used as a softening agent to counteract the stiffening inherent with using RAP. 
The DSR results for asphalt blended with RAB showed an increase in the $\mathrm{G} * / \operatorname{Sin}(\delta)$ parameter, which is indicative of an increased resistance to rutting. This supports the claim that RAP inside asphalt pavements will increase the rutting resistance. A similar increase in $\mathrm{G}^{*} / \mathrm{Sin}(\delta)$ is obtained by oven aging virgin binder. Both oven aged binder and RAB were progressively softened with the addition of waste engine oil to the mixture. This proves that waste engine oil has the potential to counteract the stiffening from using RAP in new asphalt pavements.

By oven aging in the shallow dish, asphalt binder similar to field aged, recovered binder could be mimicked in the laboratory. Once simulated RAB was created, the addition of $4 \%$ and $8 \%$ waste engine oil caused equal softening to that seen by the RAB recovered by traditional means. This result is useful because it shows waste engine oil works as a softening agent on different RAB sources.

At some point the binder blended with waste engine oil becomes softer than the virgin binder being used. Further testing should be conducted to determine at what point excessive softening occurs. Excessive softening may damage asphalt pavements, and care should be taken not to use too much waste engine oil.

At $8 \%$ waste engine oil, the aged properties of the blended binder are less than desirable. There was a two PG decrease in high temperature grade, but an extension of two PG's on the low temperature end. A lack of aged binder was the reason for the limited number of tests performed on aged binders. It is recommended in the future to acquire more aged binder and test concentrations other than $8 \%$ waste engine oil. Also, bending beam rheometer (BBR) testing is a common test for measuring the creep stiffness of PAV aged binder at low temperatures. It is highly recommended this test be conducted in the future to determine a definitive low temperature PG grading.

Using the DSR and rotational viscometer, it was shown that waste engine oil has the potential to counteract the stiffening and counter the PG increase when RAB is used. Asphalt binder testing is the first step in any research because it has a relatively low cost of operation. Many of the tests can be performed in the scope of a few days, and require small amounts of material to test. To further support this concept of a more sustainable pavement, testing on the chemical interactions between the RAB and waste engine oil 
should be studied. Lastly, conducting sample mixture testing will give insight as to how samples perform under simulated field conditions. 


\section{Advanced Asphalt Binder Testing}

\subsection{Introduction}

Fourier Transform Infrared Spectroscopy (FTIR) testing was chosen for analysis of the binder because traditional asphalt binder testing can only measure the engineering properties of asphalt binder, while FTIR testing gives insight into the changes in chemical composition between different binders. FTIR testing looks for different chemical bonds and functional groups present in the asphalt binder, and quantifies how much of each type of bond is present in the mixture. Specific chemical groups are indicative of asphalt aging and comparing the results between two different asphalt binders will yield a relative change in amount of aging which has occurred between samples. Using the relative amounts of aged material contained in samples, it is possible to identify the concentration of asphaltenes and maltenes inside asphalt binder. If waste engine oil is to be used as a recycling agent, it is important to gain insight into the molecular interactions between the used oil and the used binder.

\subsection{Methods}

In order to perform FTIR testing, several types of binder and rejuvenator were chosen for testing based the traditional asphalt binder tests conducted in Chapter 3. Table 4.1 shows the complete set of samples tested. The virgin binder was tested to compare all of the subsequent binder modifications to a standard control sample. Pure RAB was tested to quantify the amount of aging that has taken place from virgin binder. The three samples blended with virgin binder and RAB were tested to compare the results from binder testing the same materials. Waste engine oil was tested to determine the aging indices of the used oil. Then, unused engine oil was tested to compare with waste engine oil to see how much aging had taken place in the waste engine oil.

All of the samples tested were placed on a silicon substrate, since asphalt binders are unable to maintain a thin rigid shape. The binder was heated on a hotplate, and then a small amount was dripped onto the substrate. The substrate was placed on the hotplate to facilitate the thinning of the sample through heating. Additionally, a glass rod was used 
to spread the binder to the thickness of a thin film over the substrate, which was achieved when the binder appeared translucent.

Table 4.1

FTIR Samples

\begin{tabular}{|l|l|l|}
\hline \multicolumn{1}{|c|}{$\begin{array}{c}\text { Sample } \\
\text { Identification }\end{array}$} & \multicolumn{1}{|c|}{ Description } & \multicolumn{1}{c|}{ Source } \\
\hline Virgin Binder & Neat PG 58-28 Binder & Payne and Dolan - Hancock, MI \\
\hline RAB & Pure Recovered Binder & $\begin{array}{l}\text { ASTM D 2172 - 05 and ASTM } \\
\text { 1856-95a }\end{array}$ \\
\hline E. Oil & Unused Engine Oil & Chevron Delo 400 LE SAE 15 w40 \\
\hline W.E. Oil & Pure Waste Engine Oil & Used E. Oil. 144 engine hours \\
\hline 25\% RAB & Virgin Binder with 25\% RAB & Combination of above samples \\
\hline 25\% RAB, 4\% & Virgin Binder with 25\% RAB & Combination of above samples \\
W.E. Oil & and 4\% Waste Engine Oil & \\
\hline 25\% RAB, 8\% & Virgin Binder with 25\% RAB & Combination of above samples \\
W.E. Oil & and 8\% Waste Engine Oil & \\
\hline
\end{tabular}

Once the substrates with the binder had cooled, the specimens could be tested. First a blank silicon substrate was loaded into the FTIR machine and analyzed to create a background reading of absorbency. This background reading was subtracted from all subsequent tests, leaving only the absorbency of the compounds present in the sample. One at a time, samples were tested and absorbance of every frequency between $500 \mathrm{~cm}^{-1}$ to $4000 \mathrm{~cm}^{-1}$ was collected.

\subsection{Results}

The absorbance bands from $500 \mathrm{~cm}^{-1}$ to $4000 \mathrm{~cm}^{-1}$ were collected from the FTIR testing. From these tests, a plot of the wavelengths spanning that range was generated as in Figure 4.1. A majority of the absorbance seen in the figure are between 1375-1530 $\mathrm{cm}^{-1}$ and 2850-3000 $\mathrm{cm}^{-1}$. Recall from earlier these ranges correspond to aromatic hydrocarbons and saturated hydrocarbons, and for the sake of comparing hydrocarbons 
these ranges are not very useful since asphalt binder and waste engine oil are comprised almost entirely of hydrocarbons. What is meaningful are the changes in the functional groups within the binder, since they can help characterize the aging taking place.

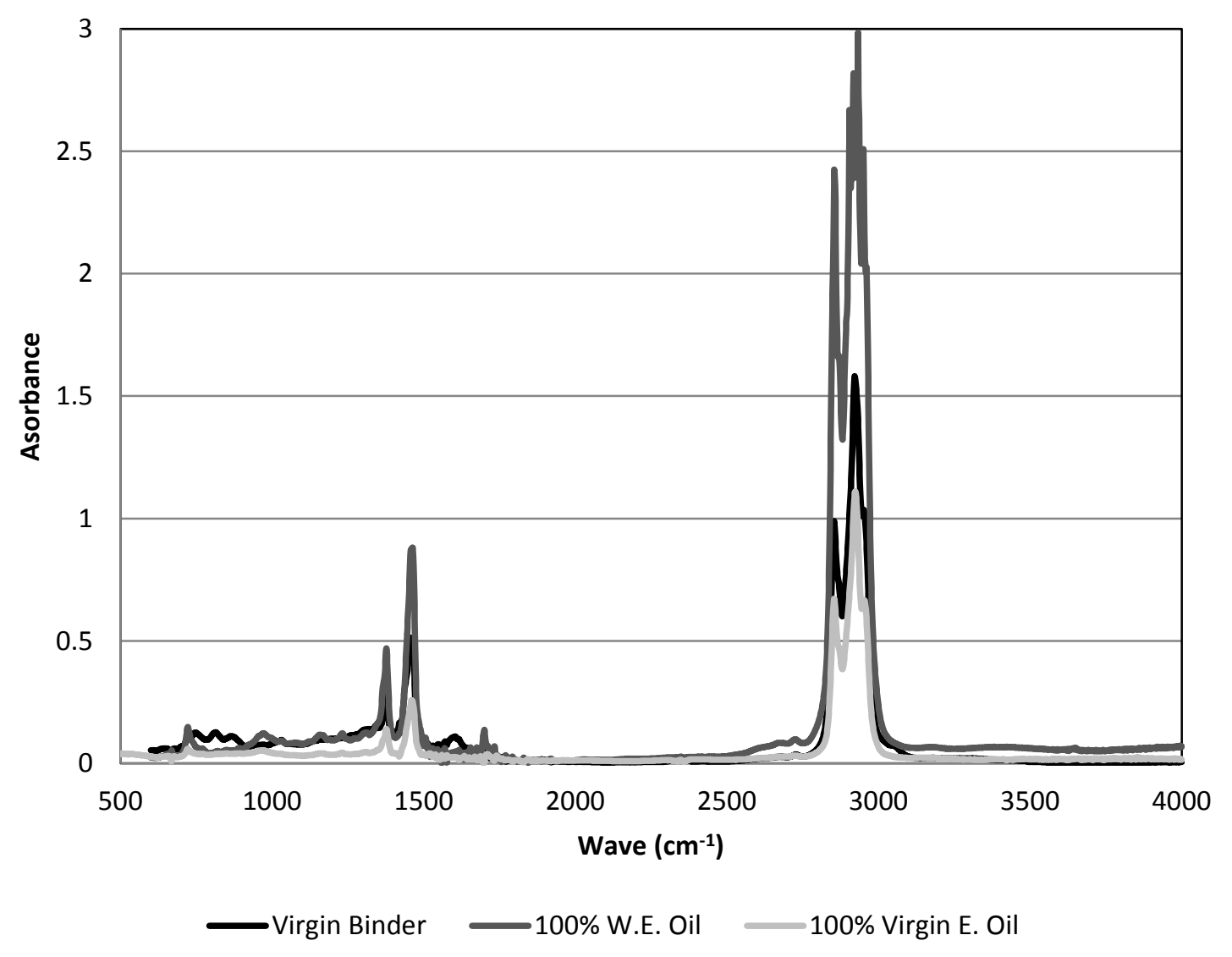

(a) FTIR Results for pure binders and engine oil 


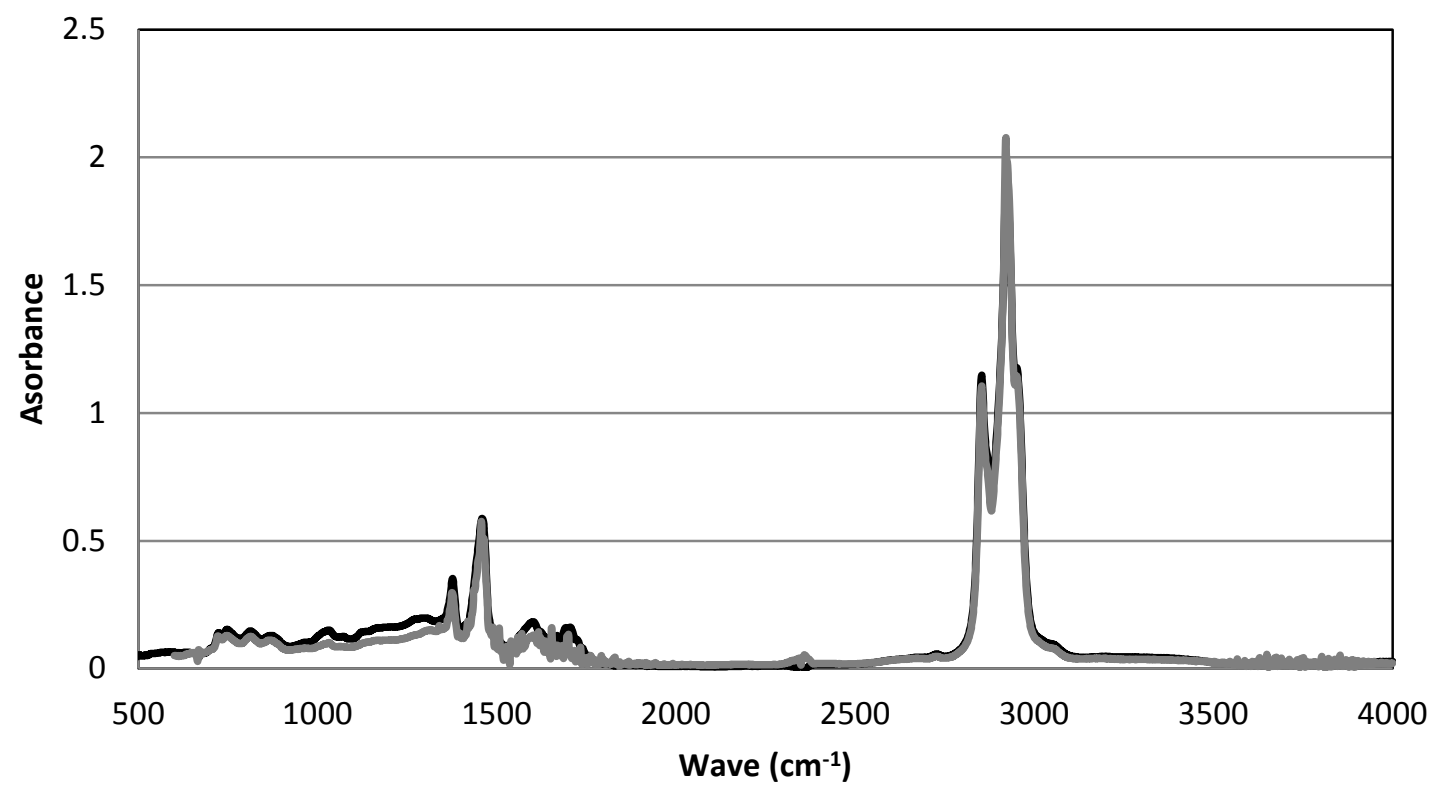

$-100 \%$ RAB $\longrightarrow 25 \%$ RAB 0\% W.E. Oil

(b) FTIR Results for pure RAB and virgin binder blended with 25\% RAB

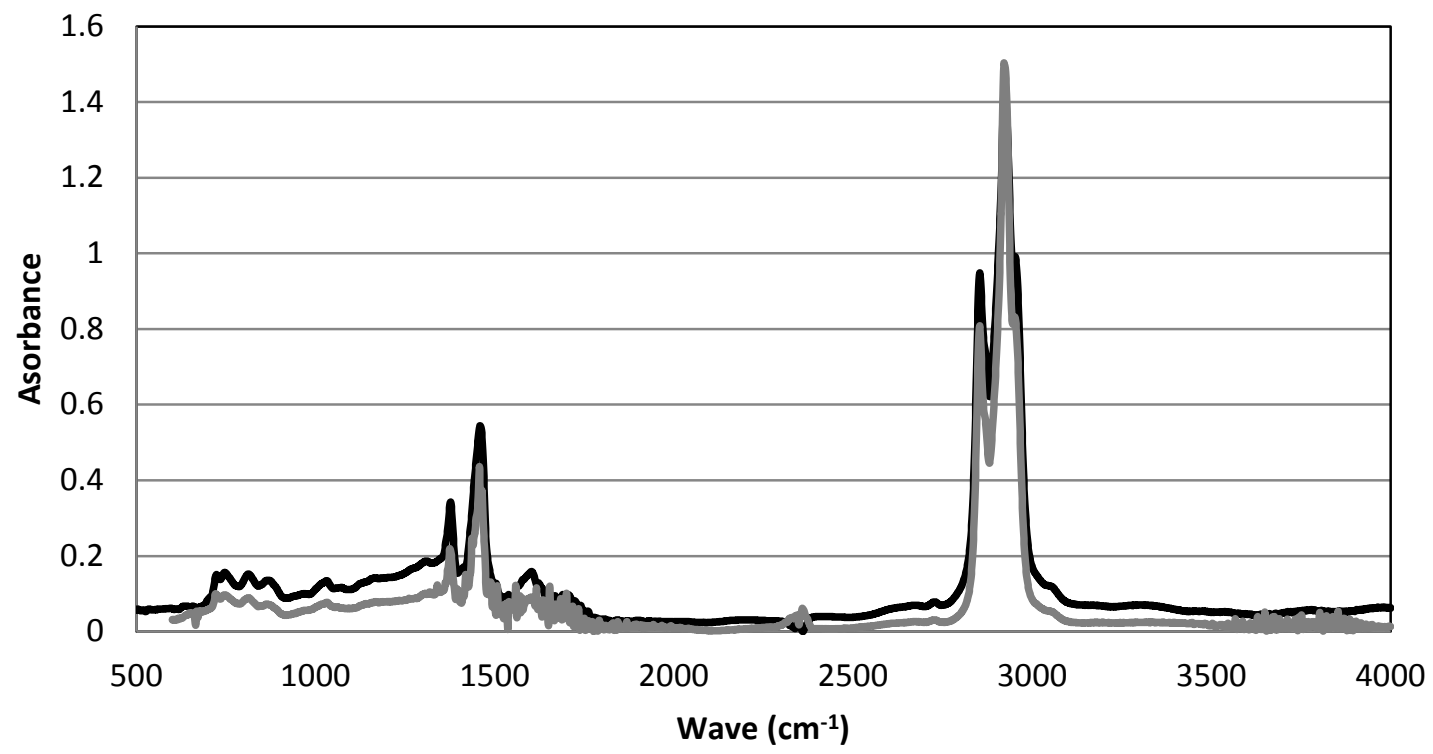

$\longrightarrow 25 \%$ RAB 4\% W.E. Oil $=25 \%$ RAB $8 \%$ W.E. Oil

(c) FTIR Results for blends of virgin binder, RAB and waste engine oil

Figure 4.1 FTIR Results for (a) pure binder and engine oil (b) pure RAB and virgin binder blended with $25 \%$ RAB (c) blends of virgin binder, RAB and waste engine oil 
Since this research is only interested in analyzing the aging taking place between the samples, only the peak areas around spectral bands at $1030 \mathrm{~cm}^{-1}$ and $1700 \mathrm{~cm}^{-1}$ will be analyzed. According to the literature, the bands at $1030 \mathrm{~cm}^{-1}$ and $1700 \mathrm{~cm}^{-1}$ correspond to sulfoxide $(\mathrm{S}=\mathrm{O})$ and carbonyl $(\mathrm{C}=\mathrm{O})$ peaks, respectively (Cortizo et al. 2004; Lins et al. 2008). These two peaks have been identified to relate to aging in asphalt binder. To better illustrate these peaks, Figure 4.2 shows a portion of the graphs of only pure RAP and pure virgin binder. The sulfoxide peak around $1030 \mathrm{~cm}-1$ is much wider and larger for the RAP sample compared to the virgin binder sample. Also, the $\mathrm{C}=\mathrm{O}$ peak at 1700 is much more pronounced for the RAP sample compared to the virgin binder.

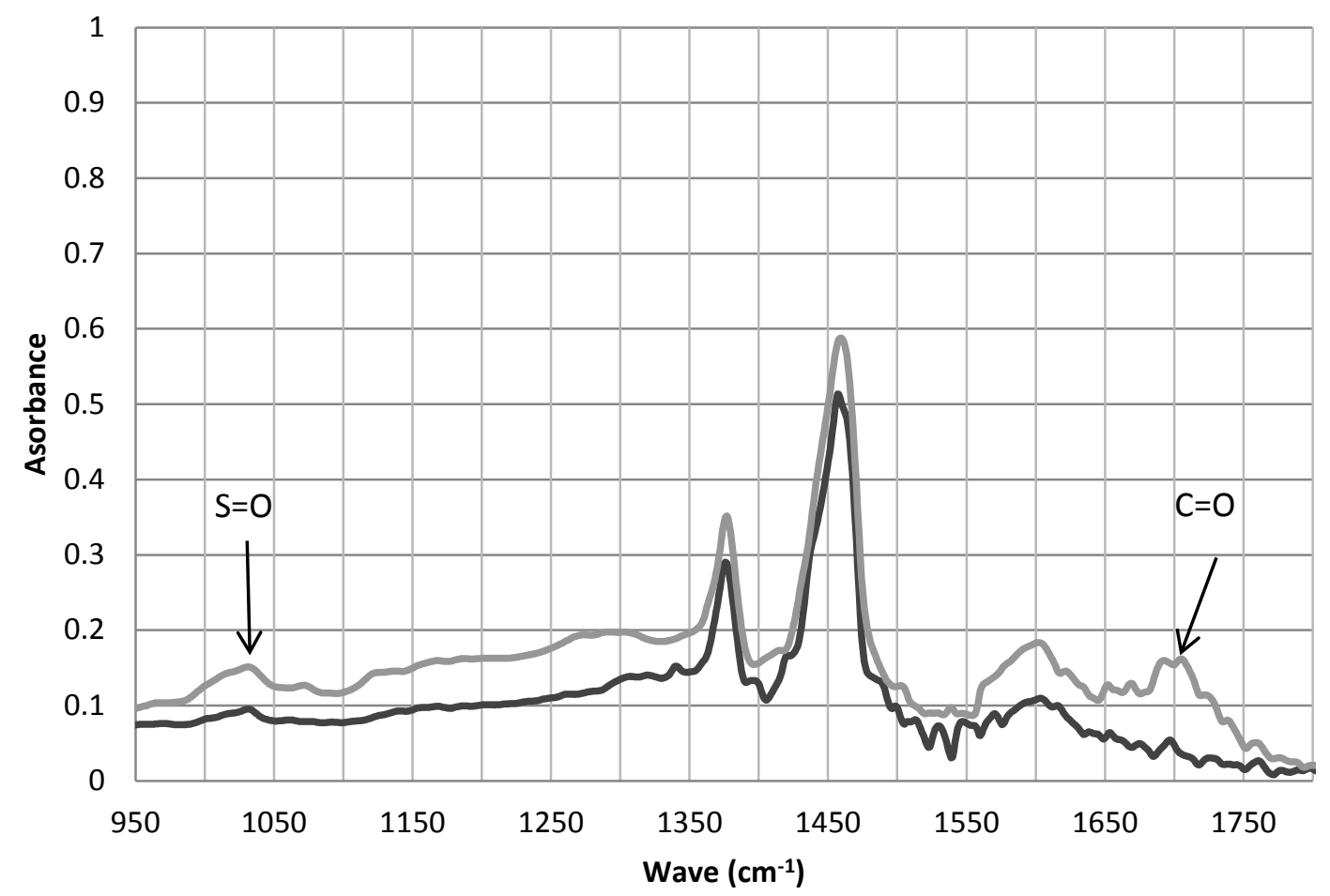

Virgin Binder $=100 \%$ RAB

Figure 4.2 FTIR Results: Virgin Binder vs. Pure RAB Binder

Both unused engine oil and waste engine oil were tested using FTIR in addition to the asphalt binders. Figure 4.3 shows only the two oils compared against each other. The figure shows that the unused engine oil sample had less sulfoxides and carbonyls 
than the waste engine oil. In fact, around the $\mathrm{C}=\mathrm{O}$ peak, the virgin engine oil appears to have considerably less carbonyls than the aged oil. Although, phase stretching is a common phenomenon in FTIR testing, meaning the $1700 \mathrm{~cm}^{-1}$ could have spread to incorporate a larger area.

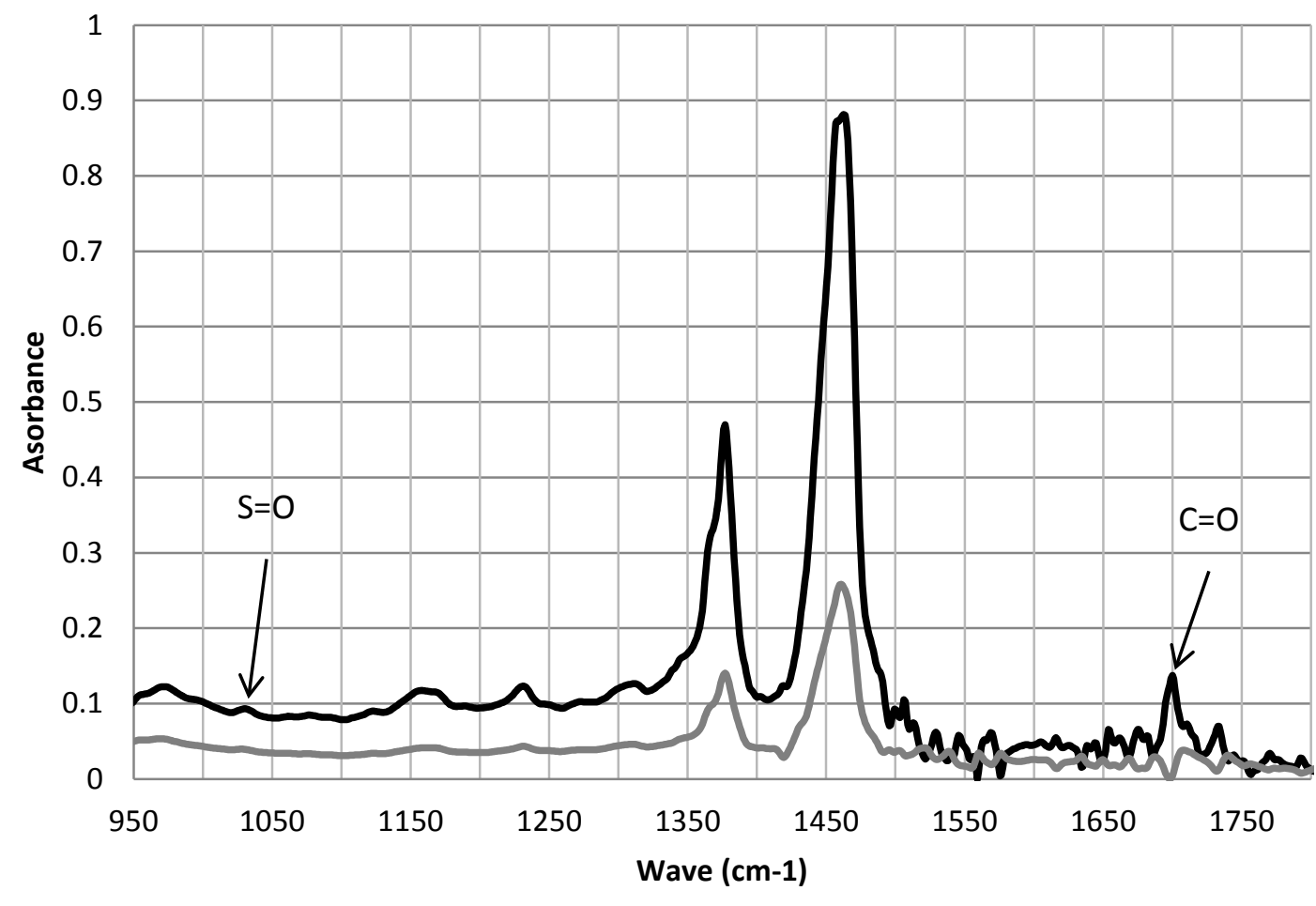

$-100 \%$ W.E. Oil $\longrightarrow 100 \%$ Virgin E. Oil

Figure 4.3 FTIR Results: Engine Oil vs. Waste Engine Oil

\subsection{Discussion and Analysis}

The easiest way to compare the amount of aging between samples is with the use of a structural index, which is a measure of the aged compounds found inside asphalt binder. To compute the structural index, the peak wavelength of interest is numerically integrating using a valley to valley approach, then the calculated area is divided by the entire area contained between $600 \mathrm{~cm}^{-1}$ to $2000 \mathrm{~cm}^{-1}$ (Lamontagne et al. 2001). The resultant ratio is referred to as the structural index for the compound of interest. The 
structural indexes assign a comparable number to peaks of interest, which can then be used to compare two like samples. It should be noted that these numbers are only relative and there is no established reference indices.

Using the structural indexes, a graph of the $\mathrm{S}=\mathrm{O}$ and $\mathrm{C}=\mathrm{O}$ structural indices is given in Figure 4.4. The increase in aging from the virgin binder to the RAP binder is significant, with two to three times higher values for the indices. This supports claims that RAP is unsuitable for use without modification. Also, it can be seen from the graph that as additional waste engine oil is added to the binder with $25 \%$ RAP, there is a reduction in both structural indices.

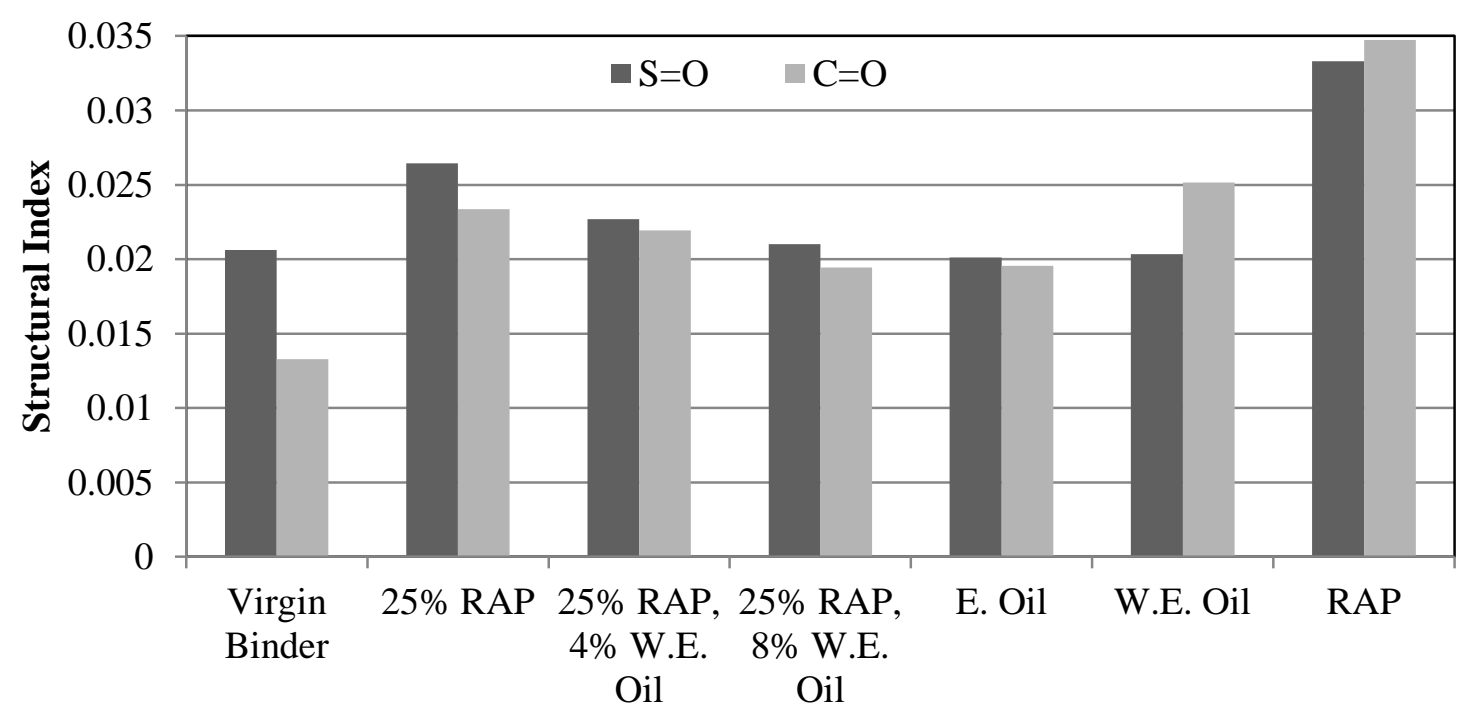

Figure 4.4 FTIR Structural Indices

Figure 4.4 shows that the engine oil sample had less sulfoxides and carbonyls than the waste engine oil. This makes since because the engine oil has been used once already in a car's engine and that use has caused aging. Even though waste engine oil has undergone some aging, it still has the ability to provide maltenes to the asphalt binder.

It looks deceptive that adding waste engine oil corresponds to a reduction in aging when comparing the $\mathrm{C}=\mathrm{O}$ structural index of the sample with $25 \%$ RAP to those with waste engine oil. The mixture of waste engine oil and RAP is not as simple as a weighted combination of each component. Since FTIR testing can only identify the compounds present, not the presence of any reactions that have taken place, the reduction 
in both structural indices means the sulfoxides and carbonyls could have been converted to other chemical compounds. These results are further supported by Carpenter and Wolosick who tested RAP with recycling agents and concluded there must be a blending of the components, taking place instead of a composite of new and old material (Carpenter and Wolosick 1980).

\subsection{Conclusions}

FTIR testing was conducted on asphalt binder samples consisting of virgin binder, virgin binder with $\mathrm{RAB}$ and virgin binder with $\mathrm{RAB}$ and two different concentrations of waste engine oil. The FTIR testing gave relative quantities of the different compounds within the samples of asphalt binder. Those results were used to calculate structural indices of the sulfoxide and carbonyl compounds for comparison between samples.

Through a review of literature, it was discovered the FTIR test was able to compare the amounts of asphaltenes to the amount of maltenes contained inside asphalt binder (NCAT 1996; Cortizo et al. 2004; Lins et al. 2008). Upon testing of asphalt binder blended with RAB, a benchmark for the sulfoxides and carbonyls was established. When waste engine oil was added to the blended asphalt, there was a reduction in both structural indices. This reduction in sulfoxides and carbonyls means the ratio of asphaltenes to maltenes has decreased and more maltenes are now present inside the binder. Thus, this analysis lends support to the waste engine oil rejuvenating the aged binder. Other research has recommended recycling agents must diffuse asphaltenes in the binder (Lin et al.). The FTIR testing shows a dispersion of asphaltenes, by a reduction in percentage of sulfoxides and carbonyls contained within the rejuvenated samples.

The difference between softening agents and rejuvenating agents can be summed up as softening agents only affect viscosity, while rejuvenating agents chemically restore asphalt binder. The change in sulfoxide and carbonyl indices is indicative of a chemical and/or compositional change that has taken place within the asphalt binder. Therefore, waste engine oil has the potential to rejuvenate the asphalt binder. This supports the theory that waste engine oil can be used as a recycling agent for RAP. 


\section{Mixture Testing}

\subsection{Introduction}

In addition to testing the asphalt binder alone, sample laboratory mixtures were created and subjected to standard performance tests to see how the addition of waste engine oil coupled with RAP would affect the asphalt pavement. Mixture testing is one relatively inexpensive way to evaluate a particular asphalt concrete mixture before paving an entire section of road. Mixture tests are empirically calibrated to pavements that have performed well, and are commonly used to estimate performance. This study looked at two different mixture tests in order to relate the expected change in field performance with the introduction of RAP and waste engine oil. The APA rutting machine simulates a traffic load while the tensile strength ratio (TSR) test determines moisture susceptibility during a freeze-thaw cycle. The APA rut test applies a constant rolling load wheel load to samples in order to measure the rutting resistance of the samples. The TSR test saturates samples with water then freezes them to investigate how much damage is induced during one freeze-thaw cycle.

\subsection{Methods}

\subsubsection{Mixture Specifications}

The JMF used for this mixture testing is for a Michigan standard 4E1 pavement, which means the nominal aggregate size is $1 / 2$ inch and the pavement will handle a traffic load of 1 million equivalent single axle loads (ESALS) over its lifetime (Michigan Department of Transportation (MDOT) 2003). A copy of the JMF can be found in Appendix A. This JMF required six different stockpiles be blended in order to achieve a Michigan Department of Transportation (MDOT) approved gradation. The aggregates for the mixture testing were collected from stockpiles in Hancock Michigan. Each stockpile was dried overnight in an oven, then sieved into respective aggregate sizes and stored in airtight steel buckets. 


\subsubsection{Trial Samples}

The JMF followed for this research was designed for a four percent air void content. In order to achieve four percent air voids, samples of asphalt were created at three different asphalt binder contents, 5.1\%, 5.6\% and 6.1\%, and the air voids of each percent was tested. For every trial of asphalt binder content, two compacted asphalt cylinders, or pucks, and one loose asphalt sample were created. The asphalt cylinders are used to calculate the bulk specific gravity, Gmb, of the asphalt sample. The Gmb is the density of a sample of compacted asphalt concrete with air voids sealed inside the sample. Testing for bulk specific gravity followed ASTM D 2726 (ASTM 2008b).

The loose asphalt samples were crushed by hand, and the density of the loose mix was then calculated. Breaking of the sample allowed for any trapped air to easily escape during a vacuum saturation with water. This test, also known as the Rice specific gravity, or "Rice test," after its developer James Rice, is used to calculate the maximum specific gravity, Gmm and follows ASTM D 2041 (ASTM 2008a). The maximum specific gravity is the density of the asphalt concrete sample with the air voids removed. Using the relationship shown in Equation 1, the air voids of the three different asphalt binder contents was calculated. The air voids results are then interpolated and the binder content which would yield a four percent air void content was chosen as the optimal binder content.

$$
\text { Air Voids (\%) }=\left(\frac{G_{m m}-G_{m b}}{G_{m m}}\right) \times 100
$$

\subsubsection{Mixing and Compaction}

Using the JMF obtained for the Hancock 4E1 mix design, the sieved aggregates were recombined into 3500 gram asphalt samples. Since the JMF used called for $24 \%$ RAP, the samples requiring RAP were broken into 840 grams of RAP and 2,660 grams of recombined virgin aggregates. In the case of the control mixture, no RAP was used to create these specimens. The asphalt samples at $5.6 \%$ binder content had an average air 
void content of $4.0 \%$, therefore that percentage of binder was chosen for the asphalt binder content. The final compacted height of the optimum asphalt samples was 86.2 $\mathrm{mm}$.

The virgin aggregates were placed in a $165^{\circ} \mathrm{C}$ oven for two hours to preheat, while the RAP was placed in a $100^{\circ} \mathrm{C}$ oven, as not to further age the $\mathrm{RAB}$ on the aggregates. From the extraction and recovery test, it was determined that $3.85 \%$ of the weight from the RAP was binder. After heating, the RAP aggregates were weighted in a large, preheated mixing drum and the effective binder weight was deducted from the total weight. Then, the virgin aggregates were added and the total weight of only aggregates could be determined. Knowing that the optimal binder content was 5.6 percent from the bulk specific gravity and Rice test, the proper amount of binder could then be added. For samples containing RAP, the effective binder contributed from the RAP aggregate was subtracted from the amount of binder needed. For the samples requiring waste engine oil, the waste engine oil was counted toward the total binder content in the mixture. This means the RAP binder, waste engine oil and virgin binder added together equal the total weight of binder in the samples.

A PG 58-28 virgin binder was added to the top of the aggregates inside the mixing drum and then the waste engine oil, where applicable, was added last. The samples were all mixed using a mechanical mixer until the aggregates were uniformly coated. At that point, the freshly mixed asphalt was placed into a pan and placed into a $145^{\circ} \mathrm{C}$ oven for two hours to simulate short term aging.

Following the short term aging, the samples were placed into compaction molds and compacted inside of a gyratory compactor until the final sample height was $86.2 \mathrm{~mm}$ high - the final height from the bulk specific gravity samples used to determine optimal binder content. From the optimum binder content testing, a sample at $86.2 \mathrm{~mm}$ high with $5.6 \%$ asphalt binder content yields a four percent air void content. To retain air void continuity, all samples created for testing will maintain an $86.2 \mathrm{~mm}$ final compaction height. This compaction required different numbers of gyrations for every sample; however it ensures a constant number of air voids in each sample. 
Once compacted and air cooled, the samples were mostly ready for testing. The APA rutting test required samples that were $75 \mathrm{~mm}$ in height to fit into the rutting molds. The samples were cut to size using a wet saw with water as the blade lubricant.

\subsubsection{Rutting Test}

The propensity for rutting was tested using a rutting machine, which simulates traffic loads by passing a 100 pound wheel load over samples at a the pavement's design high temperature. For this research, the Asphalt Pavement Analyzer (APA) rutting machine was used to conduct the rutting test. The manufacturer standards were followed for as a standard testing procedure (Pavement-Technology-INC.(PTI) 2003). To ensure a rutting failure, the pavement samples are tested at their high temperature PG. Samples are loaded into the APA rutting machine and allowed to reach thermal equilibrium before testing began. The test runs for 8000 load cycles using a 100 pound wheel on top of a rubber hose with $100 \mathrm{psi}$ internal pressure. The wheel moves constantly over the samples to apply a dynamic load. After each pass of the wheel, the machine records the depth of the rut throughout duration of the test.

In total three replicate samples were tested in rutting for each type of sample, Control, $0 \%, 4 \%$, and $8 \%$. The samples were loaded into the APA rutting machine and given three hours to reach thermal equilibrium at $58^{\circ} \mathrm{C}$. The APA machine was run for 8000 cycles and rut depth was recorded at each cycle.

\subsubsection{TSR Test}

To determine the moisture susceptibility of asphalt samples, the tensile strength ratio (TSR) test was run. TSR testing is specified under AASHTO T 283 (AASHTO 2010). This test compares the compressive strength of one group of unconditioned control samples to another set that has been vacuum-saturated with water, and then frozen. After freezing, the conditioned samples are thermally shocked in a hot water bath to further induce damage. Both groups of samples are crushed and the peak strengths recorded. Dividing the conditioned strength by the unconditioned strength gives the TSR for each sample. 
This test was chosen as a way to quantify the effect that waste engine oil would have on the amount of damage a pavement would experience at low temperatures. The conditioned samples were vacuum-saturated with water and frozen for 24 hours. Then, the samples were rapidly heated in a $60^{\circ} \mathrm{C}$ water bath for 24 hours. Meanwhile the unconditioned samples were placed in sealed bags and allowed to reach room temperature in a $25^{\circ} \mathrm{C}$ water bath. After the samples had spent the required amount of time in their respective water baths, they were tested in indirect tension until failure.

\subsection{Results}

The APA rutting test was run for four different types of samples, a standard mixture, a mixture with 25\% RAP, a mixture with 25\% RAP and 4\% waste engine oil by weight of binder, and a mixture with $25 \%$ RAP and $8 \%$ waste engine oil by weight of binder referred to as Control, 0\% Oil, 4\% Oil, and 8\% Oil respectively. Plots of the rut depth versus load cycle can be found in Figure 5.1. These results show similar resistance to rutting for the control sample and the sample of asphalt made with $24 \%$ RAP and no waste engine oil; however, the sample with $24 \%$ RAP and $0 \%$ waste engine oil did have a slightly better initial resistance to rutting. The asphalt samples with $4 \%$ waste engine oil and $8 \%$ waste engine oil both were made of $24 \%$ RAP and both had an increased amount of rutting compared to the control. 


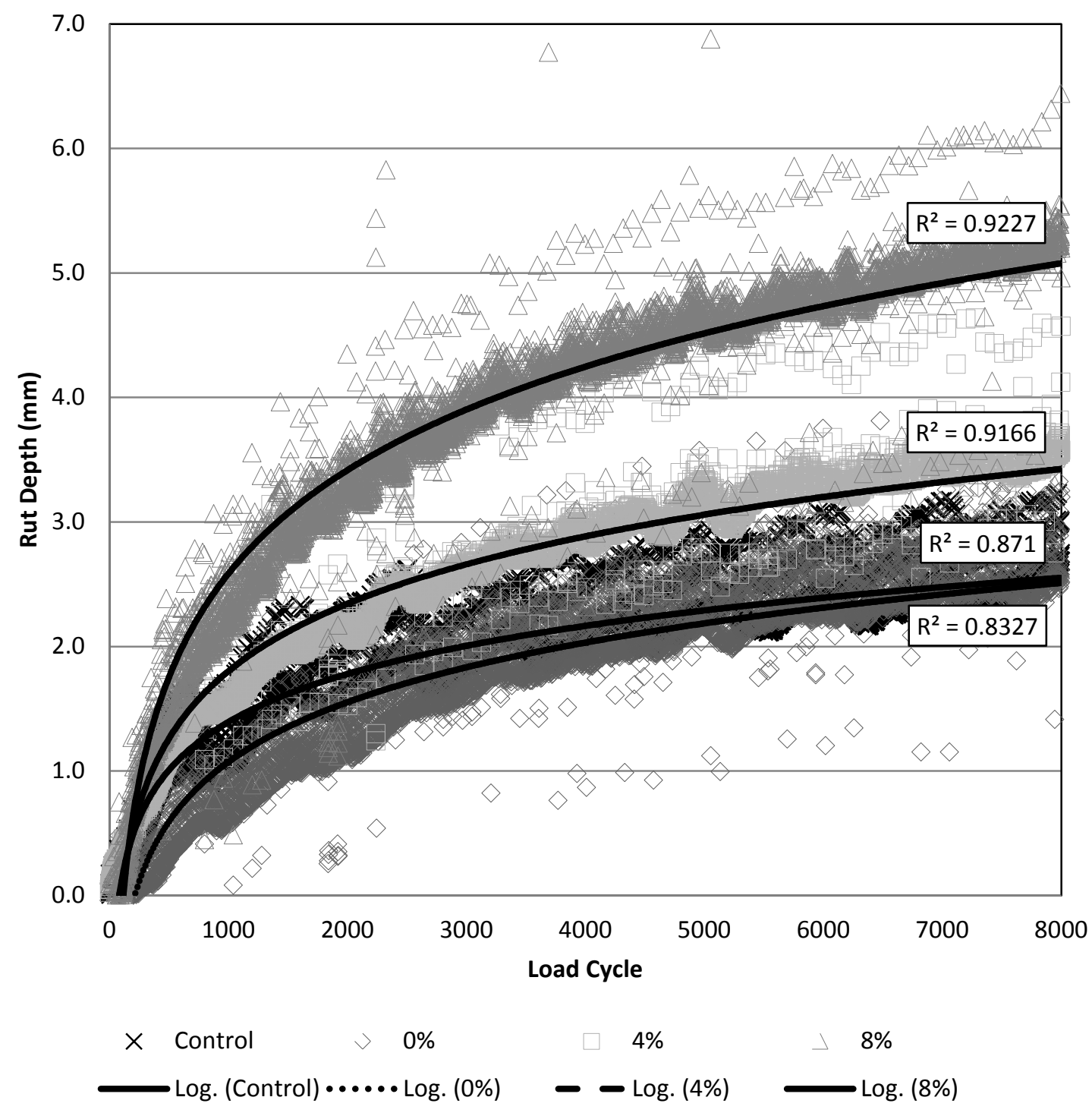

Figure 5.1 APA Rutting Results

Table 5.1 shows the results of the indirect tensile testing and the tensile strength ratio. The tensile strength ratio is simply the ratio of the conditioned samples ultimate strength to the unconditioned samples ultimate strength. The TSR values for all of the samples were between 0.80 and 0.93 , which is within the typical range for acceptable TSR values. There was also a loss in tensile strength compared to the control for both the RAP sample and the RAP samples mixed with waste engine oil. 
Table 5.1

TSR Results

\begin{tabular}{|c|c|c|c|}
\cline { 2 - 4 } \multicolumn{1}{c|}{} & $\begin{array}{c}\text { Conditioned } \\
\text { Strength }(\mathrm{kN})\end{array}$ & $\begin{array}{c}\text { Unconditioned } \\
\text { Strength }(\mathrm{kN})\end{array}$ & $\begin{array}{c}\text { TSR (Conditioned/ } \\
\text { Unconditioned) }\end{array}$ \\
\hline Control & 22.97 & 26.04 & 0.88 \\
\hline Std. Dev. & 1.43 & 2.58 & - \\
\hline $0 \%$ & 20.96 & 23.88 & 0.88 \\
\hline Std. Dev. & 3.54 & 1.50 & - \\
\hline $4 \%$ & 14.22 & 15.37 & 0.93 \\
\hline Std. Dev. & 0.86 & 0.66 & - \\
\hline $8 \%$ & 11.72 & 14.65 & 0.80 \\
\hline Std. Dev. & 0.36 & 1.30 & - \\
\hline
\end{tabular}

\subsection{Analysis}

Asphalt pavements constructed with RAP is known to produce an overall stiffer pavement (Widyatmoko 2008; Ma et al. 2010). However, the laboratory testing did not show an increase in stiffness, which would translate as an improvement in rutting resistance. In fact, the lack of increased stiffness for the $0 \%$ oil sample could lend truth to the practice of allowing low amounts of RAP without modification to the mixture. The last result worth noting is the excessive rutting achieved with $8 \%$ waste engine oil. This result agrees with previous research conducted by Katamine, who concludes that higher percentages of oil lead to increased deformations (Katamine 2000).

The waste engine oil did not adversely affect the TSR of the pavement; however the overall reduction in compressive strength could be detrimental to pavements. These TSR results are similar to previous research by in which recycling agents were shown to reduce tensile strength (Borhan et al. 2009; Lin et al. 2010). A reduction in tensile strength means the asphalt pavement may not be able to resist normal stresses in the pavement and could prematurely crack. 
The asphalt sample with 25\% RAP and no waste engine oil for both the APA rutting test and the TSR test failed to show an increase in performance, as one could expect given the results from the binder testing and FTIR testing. One explanation for the lack of stiffening from the RAP is that, even though the samples were comprised of $24 \%$ RAP by weight of the total mixture, the RAP was only 3.85\% aged binder. The final binder percentage was $5.6 \%$ by total weight of the mixture, however less than $25 \%$ of that binder was from RAB.

Another source of error could have been from the compaction results. Although the air voids was held to a constant $4 \%$ for all samples, the number of gyrations was allowed to vary between samples. This can cause the samples with fewer gyrations to behave as a tender mixture, which would be more prone to rutting and fracture with a lower indirect tensile strength. Figure 5.2 shows the distribution of gyration numbers. For the samples that were over compacted - more than 76 gyrations, they would have been more rut resistant and less prone to fail prematurely under compressive loads. Note, the control samples were all compacted to 76 gyrations during testing.

The final source of error comes from the samples created for the TSR test. AASHTO T 283 states samples with a 7\% air void content should be used for the TSR test (AASHTO 2010). The samples used in this study were all compacted to $4 \%$ air voids. Although the comparative results between samples should not be affected by this error, the amount of damage could have been reduced by closing voids that would have been filled with water before freezing. If the over compaction of the TSR samples have an effect on the amount of damage induced from freezing, then the TSR numbers could have been lower than the ones reported. 


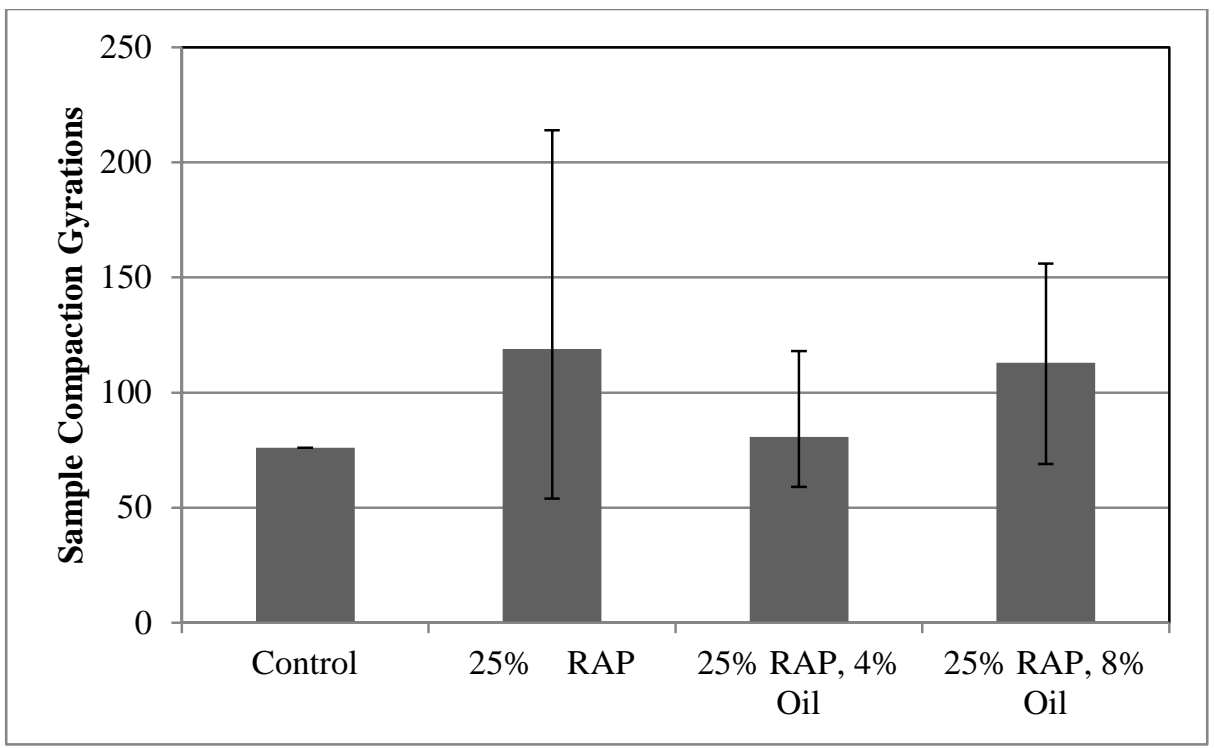

Figure 5.2 Gyration Numbers

\subsection{Conclusions}

The addition of RAP into asphalt concrete samples did not significantly improve the resistance to rutting. Subsequent testing with waste engine oil yielded an increase in the amount of rutting. This series of tests was designed to counteract the stiffening imposed by adding RAP to asphalt pavements, but there was no stiffening when the RAP was added. Since there was no stiffening, adding the waste engine oil caused the samples to deform excessively, instead of softening the stiffened specimens. Based on the literature, future work with higher percentages of RAP should produce a stiffer pavement than those tested here.

The TSR test was developed to analyze aggregates and asphalts that were prone to freeze damage due to stripping. The water would get between the binder, and inside the aggregates then, once frozen, expand and push the binder from the aggregates. This stripping effect would cause asphalt samples to have reduced indirect tensile strength. The reduced tensile strength from the binder is becoming a point of contention for this test because of the increasing use of modified binders. Modified binders usually have a lower indirect tensile strength than virgin binders, but this has yet to be proven as a cause for premature failure, as there is no standard for the minimum indirect tensile strength. 
All of the mixtures tested are not prone to moisture susceptibility. However, there are other performance tests that should also be considered to test the feasibility of waste engine oil as a rejuvenating agent for pavements containing RAP. Future work is to perform dynamic modulus testing on these samples to measure the pavement stiffness and flexure testing to measure the fatigue life of the asphalt samples.

The addition of RAP did not increase the stiffness of the samples or increase their resistance to rutting. Adding waste engine oil to pavements of similar quality to one constructed of virgin materials will cause excessive rutting. Adding waste engine oil to asphalt specimens will not adversely affect the TSR, since the reduction in indirect tensile strength is seen in both conditioned and unconditioned samples. 


\section{Conclusions}

\subsection{Introduction}

RAP and waste engine oil are two materials that both have problems when used separately in asphalt pavements. RAP is known to produce stiffer pavements with poor low temperature performance, while waste engine oil inside of asphalt pavements is known to produce softer pavement and improve the low temperature PG grade of asphalt binder. When combined, the RAP and waste engine oil could symbiotically create a viable pavement.

Asphalt binder testing has shown waste engine oil is able to reduce the stiffening caused by using $\mathrm{RAB}$ and waste engine oil has been shown to improve the low temperature PG sacrificed when using RAB. FTIR testing showed waste engine oil's ability to chemically restore maltenes to binder containing RAB. This restoration of maltenes is crucial for dispersing asphaltenes inside the asphalt binder and returning structure to the binder. The results of asphalt mixture testing showed an increased rutting when waste engine oil was added to asphalt samples, which lends evidence oils ability to soften pavements. Waste engine oil did not adversely affect the TSR of samples containing RAP; however it did cause a reduction in indirect tensile strength.

\subsection{Conclusions}

For both DSR and rotational viscometer test results, the asphalt became stiffer when RAP was added to the control binder. This stiffness is noted by an increase in viscosity and an improvement to the $\mathrm{G}^{*} / \operatorname{Sin}(\delta)$ parameter. The increased stiffness with RAP and respective decrease in stiffness and $\mathrm{G}^{*} / \operatorname{Sin}(\delta)$ parameter are supported by the advanced asphalt binder testing. The carbonyl and sulfoxide indices increased with the introduction of $25 \%$ RAB, meaning there were less maltenes present in the binder, which would cause it to be stiffer. The increased stiffness also translates to a better resistance against rutting, since the maltenes are responsible for flow within the binder and the increased asphaltenes mean an increased viscosity and structure for the binder.

When waste engine oil was added to the binder, the viscosity dropped as well as the $\mathrm{G}^{*} / \mathrm{Sin}(\delta)$ parameter. These results are supported by the FTIR testing, since the waste 
engine oil was shown to lower the carbonyl and sulfoxide indices which, in effect, mean the oil is adding maltenes to the binder structure. Since the maltenes contribute to the ability to flow and softness of binder, when oil is added the viscosity should be decreasing as well as the increase in rutting potential.

The results from the binder testing and the FTIR testing suggest stiffening should be seen with the addition of RAP to the asphalt pavement. However, in the sample asphalt samples, the resistance to rutting was increased marginally at best. Also, the TSR test did not show any increase in strength with the addition of RAP into the mix, as the results from both the binder testing and the advanced binder testing would suggest.

The sample pucks, when mixed with waste engine oil, showed an increase in rutting, which was predicted by a decrease in the $\mathrm{G}^{*} / \sin (\delta)$ parameter in the asphalt binder testing. Also, the FTIR testing showed a reduction in the structural indices for both sulfoxides and carbonyls, which means an increase in the maltenes present in the samples, therefore the increase in rutting is expected. The reduction in tensile strength from the TSR test can be explained by the same logic, physically softer binder with increased levels of maltenes will fracture sooner than stiffer, asphaltene rich binder.

This research suggests waste engine oil has the ability to counteract the stiffening from incorporating RAP into pavement and restore the PG to that of virgin binder. Waste engine oil is also capable of restoring maltenes to RAB, which will improve the structure of the asphalt binder. Mixture testing with RAP and waste engine oil was shown to soften the asphalt specimens, both by increasing the amount of rutting and lowering the samples indirect tensile strength.

\subsection{Future Work}

In order to completely investigate the feasibility of using waste engine oil in asphalt pavements, more research should be conducted on different percentages of RAP binder. Several Superpave tests were not conducted during this study and if more work be done on the subject it is recommended to include those tests. Specifically, the bending beam rheometer should be used to better assess the low temperature behavior of the asphalt binder blended with RAB and waste engine oil. 
Future work for mixture testing research is to increase the amount of RAP used in the mixture testing to provide $25 \%$ effective $\mathrm{RAB}$. This would require $36.2 \%$ of the RAP used in this study to achieve a $25 \%$ effective RAB in the asphalt samples. At this higher percentage or RAP, the results from the mixture testing would be more representative of the results from the binder and FTIR testing. Also, dynamic modulus testing would allow for testing of the stiffness modulus of the asphalt samples containing waste engine oil and beam fatigue testing would give insight into changes in fatigue properties of asphalt samples containing waste engine oil. 


\section{References}

AASHTO. 2010. T 283 - 07 Resistance of Compacted Hot Mix Asphalt (HMA) to Moisture-Induced Damage. American Association of State Highway and Transportation Officials.

ASTM. 2005a. ASTM D 1856 - 95a: Standard Test Method for Recovery of Asphalt from Solution by Abson Method. 2008 Annual Book of ASTM Standards. West Conshohocken, PA: ASTM International. p. 166-167.

ASTM. 2005b. ASTM D 2172 - 05: Standard Test Methods for Quantities Extraction of Bitumen from Bituminous Paving Mixtures (Method A). 2008 Annual Book of ASTM Standards. West Conshohocken, PA: ASTM International. p. 203-214.

ASTM. 2008a. ASTM D 2041 - 11 Standard Test Method for Theoretical Maximum Specific Gravity and Density of Bituminous Paving Mixtures. 2008 Annual Book of ASTM Standards. West Conshohocken, PA: ASTM International.

ASTM. 2008b. ASTM D 2726 - 10 Standard Test Method for Bulk Specific Gravity and Density of Non-Absorptive Compacted Bituminous Mixtures. 2008 Annual Book of ASTM Standards. West Conshohocken, PA: ASTM International.

ASTM. 2008c. ASTM D 7175 - 08 Standard Test Method for Determining the Rheological Properties of Asphalt Binder Using a Dynamic Shear Rheometer. 2008 Annual Book of ASTM Standards. West Conshohocken, PA: ASTM International.

ASTM. 2008d. ASTM D 4402 - 06 Standard Test Method for Viscosity Determination of Asphalt at Elevated Temperatures Using a Rotational Viscometer. 2008 Annual Book of ASTM Standards. West Conshohocken, PA: ASTM International.

ASTM. 2008e. ASTM D 2872 - 04 Standard Test Method for Effect of Heat and Air on a Moving Film of Asphalt (Rolling Thin-Film Oven Test). 2008 Annual Book of ASTM Standards. West Conshohocken, PA: ASTM International.

ASTM. 2008f. ASTM D 6521 - 08 Standard Practice for Accelerated Aging of Asphalt Binder Using a Pressurized Aging Vessel (PAV). 2008 Annual Book of ASTM Standards. West Conshohocken, PA: ASTM International.

Borhan MN, Suja F, Ismail A, Rahmat RAOK. 2009. The Effects of Used Cylinder Oil on Asphalt Mixes. European Journal of Sceintific Research 28(3):389-411.

Carpenter SH, Wolosick JR. 1980. Modifer influence in the characterization of hot-mix recycled material. Transportation Research Board 777:15-22. 
Chen JS, Huang CC, Chu PY, Lin KY. Engineering characterization of recycled asphalt concrete and aged bitumen mixed recycling agent. Journal of Materials Science. 2007; Van Godewijckstraat 30, Dordrecht, 3311 GZ, Netherlands: Kluwer Academic Publishers. p. 9867-9876.

Collins JH, Jones GR. 2000. Asphalt Composition and Method. In: Patent US, editor. USA.

Collins R, Ciesielski S. 1994. Recycling and use of waste materials and by-products in highway construction. Washington, DC.

Cortizo MS, Larsen DO, Bianchetto H, Alessandrini JL. 2004. Effect of the thermal degradation of SBS copolymers during the ageing of modified asphalts. Polymer Degradation and Stability 86(2):275-282.

Dunning RL, Mendenhall RL. 1978. Design of Recycled Asphalt Pavements and Selection of Modifiers. ASTM Special Technical Publication:35-46.

e-CFR. 2006. PART 261-Identification and Listing of Hazardous Waste. In: (OFR) OotFR, editor. Washington, DC.

FHWA. 2008. Highway Statistics 2008. U.S. Department of Transportation.

Hayner RE. 1999. Process for paving with asphalt containing mineral lubricating oil base stock. In: Patent US, editor. USA.

Herrington PR, Dravitzki VK, Wood CWB, Patrick JE. 1993. Waste oil distillation bottoms as bitumen extenders. Road and Transport Research 2(4):56-68.

Huang YH. 1993. Pavement Analysis and Design. Engelwood Clifs, New Jersey: Prentice Hall.

Institute TA. 1960. The Asphalt Handbook: Revised Edition. College Park, Maryland: The Asphalt Institute.

Kandhal PS, Rao SS, Watson DE, Young B. 1995. Performance of recycled hot-mix asphalt mixtures in Georgia. Transportation Research Record(1507):67-77.

Katamine NM. 2000. Physical and mechanical properties of bituminous mixtures containing oil shales. Journal of Transportation Engineering-Asce 126(2):178184.

Kiggundu BM, Nusser BJ, Newcomb DE, Zallen DM. Correlations Between Physical and Chemical Properties in Recycled-Asphalt Binder Studies. Proceedings of the Paving and Transportation Conference. 1984; Albuquerque, NM, USA: Univ of New Mexico, Dep of Civil Engineering. p. 178-200. 
Lamontagne J, Dumas P, Mouillet V, Kister J. 2001. Comparison by Fourier transform infrared (FTIR) spectroscopy of different ageing techniques: application to road bitumens. Fuel 80(4):483-488.

Lin P-S, Wu T-L, Chang C-W, Chou B-Y. 2010. Effects of recycling agents on aged asphalt binders and reclaimed asphalt concrete. Materials and Structures/Materiaux et Constructions 44(5):911-921.

Lins VFC, Araujo MFAS, Yoshida MI, Ferraz VP, Andrada DM, Lameiras FS. 2008. Photodegradation of hot-mix asphalt. Fuel 87(15-16):3254-3261.

Ma T, Bahia HU, Mahmoud E, Hajj EY. Estimating allowable RAP in asphalt mixes to meet target low temperature PG requirements. Asphalt Paving Technology: Association of Asphalt Paving Technologists-Proceedings of the Technical Sessions. 2010; Sacramento, CA, United States: Association of Asphalt Paving Technologist. p. 473-495.

Mamlouk MS, Zaniewski JP. 2006. Materials for Civil and Construction Engineers. Upper Saddle River, NJ 07458: Pearson Prentice Hall.

Michigan Department of Transportation (MDOT). 2003. Special Provision for Superpave HMA Mixtures. Lansing, MI. No. 03SP501(F).

NCAT. 1996. Hot Mix Asphalt Materials, Mixture Design and Construction. Auburn, Alabama: NCAT.

Newcomb DE, Nusser BJ, Kiggundu BM, Zallen DM. 1984. Laboratory Study of the Effects of Recycling Modifiers on Aged Asphalt Cement Transportation Research Record:66-77.

Ouyang C, Wang S, Zhang Y, Zhang Y. 2006a. Improving the aging resistance of styrene-butadiene-styrene tri-block copolymer modified asphalt by addition of antioxidants. Polymer Degradation and Stability 91(4):795-804.

Ouyang C, Wang S, Zhang Y, Zhang Y. 2006b. Improving the aging resistance of asphalt by addition of Zinc dialkyldithiophosphate. Fuel 85(7-8):1060-1066.

Ozer H, Al-Qadi IL, Carpenter SH, Aurangzeb Q, Roberts GL, Trepanier J. Evaluation of RAP impact on hot-mix asphalt design and performance. Asphalt Paving Technology: Association of Asphalt Paving Technologists-Proceedings of the Technical Sessions. 2009; Minneapolis, MN, United States: Association of Asphalt Paving Technologist. p. 317-348.

Pavement-Technology-INC.(PTI). Asphalt Pavement Analyzer Test Method Asphalt Pavement Analyser (APA) User's Guide [Internet].Pavement Technology INC.(PTI) 
Shakirullah M, Ahamd I, Ishaq M, Shah AA, Kahn MA, Rehman HU, Kahn H. 2007. FTIR Analysis of the Whole Asphalt and Some Crackates. Journal of the Chemical Society of Pakistan 29(5).

Soleimani A, Walsh S, Hesp SAM. 2009. Asphalt cement loss tangent as surrogate performance indicator for control of thermal cracking. Transportation Research Record(2126):39-46.

Villanueva A, Ho S, Zanzotto L. 2008. Asphalt modification with used lubricating oil. Canadian Journal of Civil Engineering 35(2):148-157.

Widyatmoko I. 2008. Mechanistic-empirical mixture design for hot mix asphalt pavement recycling. Construction and Building Materials 22(2):77-87.

Wu S-p, Pang L, Mo L-t, Chen Y-c, Zhu G-j. 2009. Influence of aging on the evolution of structure, morphology and rheology of base and SBS modified bitumen. Construction and Building Materials 23(2):1005-1010.

Zhang F, Yu J. 2009. The research for high-performance SBR compound modified asphalt. Construction and Building Materials 24(3):410-418.

Zhang F, Yu J, Han J. 2011. Effects of thermal oxidative ageing on dynamic viscosity, TG/DTG, DTA and FTIR of SBS- and SBS/sulfur-modified asphalts. Construction and Building Materials 25(1):129-137. 


\section{Appendix A. Job Mix Formula (JMF)}

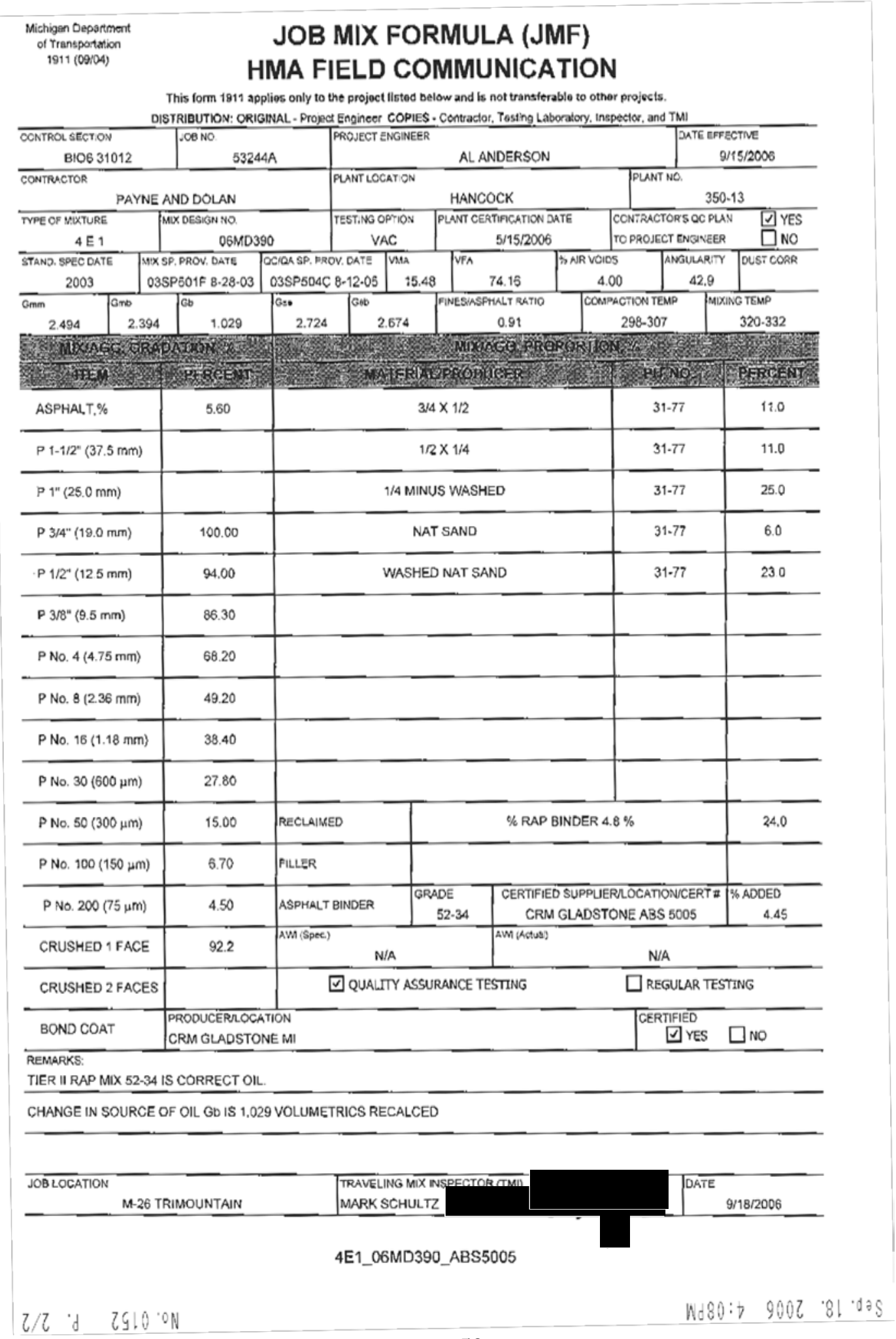




\section{Appendix B. Compaction Results}

Table B.1:

Compaction Data

\begin{tabular}{|c|c|c|c|c|c|c|c|c|c|c|}
\hline $\begin{array}{l}\text { Gyration } \\
\text { Number }\end{array}$ & $\begin{array}{l}25 \% \\
\text { RAP }\end{array}$ & $\begin{array}{l}25 \% \\
\text { RAP }\end{array}$ & $\begin{array}{l}25 \% \\
\text { RAP }\end{array}$ & $\begin{array}{l}25 \% \\
\text { RAP }\end{array}$ & $\begin{array}{l}25 \% \\
\text { RAP }\end{array}$ & $\begin{array}{l}25 \% \\
\text { RAP }\end{array}$ & $\begin{array}{c}25 \% \text { RAP } \\
4 \% \text { Oil }\end{array}$ & $\begin{array}{c}25 \% \text { RAP } \\
4 \% \text { Oil }\end{array}$ & $\begin{array}{c}25 \% \text { RAP } \\
4 \% \text { Oil }\end{array}$ & $\begin{array}{c}25 \% \text { RAP, } \\
4 \% \text { Oil }\end{array}$ \\
\hline 1 & 97.8 & 100.2 & 99.5 & 101.5 & 100.5 & 102.8 & 99.8 & 100.7 & 100.4 & 101. \\
\hline 2 & 96.9 & 96.6 & 95.9 & 97.8 & 96.9 & 99.0 & 96.3 & 97.0 & 96.7 & 97. \\
\hline 3 & 95.4 & 95.0 & 94.3 & 96.2 & 95.3 & 97.3 & 94.6 & 95.3 & 95.1 & 95 \\
\hline 4 & 94.4 & 93.9 & 93.1 & 95.1 & 94.3 & 96.1 & 93.5 & 94.3 & 94.0 & 94.7 \\
\hline 5 & 93.7 & 93.1 & \begin{tabular}{|l|}
92.4 \\
\end{tabular} & 94.2 & 93.5 & 95.3 & 92.7 & 93.4 & 93.2 & 93.9 \\
\hline 6 & 93.1 & 92.5 & \begin{tabular}{|l|}
91.7 \\
\end{tabular} & 93.6 & 92.9 & 94.6 & 92.0 & 92.8 & 92.5 & 93.3 \\
\hline 7 & 92.7 & 91.9 & 91.2 & 93.1 & 92.4 & 94.0 & 91.5 & 92.3 & 92.0 & 92.7 \\
\hline 8 & 92.3 & 91.5 & \begin{tabular}{|l|}
90.8 \\
\end{tabular} & 92.7 & 92.0 & 93.6 & 91.1 & 91.8 & 91.5 & 92.3 \\
\hline 9 & 91.9 & 91.1 & \begin{tabular}{|l|}
90.4 \\
\end{tabular} & 92.3 & 91.6 & 93.2 & 90.7 & 91.5 & 91.2 & 91. \\
\hline 10 & 91.6 & 90.8 & \begin{tabular}{|l|}
90.1 \\
\end{tabular} & 91.9 & 91.3 & 92.8 & 90.4 & 91.1 & 90.9 & 91.6 \\
\hline 11 & 91.4 & 90.5 & 89.8 & 91.7 & 91.0 & 92.5 & 90.1 & 90.8 & 90.6 & 91. \\
\hline 12 & 91.1 & 90.3 & 89.6 & 91.4 & 90.8 & 92.2 & 89.9 & 90.6 & 90.3 & 91. \\
\hline 13 & 90.9 & 90.1 & 89.4 & 91.2 & 90.5 & 92.0 & 89.6 & 90.4 & 90.1 & 90.9 \\
\hline 14 & 90.7 & 89.8 & \begin{tabular}{|l|}
89.2 \\
\end{tabular} & 91.0 & 90.3 & 91.8 & 89.4 & 90.2 & 89.9 & 90.6 \\
\hline 15 & 90.6 & 89.7 & 89.0 & 90.8 & 90.1 & 91.6 & 89.2 & 90.0 & 89.7 & 90.5 \\
\hline 16 & 90.4 & 89.5 & 88.8 & 90.6 & 90.0 & 91.4 & 89.1 & 89.8 & 89.5 & 90.3 \\
\hline 17 & 90.2 & 89.3 & 88.7 & 90.4 & 89.8 & 91.2 & 88.9 & 89.6 & 89.3 & 90.1 \\
\hline 18 & 90.1 & 89.2 & 88.5 & 90.3 & 89.7 & 91.0 & 88.8 & 89.5 & 89.2 & 90.0 \\
\hline 19 & 90.0 & 89.0 & 88.4 & 90.1 & 89.5 & 90.9 & 88.6 & 89.3 & 89.1 & 89.8 \\
\hline 20 & 89.9 & 88.9 & 88.2 & 90.0 & 89.4 & 90.7 & 88.5 & 89.2 & 88.9 & 89.7 \\
\hline 21 & 89.7 & 88.8 & 88.1 & 89.9 & 89.3 & 90.6 & 88.4 & 89.1 & 88.8 & 89.6 \\
\hline 22 & 89.6 & 88.7 & 88.0 & 89.8 & 89.2 & 90.5 & 88.3 & 89.0 & 88.7 & 89.5 \\
\hline 23 & 89.5 & 88.6 & 87.9 & 89.7 & 89.1 & 90.4 & 88.2 & 88.9 & 88.6 & 89.3 \\
\hline
\end{tabular}




\begin{tabular}{|c|c|c|c|c|c|c|c|c|c|c|}
\hline 24 & 89.4 & 88.5 & 87.8 & 89.6 & 89.0 & 90.3 & 88.1 & 88.8 & 88.5 & 89.2 \\
\hline 25 & 89.3 & 88.4 & 87.7 & 89.5 & 88.9 & 90.2 & 88.0 & 88.7 & 88.4 & 89.1 \\
\hline 26 & 89.2 & 88.3 & 87.6 & 89.4 & 88.8 & 90.1 & 87.9 & 88.6 & 88.3 & 89.1 \\
\hline 27 & 89.2 & 88.2 & 87.5 & 89.3 & 88.7 & 90.0 & 87.8 & 88.5 & 88.2 & 89.0 \\
\hline 28 & 89.1 & 88.1 & 87.5 & 89.2 & 88.6 & 89.9 & 87.7 & 88.4 & 88.1 & 88.9 \\
\hline 29 & 89.0 & 88.0 & 87.4 & 89.1 & 88.5 & 89.8 & 87.6 & 88.3 & 88.0 & 88.8 \\
\hline 30 & 88.9 & 87.9 & 87.3 & 89.0 & 88.4 & 89.7 & 87.5 & 88.2 & 87.9 & 88.7 \\
\hline 31 & 88.8 & 87.9 & 87.2 & 89.0 & 88.4 & 89.6 & 87.5 & 88.2 & 87.9 & 88.6 \\
\hline 32 & 88.8 & 87.8 & 87.2 & 88.9 & 88.3 & 89.5 & 87.4 & 88.1 & 87.8 & 88.6 \\
\hline 33 & 88.7 & 87.7 & 87.1 & 88.8 & 88.2 & 89.5 & 87.3 & 88.0 & 87.7 & 88.5 \\
\hline 34 & 88.7 & 87.7 & 87.0 & 88.8 & 88.2 & 89.4 & 87.3 & 88.0 & 87.7 & 88.4 \\
\hline 35 & 88.6 & 87.6 & 87.0 & 88.7 & 88.1 & 89.3 & 87.2 & 87.9 & 87.6 & 88.4 \\
\hline 36 & 88.5 & 87.5 & \begin{tabular}{|l|}
86.9 \\
\end{tabular} & 88.6 & 88.0 & 89.3 & 87.1 & 87.9 & 87.5 & 88.3 \\
\hline 37 & 88.5 & 87.5 & 86.9 & 88.6 & 88.0 & 89.2 & 87.1 & 87.8 & 87.5 & 88.3 \\
\hline 38 & 88.4 & 87.4 & 86.8 & 88.5 & 87.9 & 89.1 & 87.0 & 87.7 & 87.4 & 88.2 \\
\hline 39 & 88.4 & 87.4 & 86.8 & 88.5 & 87.9 & 89.1 & 87.0 & 87.7 & 87.4 & 88.1 \\
\hline 40 & 88.3 & 87.3 & 86.7 & 88.4 & 87.8 & 89.0 & 86.9 & 87.6 & 87.3 & 88.1 \\
\hline 41 & 88.3 & 87.3 & 86.7 & 88.4 & 87.8 & 89.0 & 86.9 & 87.6 & 87.3 & 88.0 \\
\hline 42 & 88.2 & 87.2 & 86.6 & 88.3 & 87.7 & 88.9 & 86.8 & 87.5 & 87.2 & 88.0 \\
\hline 43 & 88.2 & 87.2 & 86.6 & 88.3 & 87.7 & 88.9 & 86.8 & 87.5 & 87.2 & 87.9 \\
\hline 44 & 88.1 & 87.1 & 86.5 & 88.2 & 87.6 & 88.8 & 86.7 & 87.4 & 87.1 & 87.9 \\
\hline 45 & 88.1 & 87.1 & 86.5 & 88.2 & 87.6 & 88.8 & 86.7 & 87.4 & 87.1 & 87.9 \\
\hline 46 & 88.0 & 87.0 & 86.4 & 88.1 & 87.5 & 88.7 & 86.6 & 87.3 & 87.0 & 87.8 \\
\hline 47 & 88.0 & 87.0 & 86.4 & 88.1 & 87.5 & 88.7 & 86.6 & 87.3 & 87.0 & 87.8 \\
\hline 48 & 87.9 & 86.9 & 86.4 & 88.1 & 87.5 & 88.6 & 86.5 & 87.3 & 86.9 & 87.7 \\
\hline 49 & 87.9 & 86.9 & 86.3 & 88.0 & 87.4 & 88.6 & 86.5 & 87.2 & 86.9 & 87.7 \\
\hline 50 & 87.9 & 86.9 & 86.3 & 88.0 & 87.4 & 88.6 & 86.5 & 87.2 & 86.9 & 87.6 \\
\hline 51 & 87.8 & 86.8 & 86.2 & 87.9 & 87.3 & 88.5 & 86.4 & 87.1 & 86.8 & 87.6 \\
\hline 52 & 87.8 & 86.8 & 86.2 & 87.9 & 87.3 & 88.5 & 86.4 & 87.1 & 86.8 & 87.6 \\
\hline
\end{tabular}




\begin{tabular}{|c|c|c|c|c|c|c|c|c|c|c|}
\hline 53 & 87.7 & 86.7 & 86.2 & 87.9 & 87.3 & 88.4 & 86.4 & 87.1 & 86.7 & 87.5 \\
\hline 54 & 87.7 & 86.7 & 86.1 & 87.8 & 87.2 & 88.4 & 86.3 & 87.0 & 86.7 & 87.5 \\
\hline 55 & 87.7 & 86.7 & & 87.8 & 87.2 & 88.4 & 86.3 & 87.0 & 86.7 & 87.5 \\
\hline 56 & 87.6 & 86.6 & & 87.8 & 87.2 & 88.3 & 86.3 & 87.0 & 86.6 & 87.4 \\
\hline 57 & 87.6 & 86.6 & & 87.7 & 87.1 & 88.3 & 86.2 & 86.9 & 86.6 & 87.4 \\
\hline 58 & 87.6 & 86.6 & & 87.7 & 87.1 & 88.3 & 86.2 & 86.9 & 86.6 & 87.4 \\
\hline 59 & 87.5 & 86.5 & & 87.7 & 87.1 & 88.2 & 86.2 & 86.9 & 86.5 & 87.3 \\
\hline 60 & 87.5 & 86.5 & & 87.6 & 87.0 & 88.2 & & 86.8 & 86.5 & 87.3 \\
\hline 61 & 87.5 & 86.5 & & 87.6 & 87.0 & 88.2 & & 86.8 & 86.5 & 87.3 \\
\hline 62 & 87.5 & 86.4 & & 87.6 & 87.0 & 88.1 & & 86.8 & 86.4 & 87.2 \\
\hline 63 & 87.4 & 86.4 & & 87.6 & 86.9 & 88.1 & & 86.7 & 86.4 & 87.2 \\
\hline 64 & 87.4 & 86.4 & & 87.5 & 86.9 & 88.1 & & 86.7 & 86.4 & 87.2 \\
\hline 65 & 87.4 & 86.4 & & 87.5 & 86.9 & 88.0 & & 86.7 & 86.4 & 87.2 \\
\hline 66 & 87.3 & 86.3 & & 87.5 & 86.9 & 88.0 & & 86.7 & 86.3 & 87.1 \\
\hline 67 & 87.3 & 86.3 & & 87.5 & 86.8 & 88.0 & & 86.6 & 86.3 & 87.1 \\
\hline 68 & 87.3 & 86.3 & & 87.4 & 86.8 & 88.0 & & 86.6 & 86.3 & 87.1 \\
\hline 69 & 87.3 & 86.3 & & 87.4 & 86.8 & 87.9 & & 86.6 & 86.3 & 87.0 \\
\hline 70 & 87.2 & 86.2 & & 87.4 & 86.7 & 87.9 & & 86.6 & 86.2 & 87.0 \\
\hline 71 & 87.2 & 86.2 & & 87.3 & 86.7 & 87.9 & & 86.5 & 86.2 & 87.0 \\
\hline 72 & 87.2 & 86.2 & & 87.3 & 86.7 & 87.9 & & 86.5 & 86.2 & 87.0 \\
\hline 73 & 87.2 & 86.2 & & 87.3 & 86.7 & 87.8 & & 86.5 & & 87.0 \\
\hline 74 & 87.1 & & & 87.3 & 86.7 & 87.8 & & 86.5 & & 86.9 \\
\hline 75 & 87.1 & & & 87.3 & 86.6 & 87.8 & & 86.4 & & 86.9 \\
\hline 76 & 87.1 & & & 87.2 & 86.6 & 87.8 & & 86.4 & & 86.9 \\
\hline 77 & 87.1 & & & 87.2 & 86.6 & 87.7 & & 86.4 & & 86.9 \\
\hline 78 & 87.0 & & & 87.2 & 86.6 & 87.7 & & 86.4 & & 86.8 \\
\hline 79 & 87.0 & & & 87.2 & 86.5 & 87.7 & & 86.3 & & 86.8 \\
\hline 80 & 87.0 & & & 87.2 & 86.5 & 87.7 & & 86.3 & & 86.8 \\
\hline 81 & 87.0 & & & 87.1 & 86.5 & 87.6 & & 86.3 & & 86.8 \\
\hline
\end{tabular}




\begin{tabular}{|c|c|c|c|c|c|c|}
\hline 82 & 87.0 & 87.1 & 86.5 & 87.6 & 86.3 & 86.8 \\
\hline 83 & 86.9 & 87.1 & 86.5 & 87.6 & 86.3 & 86.7 \\
\hline 84 & 86.9 & 87.1 & 86.4 & 87.6 & 86.2 & 86.7 \\
\hline 85 & 86.9 & 87.1 & 86.4 & 87.6 & 86.2 & 86.7 \\
\hline 86 & 86.9 & 87.0 & 86.4 & 87.5 & 86.2 & 86.7 \\
\hline 87 & 86.9 & 87.0 & 86.4 & 87.5 & 86.2 & 86.7 \\
\hline 88 & 86.8 & 87.0 & 86.4 & 87.5 & & 86.6 \\
\hline 89 & 86.8 & 87.0 & 86.3 & 87.5 & & 86.6 \\
\hline 90 & 86.8 & 87.0 & 86.3 & 87.5 & & 86.6 \\
\hline 91 & 86.8 & 86.9 & 86.3 & 87.4 & & 86.6 \\
\hline 92 & 86.7 & 86.9 & 86.3 & 87.4 & & 86.6 \\
\hline 93 & 86.7 & 86.9 & 86.3 & 87.4 & & 86.5 \\
\hline 94 & 86.7 & 86.9 & 86.3 & 87.4 & & 86.5 \\
\hline 95 & 86.7 & 86.9 & 86.2 & 87.4 & & 86.5 \\
\hline 96 & 86.7 & 86.9 & 86.2 & 87.4 & & 86.5 \\
\hline 97 & 86.7 & 86.8 & 86.2 & 87.3 & & 86.5 \\
\hline 98 & 86.6 & 86.8 & 86.2 & 87.3 & & 86.5 \\
\hline 99 & 86.6 & 86.8 & & 87.3 & & 86.5 \\
\hline 100 & 86.6 & 86.8 & & 87.3 & & 86.4 \\
\hline 101 & 86.6 & 86.8 & & 87.3 & & 86.4 \\
\hline 102 & 86.6 & 86.8 & & 87.3 & & 86.4 \\
\hline 103 & 86.5 & 86.8 & & 87.2 & & 86.4 \\
\hline 104 & 86.5 & 86.7 & & 87.2 & & 86.4 \\
\hline 105 & 86.5 & 86.7 & & 87.2 & & 86.4 \\
\hline 106 & 86.5 & 86.7 & & 87.2 & & 86.3 \\
\hline 107 & 86.5 & 86.7 & & 87.2 & & 86.3 \\
\hline 108 & 86.5 & 86.7 & & 87.2 & & 86.3 \\
\hline 109 & 86.5 & 86.7 & & 87.1 & & 86.3 \\
\hline 110 & 86.4 & 86.7 & & 87.1 & & 86.3 \\
\hline
\end{tabular}




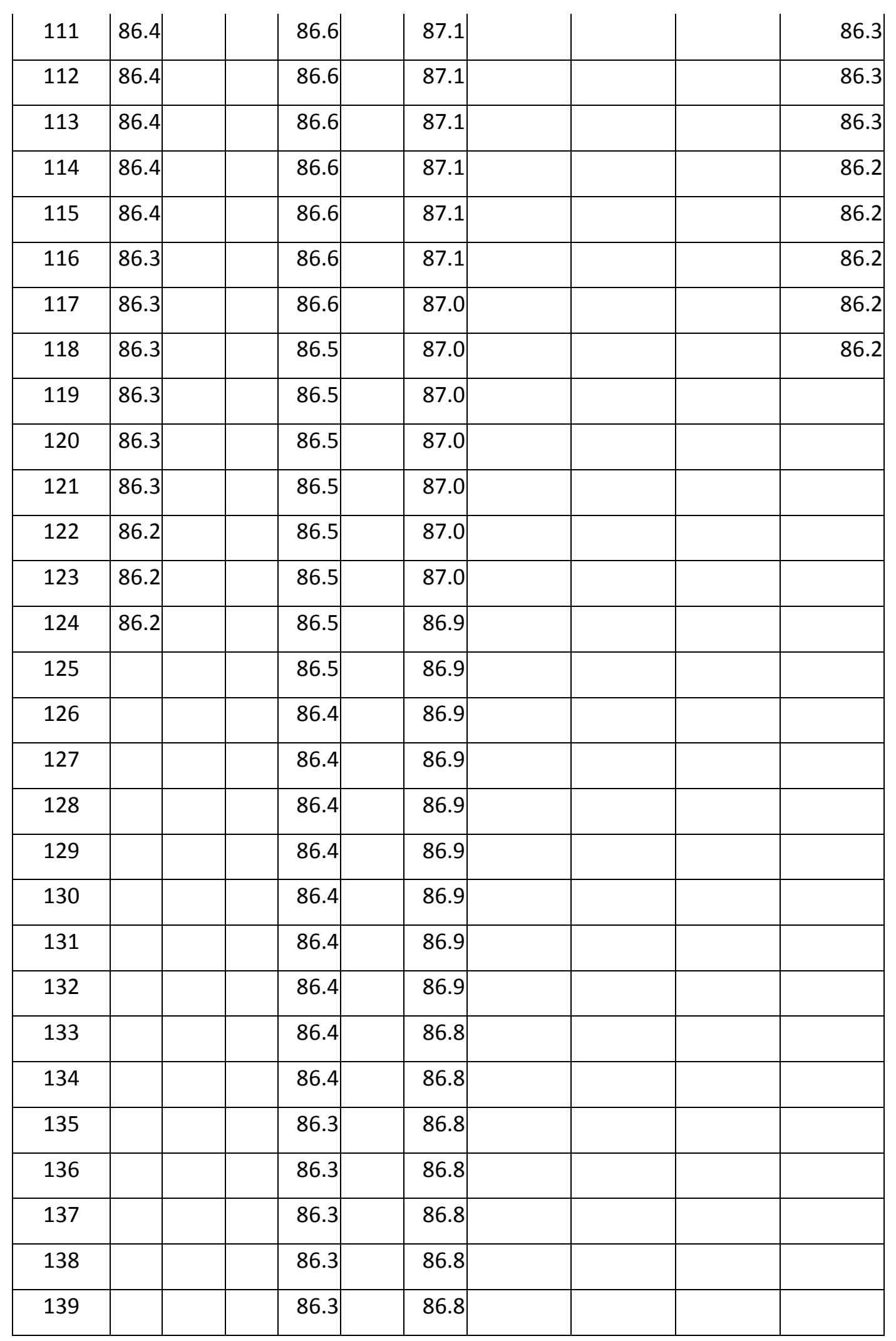




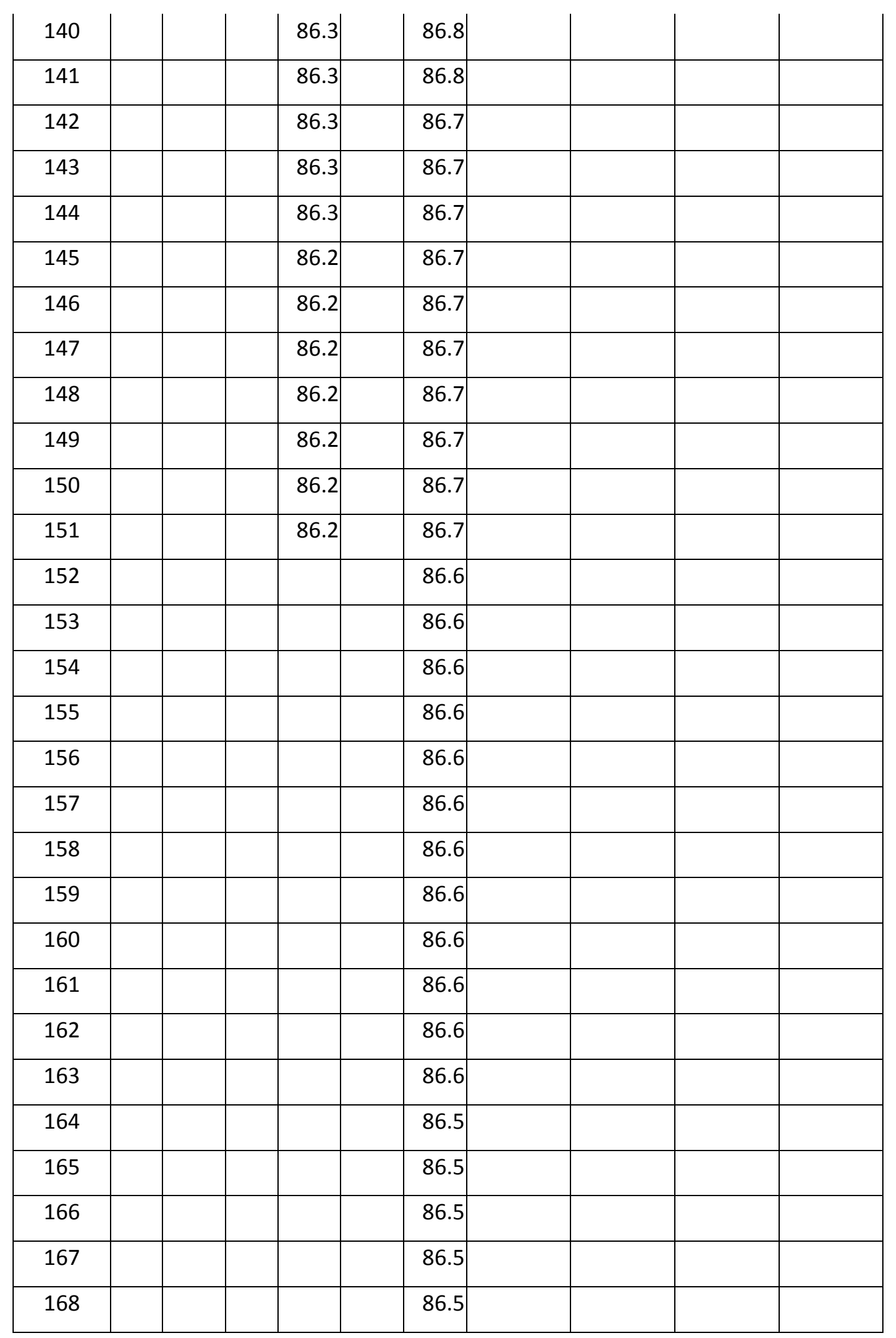




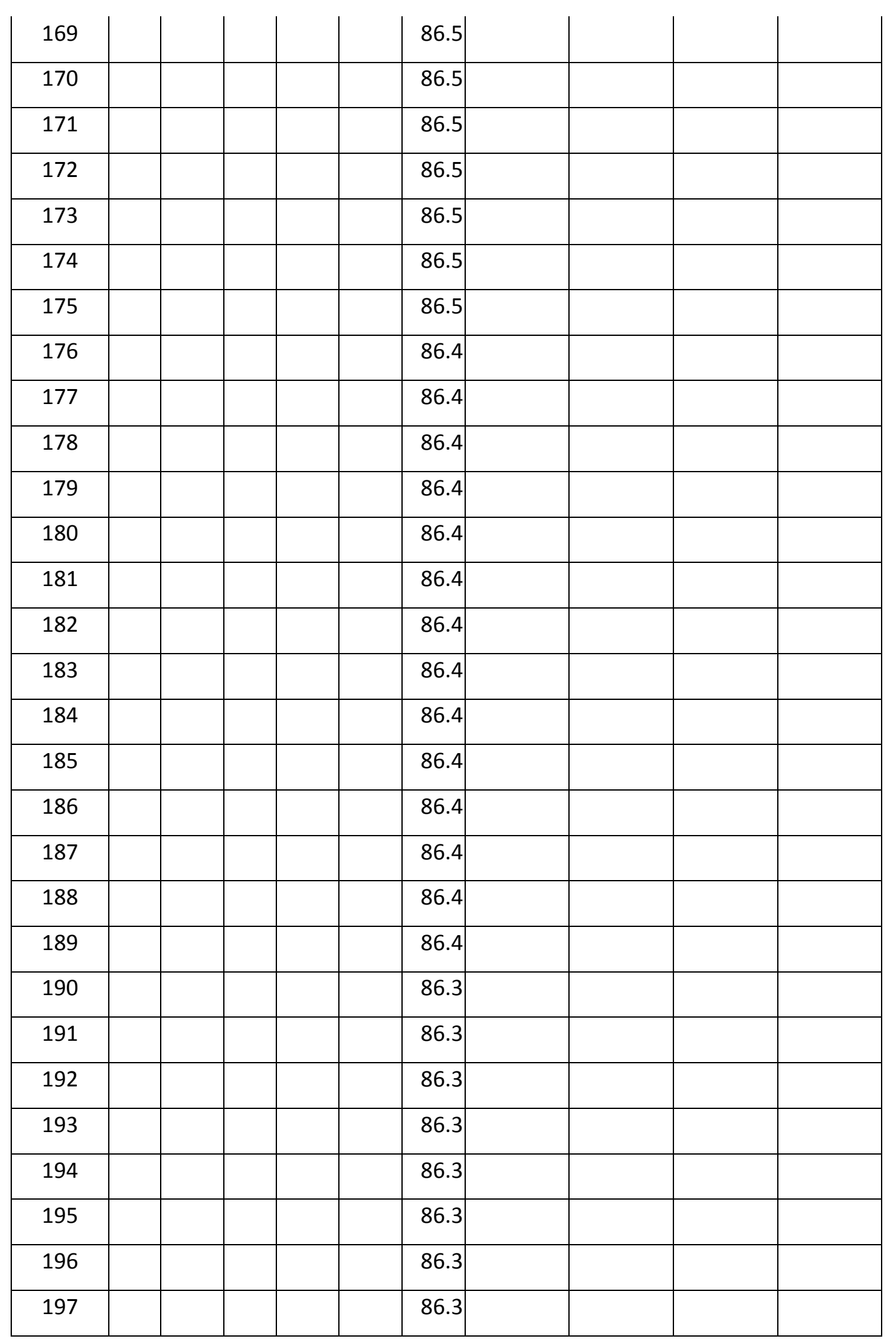




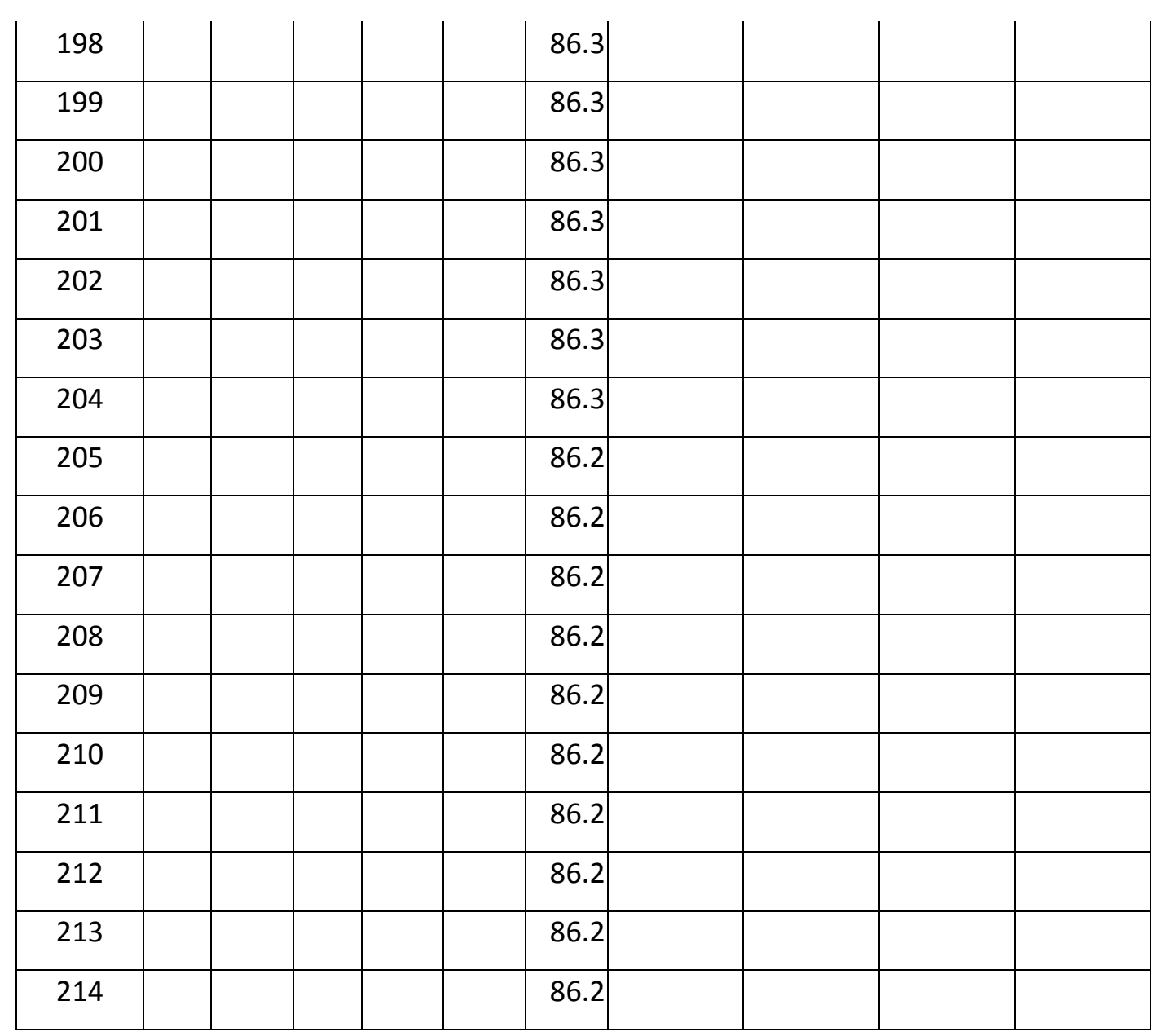

Table B.2:

Compaction Data

\begin{tabular}{|c|c|c|c|c|c|c|c|c|}
\hline $\begin{array}{l}\text { Gyration } \\
\text { Number }\end{array}$ & $\begin{array}{c}25 \% \text { RAP, } \\
4 \% \text { Oil }\end{array}$ & $\begin{array}{c}25 \% \text { RAP, } \\
4 \% \text { Oil }\end{array}$ & $\begin{array}{c}25 \% \text { RAP } \\
8 \% \text { Oil }\end{array}$ & $\begin{array}{c}25 \% \text { RAP, } \\
8 \% \text { Oil }\end{array}$ & $\begin{array}{c}25 \% \text { RAP, } \\
8 \% \text { Oil }\end{array}$ & $\begin{array}{c}25 \% \text { RAP, } \\
8 \% \text { Oil }\end{array}$ & $\begin{array}{c}25 \% \text { RAP } \\
8 \% \text { Oil }\end{array}$ & $\begin{array}{c}25 \% \text { RAP, } \\
8 \% \text { Oil }\end{array}$ \\
\hline 1 & 99.9 & 100.6 & 100.3 & *ERROR ${ }^{1}$ & ${ }^{*} \mathrm{ERROR}^{1}$ & 99.9 & 101.0 & 101.8 \\
\hline 2 & 96.3 & 97.0 & 96.7 & *ERROR & *ERROR & 96.4 & 97.4 & 98.1 \\
\hline 3 & 94.7 & 95.4 & 95.1 & *ERROR & *ERROR & 94.8 & 95.8 & 96.4 \\
\hline 4 & 93.6 & 94.2 & 94.0 & *ERROR & *ERROR & 93.7 & 94.7 & 95.3 \\
\hline 5 & 92.8 & 93.4 & 93.2 & *ERROR & *ERROR & 92.9 & 93.9 & 94.5 \\
\hline 6 & 92.2 & 92.8 & 92.6 & *ERROR & *ERROR & 92.3 & 93.3 & 93.8 \\
\hline 7 & 91.7 & 92.3 & 92.1 & *ERROR & *ERROR & 91.8 & 92.7 & 93.3 \\
\hline 8 & 91.3 & 91.9 & 91.6 & *ERROR & *ERROR & 91.4 & 92.3 & 92.9 \\
\hline
\end{tabular}




\begin{tabular}{|c|c|c|c|c|c|c|c|c|}
\hline 9 & 90.9 & 91.5 & 91.2 & *ERROR & *ERROR & 91.0 & 91.9 & 92.5 \\
\hline 10 & 90.6 & 91.2 & $90.9=$ & *ERROR & *ERROR & 90.7 & 91.6 & 92.2 \\
\hline 11 & 90.3 & 90.9 & 90.6 & *ERROR & *ERROR & 90.4 & 91.3 & 91.9 \\
\hline 12 & 90.1 & 90.6 & 90.4 & *ERROR & *ERROR & 90.2 & 91.1 & 91.6 \\
\hline 13 & 89.8 & 90.4 & 90.2 & *ERROR & *ERROR & 90.0 & 90.8 & 91.4 \\
\hline 14 & 89.6 & 90.2 & 90.0 & *ERROR & *ERROR & 89.8 & 90.6 & 91.2 \\
\hline 15 & 89.4 & 90.0 & 89.8 & *ERROR & *ERROR & 89.6 & 90.4 & 91.0 \\
\hline 16 & 89.3 & 89.8 & 89.6 & *ERROR & *ERROR & 89.4 & 90.3 & 90.8 \\
\hline 17 & 89.1 & 89.6 & 89.4 & *ERROR & *ERROR & 89.2 & 90.1 & 90.6 \\
\hline 18 & 89.0 & 89.5 & 89.3 & *ERROR & *ERROR & 89.1 & 90.0 & 90.5 \\
\hline 19 & 88.8 & 89.3 & 89.1 & *ERROR & *ERROR & 88.9 & 89.8 & 90.3 \\
\hline 20 & 88.7 & 89.2 & 89.0 & *ERROR & *ERROR & 88.8 & 89.7 & 90.2 \\
\hline 21 & 88.6 & 89.1 & $88.9=$ & *ERROR & *ERROR & 88.7 & 89.6 & 90.1 \\
\hline 22 & 88.5 & 89.0 & 88.8 & *ERROR & *ERROR & 88.6 & 89.4 & 90.0 \\
\hline 23 & 88.4 & 88.8 & 88.7 & *ERROR & *ERROR & 88.5 & 89.3 & 89.8 \\
\hline 24 & 88.3 & 88.7 & 88.6 & *ERROR & *ERROR & 88.4 & 89.2 & 89.7 \\
\hline 25 & 88.2 & 88.6 & 88.5 & *ERROR & *ERROR & 88.3 & 89.1 & 89.6 \\
\hline 26 & 88.1 & 88.5 & 88.4 & *ERROR & *ERROR & 88.2 & 89.0 & 89.5 \\
\hline 27 & 88.0 & 88.5 & 88.3 & *ERROR & *ERROR & 88.1 & 89.0 & 89.5 \\
\hline 28 & 87.9 & 88.4 & 88.2 & *ERROR & *ERROR & 88.0 & 88.9 & 89.4 \\
\hline 29 & 87.8 & 88.3 & $88.1=$ & *ERROR & *ERROR & 87.9 & 88.8 & 89.3 \\
\hline 30 & 87.7 & 88.2 & 88.0 & *ERROR & *ERROR & 87.9 & 88.7 & 89.2 \\
\hline 31 & 87.7 & 88.1 & 88.0 & *ERROR & *ERROR & 87.8 & 88.6 & 89.1 \\
\hline 32 & 87.6 & 88.1 & $87.9=$ & *ERROR & *ERROR & 87.7 & 88.6 & 89.1 \\
\hline 33 & 87.5 & 88.0 & 87.8 & *ERROR & *ERROR & 87.6 & 88.5 & 89.0 \\
\hline 34 & 87.5 & 87.9 & 87.8 & *ERROR & *ERROR & 87.6 & 88.4 & 88.9 \\
\hline 35 & 87.4 & 87.9 & 87.7 & *ERROR & *ERROR & 87.5 & 88.4 & 88.9 \\
\hline 36 & 87.3 & 87.8 & 87.6 & *ERROR & *ERROR & 87.5 & 88.3 & 88.8 \\
\hline 37 & 87.3 & 87.7 & 87.6 & *ERROR & *ERROR & 87.4 & 88.3 & 88.7 \\
\hline
\end{tabular}




\begin{tabular}{|c|c|c|c|c|c|c|c|c|}
\hline 38 & 87.2 & 87.7 & 87.5 & *ERROR & *ERROR & 87.3 & 88.2 & 88.7 \\
\hline 39 & 87.2 & 87.6 & 87.5 & *ERROR & *ERROR & 87.3 & 88.2 & 88.6 \\
\hline 40 & 87.1 & 87.6 & 87.4 & *ERROR & *ERROR & 87.2 & 88.1 & 88.6 \\
\hline 41 & 87.1 & 87.5 & 87.3 & *ERROR & *ERROR & 87.2 & 88.1 & 88.5 \\
\hline 42 & 87.0 & 87.5 & 87.3 & *ERROR & *ERROR & 87.1 & 88.0 & 88.5 \\
\hline 43 & 87.0 & 87.4 & 87.3 & *ERROR & *ERROR & 87.1 & 88.0 & 88.4 \\
\hline 44 & 86.9 & 87.4 & 87.2 & *ERROR & *ERROR & 87.0 & 87.9 & 88.4 \\
\hline 45 & 86.9 & 87.3 & 87.2 & *ERROR & *ERROR & 87.0 & 87.9 & 88.3 \\
\hline 46 & 86.8 & 87.3 & 87.1 & *ERROR & *ERROR & 86.9 & 87.8 & 88.3 \\
\hline 47 & 86.8 & 87.2 & 87.1 & *ERROR & *ERROR & 86.9 & 87.8 & 88.2 \\
\hline 48 & 86.8 & 87.2 & 87.0 & *ERROR & *ERROR & 86.9 & 87.7 & 88.2 \\
\hline 49 & 86.7 & 87.1 & 87.0 & *ERROR & *ERROR & 86.8 & 87.7 & 88.1 \\
\hline 50 & 86.7 & 87.1 & 86.9 & *ERROR & *ERROR & 86.8 & 87.7 & 88.1 \\
\hline 51 & 86.6 & 87.1 & 86.9 & *ERROR & *ERROR & 86.7 & 87.6 & 88.1 \\
\hline 52 & 86.6 & 87.0 & 86.9 & *ERROR & *ERROR & 86.7 & 87.6 & 88.0 \\
\hline 53 & 86.6 & 87.0 & 86.8 & *ERROR & *ERROR & 86.7 & 87.5 & 88.0 \\
\hline 54 & 86.5 & 86.9 & 86.8 & *ERROR & *ERROR & 86.6 & 87.5 & 88.0 \\
\hline 55 & 86.5 & 86.9 & 86.8 & *ERROR & *ERROR & 86.6 & 87.5 & 87.9 \\
\hline 56 & 86.5 & 86.9 & 86.7 & *ERROR & *ERROR & 86.6 & 87.4 & 87.9 \\
\hline 57 & 86.4 & 86.8 & 86.7 & *ERROR & *ERROR & 86.5 & 87.4 & 87.9 \\
\hline 58 & 86.4 & 86.8 & 86.7 & *ERROR & *ERROR & 86.5 & 87.4 & 87.8 \\
\hline 59 & 86.4 & 86.8 & 86.6 & *ERROR & *ERROR & 86.5 & 87.3 & 87.8 \\
\hline 60 & 86.3 & 86.7 & 86.6 & *ERROR & *ERROR & 86.4 & 87.3 & 87.8 \\
\hline 61 & 86.3 & 86.7 & 86.6 & *ERROR & *ERROR & 86.4 & 87.3 & 87.7 \\
\hline 62 & 86.3 & 86.7 & 86.5 & *ERROR & *ERROR & 86.4 & 87.3 & 87.7 \\
\hline 63 & 86.2 & 86.7 & 86.5 & *ERROR & *ERROR & 86.3 & 87.2 & 87.7 \\
\hline 64 & 86.2 & 86.6 & 86.5 & *ERROR & *ERROR & 86.3 & 87.2 & 87.6 \\
\hline 65 & 86.2 & 86.6 & 86.4 & *ERROR & *ERROR & 86.3 & 87.2 & 87.6 \\
\hline 66 & 86.2 & 86.6 & 86.4 & *ERROR & *ERROR & 86.2 & 87.1 & 87.6 \\
\hline
\end{tabular}




\begin{tabular}{|c|c|c|c|c|c|c|c|}
\hline 67 & 86.5 & 86.4 & *ERROR & *ERROR & 86.2 & 87.1 & 87.6 \\
\hline 68 & 86.5 & 86.4 & *ERROR & *ERROR & 86.2 & 87.1 & 87.5 \\
\hline 69 & 86.5 & 86.3 & *ERROR & *ERROR & 86.2 & 87.1 & 87.5 \\
\hline 70 & 86.5 & 86.3 & *ERROR & *ERROR & & 87.0 & 87.5 \\
\hline 71 & 86.4 & 86.3 & *ERROR & *ERROR & & 87.0 & 87.4 \\
\hline 72 & 86.4 & 86.2 & *ERROR & *ERROR & & 87.0 & 87.4 \\
\hline 73 & 86.4 & 86.2 & *ERROR & *ERROR & & 87.0 & 87.4 \\
\hline 74 & 86.4 & 86.2 & *ERROR & *ERROR & & 86.9 & 87.4 \\
\hline 75 & 86.3 & 86.2 & *ERROR & *ERROR & & 86.9 & 87.3 \\
\hline 76 & 86.3 & & *ERROR & *ERROR & & 86.9 & 87.3 \\
\hline 77 & 86.3 & & *ERROR & *ERROR & & 86.9 & 87.3 \\
\hline 78 & 86.3 & & *ERROR & *ERROR & & 86.8 & 87.3 \\
\hline 79 & 86.3 & & *ERROR & *ERROR & & 86.8 & 87.3 \\
\hline 80 & 86.2 & & *ERROR & *ERROR & & 86.8 & 87.2 \\
\hline 81 & 86.2 & & *ERROR & *ERROR & & 86.8 & 87.2 \\
\hline 82 & 86.2 & & *ERROR & *ERROR & & 86.8 & 87.2 \\
\hline 83 & 86.2 & & *ERROR & *ERROR & & 86.7 & 87.2 \\
\hline 84 & & & *ERROR & *ERROR & & 86.7 & 87.2 \\
\hline 85 & & & *ERROR & *ERROR & & 86.7 & 87.1 \\
\hline 86 & & & 86. & *ERROR & & 86.7 & 87.1 \\
\hline 87 & & & 86. & *ERROR & & 86.7 & 87.1 \\
\hline 88 & & & 86. & *ERROR & & 86.6 & 87.1 \\
\hline 89 & & & 86. & *ERROR & & 86.6 & 87.1 \\
\hline 90 & & & 86. & *ERROR & & 86.6 & 87.0 \\
\hline 91 & & & 86. & *ERROR & & 86.6 & 87.0 \\
\hline 92 & & & 86. & *ERROR & & 86.6 & 87.0 \\
\hline 93 & & & 86. & $*$ ERROR & & 86.6 & 87.0 \\
\hline 94 & & & 86. & *ERROR & & 86.5 & 87.0 \\
\hline 95 & & & 86. & *ERROR & & 86.5 & 87.0 \\
\hline
\end{tabular}




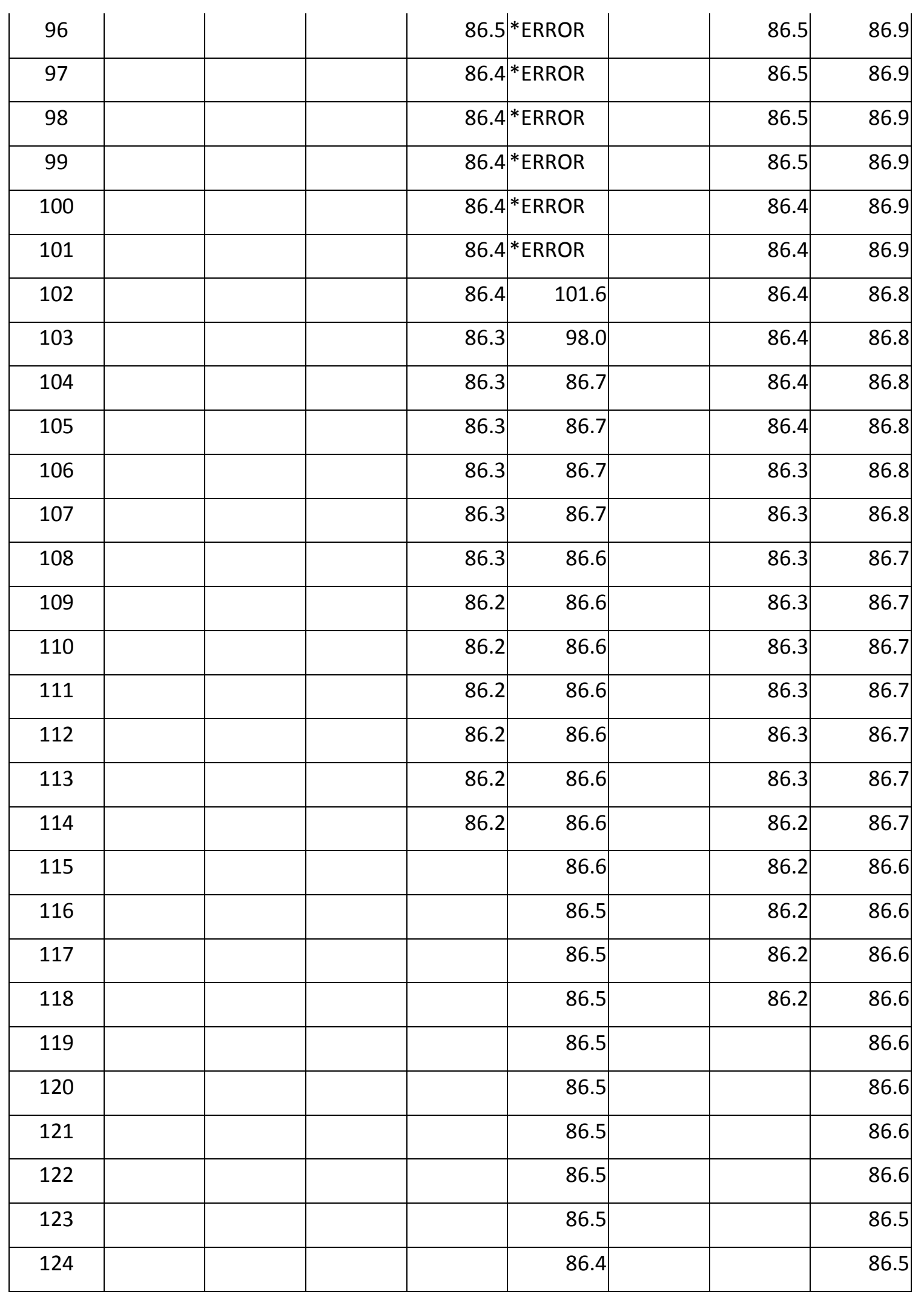




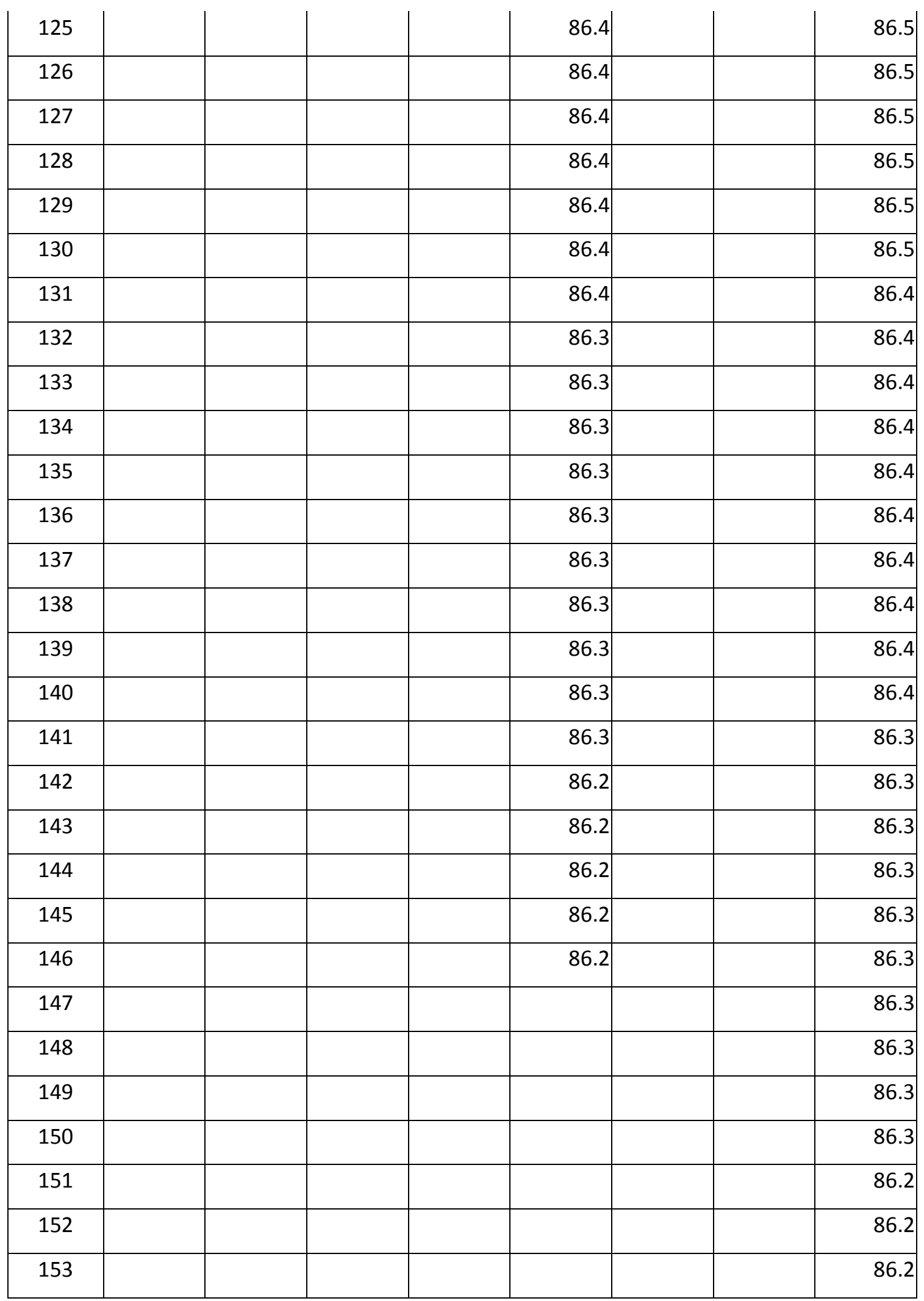




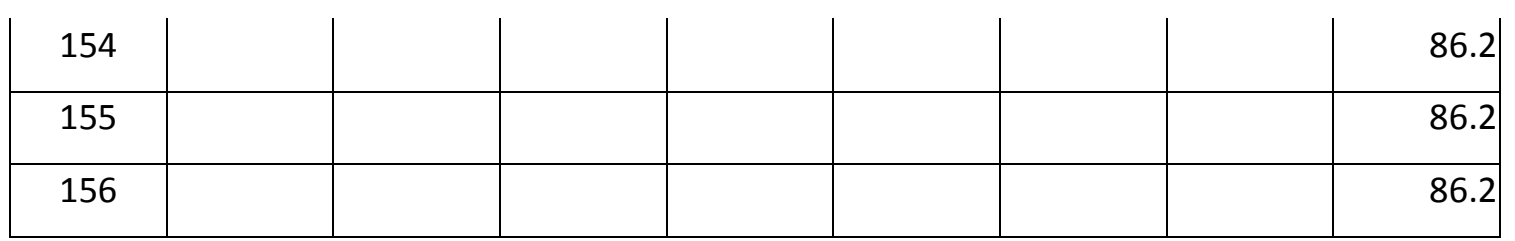

Error $^{1}$ : The computer malfunctioned during the compaction testing, causing a loss in some of the data. Some of the testing data was recovered, and the reported gyration numbers and specimen heights are accurate. 


\section{Appendix C. DSR Data}

Table C.1:

DSR Data

Original Binder

Temp $\quad G^{*} / \operatorname{Sin}(\delta)$

\begin{tabular}{|r|r|r|r|}
\hline & \multicolumn{1}{|l|}{ Test 1 } & Test 2 & Average \\
\hline 13 & 78331.53 & 4490340 & 2284336 \\
\hline 21 & 102037.9 & 1194270 & 648154 \\
\hline 39 & 2878.468 & 62012.26 & 32445.36 \\
\hline 52 & 10858.05 & 7882.055 & 9370.054 \\
\hline 64 & 2594.192 & 1591.402 & 2092.797 \\
\hline 70 & 1700.078 & 1720.545 & 1710.311 \\
\hline
\end{tabular}

REP 1

$75 \%$ OB 25\% RAP

Temp $\quad G^{*} / \operatorname{Sin}(\delta)$

\begin{tabular}{|r|r|r|r|}
\hline & Test 1 & \multicolumn{1}{l|}{ Test 2 } & \multicolumn{1}{l|}{ Average } \\
\hline 58 & 17545.4 & 14505.14 & 16025.27 \\
\hline 64 & 8093.727 & 6643.79 & 7368.759 \\
\hline 70 & 3856.811 & 3064.112 & 3460.461 \\
\hline 76 & 1972.944 & 1422.905 & 1697.924 \\
\hline 82 & 905.0734 & 702.2766 & 803.675 \\
\hline
\end{tabular}

4\% Oil

Temp $\quad G^{*} / \operatorname{Sin}(\delta)$

\begin{tabular}{|r|r|r|r|}
\hline & \multicolumn{1}{|l|}{ Test 1 } & Test 2 & \multicolumn{1}{l|}{ Average } \\
\hline 58 & 6547.341 & 6477.054 & 6512.197 \\
\hline 64 & 3071.989 & 3143.627 & 3107.808 \\
\hline 70 & 1456.156 & 1462.7 & 1459.428 \\
\hline 76 & 695.86 & 739.2604 & 717.5602 \\
\hline
\end{tabular}


8\% Oil

Temp $\quad G^{*} / \operatorname{Sin}(\delta)$

\begin{tabular}{|r|r|l|r|}
\hline & Test 1 & Test 2 & Average \\
\hline 58 & 3111.982 & 3235.839 & 3173.91 \\
\hline 64 & 1521.415 & 1550.648 & 1536.031 \\
\hline 70 & 740.1543 & 758.0342 & 749.0942 \\
\hline
\end{tabular}

REP 2

$75 \%$ OB $25 \%$ RAP

Temp $\quad G^{*} / \operatorname{Sin}(\delta)$

\begin{tabular}{|r|r|r|r|}
\hline & Test 1 & Test 2 & Average \\
\hline 58 & 19039.14 & 17511.03 & 18275.09 \\
\hline 64 & 8269.061 & 7680.786 & 7974.924 \\
\hline 70 & 3709.847 & 3624.48 & 3667.163 \\
\hline 76 & 1815.012 & 1654.29 & 1734.651 \\
\hline 82 & 886.5491 & 799.3603 & 842.9547 \\
\hline
\end{tabular}

4\% Oil

Temp $\quad G^{*} / \operatorname{Sin}(\delta)$

\begin{tabular}{|r|r|r|r|}
\hline & Test 1 & Test 2 & Average \\
\hline 58 & 8371.727 & 8425.578 & 8398.652 \\
\hline 64 & 3661.056 & 3873.404 & 3767.23 \\
\hline 70 & 1803.733 & 1759.355 & 1781.544 \\
\hline 76 & 882.9963 & 862.5279 & 872.7621 \\
\hline
\end{tabular}

8\% Oil

Temp $\quad G^{*} / \operatorname{Sin}(\delta)$

\begin{tabular}{|r|r|l|r|}
\hline & Test 1 & Test 2 & Average \\
\hline 58 & 3447.587 & 3648.597 & 3548.092 \\
\hline 64 & 1568.353 & 1714.176 & 1641.265 \\
\hline 70 & 767.9532 & 794.7723 & 781.3627 \\
\hline
\end{tabular}


REP 3

$75 \%$ OB $25 \%$ RAP

Temp $\quad G^{*} / \operatorname{Sin}(\delta)$

\begin{tabular}{|r|r|r|r|}
\hline & Test 1 & Test 2 & \multicolumn{1}{|l|}{ Average } \\
\hline 58 & 17557.02 & 16888.9 & 17222.96 \\
\hline 64 & 7910.722 & 7608.938 & 7759.83 \\
\hline 70 & 3555.931 & 3551.812 & 3553.871 \\
\hline 76 & 1674.182 & 1614.271 & 1644.226 \\
\hline 82 & 829.8321 & 816.5849 & 823.2085 \\
\hline
\end{tabular}

4\% Oil

Temp $\quad G^{*} / \operatorname{Sin}(\delta)$

\begin{tabular}{|r|r|l|r|r|}
\hline & Test 1 & Test 2 & Test 2- GAP & \\
\hline 58 & 8574.954 & 7906.633 & 7629.611 & 8102.283 \\
\hline 64 & 3941.176 & 3758.348 & 3602.505 & 3771.84 \\
\hline 70 & 1846.91 & 1718.334 & 1689.875 & 1768.393 \\
\hline 76 & 925.7096 & 867.9838 & 815.5547 & 870.6321 \\
\hline
\end{tabular}

8\% Oil

Temp $\quad G^{*} / \operatorname{Sin}(\delta)$

\begin{tabular}{|r|r|l|r|}
\hline & Test 1 & Test 2 & Average \\
\hline 58 & 3891.057 & 3586.581 & 3738.819 \\
\hline 64 & 1761.926 & 1639.233 & 1700.579 \\
\hline 70 & 837.1898 & 801.1952 & 819.1925 \\
\hline
\end{tabular}




\section{Appendix D. Rotational Viscometer Data}

Table D.1:

Rotational Viscometer Data

\begin{tabular}{|r|r|r|r|r|}
\hline \multicolumn{1}{|l|}{ Temp } & Control & $0 \%$ & $4 \%$ & $8 \%$ \\
\hline 100 & 8616.7 & 13400.0 & 7300.0 & 4104.2 \\
\hline 125 & 1474.7 & 1578.8 & 1226.7 & 788.3 \\
\hline 140 & 613.3 & 760.0 & 539.2 & 358.8 \\
\hline 160 & 253.3 & 287.1 & 223.3 & 169.2 \\
\hline
\end{tabular}




\section{Appendix E. FTIR Data}

Table E.1

FTIR

\begin{tabular}{|c|c|c|c|c|c|c|c|}
\hline & $\begin{array}{c}\text { Virgin } \\
\text { Binder }\end{array}$ & $25 \%$ RAP & $\begin{array}{c}25 \% \text { RAP, } \\
4 \% \text { W.E. Oil }\end{array}$ & $\begin{array}{c}25 \% \text { RAP, } \\
8 \% \text { W.E. Oil }\end{array}$ & W.E. Oil & E. Oil & $100 \%$ RAP \\
\hline $\mathrm{S}=\mathrm{O}$ & 0.0206116 & 0.0264427 & 0.0227044 & 0.0210243 & 0.020335 & 0.0201132 & 0.0332944 \\
\hline $\mathrm{C}=\mathrm{O}$ & 0.0132811 & 0.0233528 & 0.0219326 & 0.0194555 & 0.0251615 & 0.0195623 & 0.0347344 \\
\hline
\end{tabular}




\section{Appendix F. APA Rutting Data}

Table F.1

Rutting Data

\begin{tabular}{|c|r|r|r|r|}
\hline & Control & $0 \%$ & $4 \%$ & $8 \%$ \\
\hline 0 & 0.000 & 0.000 & 0.000 & 0.000 \\
\hline 100 & 0.127 & 0.000 & 0.374 & 0.020 \\
\hline 500 & 0.962 & 0.314 & 1.106 & 1.420 \\
\hline 1000 & 1.143 & 0.595 & 1.506 & 2.195 \\
\hline 1500 & 1.640 & 1.016 & 1.984 & 2.872 \\
\hline 2000 & 2.202 & 1.754 & 2.242 & 3.650 \\
\hline 2500 & 1.946 & 1.965 & 2.471 & 3.898 \\
\hline 3000 & 1.886 & 2.120 & 2.709 & 4.107 \\
\hline 3500 & 2.060 & 1.741 & 2.726 & 3.995 \\
\hline 4000 & 2.133 & 1.917 & 2.834 & 4.262 \\
\hline 4500 & 2.021 & 2.085 & 3.011 & 4.458 \\
\hline 5000 & 2.274 & 2.242 & 3.191 & 4.622 \\
\hline 5500 & 2.130 & 2.969 & 3.315 & 4.811 \\
\hline 6000 & 2.500 & 2.821 & 3.371 & 4.931 \\
\hline 6500 & 2.292 & 3.046 & 3.432 & 4.984 \\
\hline 7000 & 2.565 & 2.680 & 3.466 & 5.005 \\
\hline 7500 & 2.478 & 3.243 & 3.671 & 5.447 \\
\hline
\end{tabular}




\section{Appendix G. TSR Data}

Table G.1

\section{TSR Data}

\begin{tabular}{|c|c|c|c|c|}
\hline & $\begin{array}{l}\text { Unconditioned } \\
\text { Strength }(\mathrm{kN})\end{array}$ & $\begin{array}{l}\text { Conditioned } \\
\text { Strength }(\mathrm{kN})\end{array}$ & $\mid \begin{array}{lr}\text { Std. } & \text { Dev. } \\
\text { (unconditioned) }\end{array}$ & $\begin{array}{l}\text { Std. } \\
\text { (conditioned) }\end{array}$ \\
\hline \multirow[t]{3}{*}{ Control } & 24.808 & 21.704 & 2.578 & 1.433 \\
\hline & 29.001 & 22.69 & & \\
\hline & 24.305 & 24.527 & & \\
\hline \multirow[t]{3}{*}{$0 \%$} & 22.376 & 10.422 & 1.499 & 6.580 \\
\hline & 25.373 & 18.46 & & \\
\hline & 23.886 & 23.465 & & \\
\hline \multirow[t]{3}{*}{$4 \%$} & 16.071 & 14.832 & 0.658 & 2.519 \\
\hline & 14.768 & 13.611 & & \\
\hline & 15.262 & 18.454 & & \\
\hline \multirow[t]{3}{*}{$8 \%$} & 15.427 & 11.987 & 1.296 & 0.355 \\
\hline & 15.375 & 11.319 & & \\
\hline & 13.156 & 11.862 & & \\
\hline
\end{tabular}




\section{Appendix H. Volumetric Data}

Table H.1

5.1\% Binder Content Volumetrics

\begin{tabular}{|c|r|r|r|}
\hline \multicolumn{2}{|c|}{ 5.1\% Binder Content } & \multicolumn{3}{l|}{} \\
\hline TEST ITEM & Test 1 & Test 2 \\
\hline Pycnometer & Test 1 & Test 2 \\
\hline Pycnometer + Sample( 2000g) & 2179.1 & 2226.1 \\
\hline Pycnometer + Sample( 2000g) in Water & 4278.9 & 4305.1 \\
\hline Pycnometer in water & 2634.8 & 2655.7 \\
\hline Gmm & 1375.70 & 1405.80 \\
\hline Average Gmm & 2.50 & 2.507538 \\
\hline & 2.502609 & \\
\hline
\end{tabular}

\begin{tabular}{|r|r|r|l|r|}
\hline \multicolumn{1}{|l|}{ Dry } & Submerge in Water & \multicolumn{1}{l|}{ SSD } & Gmb & Air Void \\
\hline 3581.8 & 2082.4 & 3587 & 2.380566 & 0.048766 \\
\hline 3588.6 & 2086.7 & 3600.7 & 2.370277 & 0.052878 \\
\hline & & & & 0.05 \\
\hline
\end{tabular}


Table H.2

5.6\% Binder Content Volumetrics

\begin{tabular}{|c|r|r|}
\hline \multicolumn{2}{|c|}{ 5.6\% Binder Content } & \multicolumn{2}{l}{} \\
\hline TEST ITEM & Test 1 & Test 2 \\
\hline Pycnometer & 2179.1 & 2226.1 \\
\hline Pycnometer + Sample( $\sim 2000 \mathrm{~g})$ & 4241.5 & 4311.1 \\
\hline Pycnometer in water & 2608.9 & 2658.9 \\
\hline Gmm $2000 \mathrm{~g})$ in Water & 1375.7 & 1405.8 \\
\hline Average Gmm & 2.49 & 2.51 \\
\hline
\end{tabular}

\begin{tabular}{|r|r|r|l|r|}
\hline \multicolumn{1}{|l|}{ Sry } & Submerge in Water & SSD & Gmb & \multicolumn{1}{l|}{ Air Void } \\
\hline 3627 & 2116 & 3629.8 & 2.395957 & 0.040375 \\
\hline 3577.8 & 2089.1 & 3581.3 & 2.397668 & 0.03969 \\
\hline & & & & 0.04 \\
\hline
\end{tabular}


Table H.3

6.1\% Binder Content Volumetrics

\begin{tabular}{|c|r|r|}
\hline \multicolumn{2}{|c|}{$6.1 \%$ Binder Content } & \multicolumn{2}{l|}{} \\
\hline TEST ITEM & Test 1 & \multicolumn{1}{l|}{ Test 2 } \\
\hline Pycnometer & 2179.1 & 2226.1 \\
\hline Pycnometer + Sample( 2000g) & 4250.5 & 4349.8 \\
\hline Pycnometer + Sample( 2000g) in Water & 2605.9 & 2668.4 \\
\hline Pycnometer in water & 1375.7 & 1405.8 \\
\hline Gmm & 2.46 & 2.47 \\
\hline Average Gmm & 2.46 & \\
\hline
\end{tabular}

\begin{tabular}{|r|r|r|l|l|}
\hline \multicolumn{1}{|l|}{ Dry } & Submerge in Water & SSD & Gmb & Air Void \\
\hline 3640.3 & 2133.3 & 3643.5 & 2.410475 & 0.021861 \\
\hline 3655.5 & 2144.6 & 3658.3 & 2.414944 & 0.020048 \\
\hline & & & & 0.02 \\
\hline
\end{tabular}

